\title{
Age-Dependent Salt Hypertension in Dahl Rats: Fifty Years of Research
}

\author{
J. ZICHA ${ }^{1,2}$, Z. DOBEŠOVÁ ${ }^{1,2}$, M. VOKURKOVÁ ${ }^{1,2}$, H. RAUCHOVÁ ${ }^{1,2}$, S. HOJNÁ $^{1,2}$, \\ M. KADLECOVÁ ${ }^{1,2}$, M. BEHULIAK ${ }^{1,2}$, I. VANĚCKOVÁ ${ }^{1,2}$, J. KUNEŚ $^{1,2}$ \\ ${ }^{1}$ Centre for Cardiovascular Research, Prague, Czech Republic, ${ }^{2}$ Institute of Physiology, Academy of \\ Sciences of the Czech Republic, Prague, Czech Republic
}

Received April 2, 2012

Accepted May 22, 2012

\section{Summary}

Fifty years ago, Lewis K. Dahl has presented a new model of salt hypertension - salt-sensitive and salt-resistant Dahl rats. Twenty years later, John P. Rapp has published the first and so far the only comprehensive review on this rat model covering numerous aspects of pathophysiology and genetics of salt hypertension. When we summarized 25 years of our own research on Dahl/Rapp rats, we have realized the need to outline principal abnormalities of this model, to show their interactions at different levels of the organism and to highlight the ontogenetic aspects of salt hypertension development. Our attention was focused on some cellular aspects (cell membrane function, ion transport, cell calcium handling), intra- and extrarenal factors affecting renal function and/or renal injury, local and systemic effects of reninangiotensin-aldosterone system, endothelial and smooth muscle changes responsible for abnormal vascular contraction or relaxation, altered balance between various vasoconstrictor and vasodilator systems in blood pressure maintenance as well as on the central nervous and peripheral mechanisms involved in the regulation of circulatory homeostasis. We also searched for the age-dependent impact of environmental and pharmacological interventions, which modify the development of high blood pressure and/or organ damage, if they influence the saltsensitive organism in particular critical periods of development (developmental windows). Thus, severe self-sustaining salt hypertension in young Dahl rats is characterized by pronounced dysbalance between augmented sympathetic hyperactivity and relative nitric oxide deficiency, attenuated baroreflex as well as by a major increase of residual blood pressure indicating profound remodeling of resistance vessels. Salt hypertension development in young but not in adult Dahl rats can be attenuated by preventive increase of potassium or calcium intake. On the contrary, moderate salt hypertension in adult Dahl rats is attenuated by superoxide scavenging or endothelin-A receptor blockade which do not affect salt hypertension development in young animals.

\section{Key words}

Blood pressure - Ion transport - Cell membrane function • Cytosolic calcium - Body fluids - Hemodynamics • Vasoactive systems • Sympathetic nervous system • Nitric oxide • Calcium influx $\bullet$ Calcium sensitization

\section{Corresponding author}

J. Zicha, Institute of Physiology, Academy of Sciences of the Czech Republic, Vídeňská 1083, CZ-142 20 Prague 4, Czech Republic. E-mail: zicha@biomed.cas.cz

\section{Ontogenetic aspects of salt hypertension development in the rat}

It is well known that ontogenetic factors play an important role in the development of hypertension and/or its complication (Zicha et al. 1986, Zicha and Kuneš 1999a, Kuneš and Zicha 2006). Young immature organism often responds to various dietary stimuli (such as high sodium intake, low potassium intake or protein malnutrition) in a different manner than the adult organism does. The same is true for the effects of antihypertensive drugs (e.g. ACE inhibitors) or dietary interventions aimed to lower blood pressure (BP) (high potassium intake, antioxidants, polyunsaturated fatty 
acids) if they are applied to spontaneously hypertensive rats (SHR) prior to the onset or after the development of hypertension.

Increased $\mathrm{NaCl}$ intake is an integral part of numerous models of experimental hypertension [deoxycorticosterone acetate (DOCA)-salt, triiodothyronine-salt, partial nephrectomy-salt, adrenalregeneration-salt, etc] in which BP elevation is always higher in immature animals (Zicha et al. 1986). Saltdependent hypertension in sexually immature rats is usually more pronounced, occurs earlier after the application of the above hypertensive stimuli and is accompanied by a severe end-organ damage leading to its self-sustained persistence even if salt intake is reduced to normal values.

A greater susceptibility of weanling or prepubertal rats to salt-dependent hypertension has been first described by Skelton and Guillebeau (1956) who studied adrenal-regeneration-salt hypertension. This characteristic age dependence (Brownie et al. 1966) was later confirmed in our institute by Jiří Jelínek (Jelínek et al. 1966, Musilová et al. 1966, Kuneš and Jelínek 1984) and Jiří Křeček (Dlouhá et al. 1977, 1979) who studied various salt-dependent forms of experimental hypertension. Enhanced hypertensive response to high salt intake has also been reported in immature baboons compared to adult ones (Cherchovich et al. 1976).

Early interventions during critical periods of development (developmental windows) might have some late unexpected consequences (Křeček 1971, Kuneš and Zicha 2006, 2009). Recently, a nice example has been demonstrated in salt-sensitive Dahl/Rapp rats in which the early exposure to high-fat diet in prepuberty increased the incidence and severity of atherosclerotic coronary lesions elicited by high-fat/high-salt diet feeding in adulthood (Kiefer et al. 2002). High salt intake during lactation was reported to increase later salt preference in salt-sensitive but not in salt-resistant Dahl rats (Ferrell et al. 1986). Another interesting example was reported in salt-sensitive Dahl rats transgenic for human cholesteryl ester transfer protein. Decano et al. (2009) found that the early-life exposure of fetal or weanling rats to a moderate increase of salt intake $(0.40 \% \mathrm{NaCl}$ diet instead of $0.23 \% \mathrm{NaCl}$ diet) caused earlier BP increase and unmasked the susceptibility to adult-onset stroke. Both changes were more pronounced in females than in males. Surprisingly, early salt intake did not increase coronary heart disease (Decano et al. 2009), although a very lowsalt diet $(0.008 \% \mathrm{NaCl})$ applied from the age of
6 months significantly attenuated the incidence of coronary artery disease in late adulthood (Herrera et al. 2001).

\section{Age-dependent salt hypertension in Dahl rats - ontogenetic aspects}

George R. Meneely and Lewis K. Dahl were the prominent pioneers in the research of salt hypertension, who demonstrated that hypertensive effects of excess $\mathrm{NaCl}$ intake in the rat are proportional to the amount of salt ingested (Meneely et al. 1953, Dahl et al. 1968) and that these effects are attenuated by increased potassium intake (Meneely et al. 1957, Dahl et al. 1972). Fifty years ago, Dahl et al. (1962) succeeded to select two contrasting lines of Sprague Dawley rats - outbred saltsensitive (DS) and salt-resistant (DR) rats. From these original outbred Brookhaven strains Rapp and Dene (1985) have derived Dahl/Rapp inbred salt-sensitive (SS/Jr) and salt-resistant (SR/Jr) strains which were later distributed by Harlan, Moellegaard, Seiwa and other commercial breeders. In parallel, Iwai and Heine (1986) have produced Dahl/Iwai inbred strains (DIS, DIR) which are currently used in Japan (Yamazaki et al. 1994). The research on Dahl rats in the Institute of Physiogy (Academy of Sciences of the Czech Republic, Prague) started after the establishment of our colony in 1985 when the breeding pairs of inbred SS/Jr and SR/Jr rats were kindly donated by John P. Rapp. For the nomeclature of currently used Dahl rat strains see Table 1.

Table 1. Principal outbred and inbred strains of Dahl rats.

\begin{tabular}{lccc}
\hline & $\begin{array}{c}\text { Original } \\
\text { location }\end{array}$ & $\begin{array}{c}\text { Salt- } \\
\text { sensitive }\end{array}$ & $\begin{array}{c}\text { Salt- } \\
\text { resistant }\end{array}$ \\
\hline $\begin{array}{l}\text { Outbred Dahl rats } \\
\text { Inbred Dahl/ }\end{array}$ & Brookhaven & $\mathrm{DS}$ & $\mathrm{DR}$ \\
$\begin{array}{l}\text { Rapp rats } \\
\text { Inbred Dahl/ } \\
\text { Iwai rats }\end{array}$ & Toledo & $\mathrm{SS} / \mathrm{Jr}$ & $\mathrm{SR} / \mathrm{Jr}$ \\
\hline
\end{tabular}

Actually there are almost 2000 papers concerning this model of hypertension. Phenotypic differences between salt-sensitive and salt-resistant animals were reviewed by John P. Rapp (1982), who later summarized the genetic analysis of this model (Rapp 
2000). Currently, the research on physiological genomics of salt hypertension is facilitated by the existence of a panel of consomic strains derived from SS/Jr and Brown Norway (BN) rats (Roman et al. 2002, Cowley 2003, Cowley et al. 2004).

\section{A}

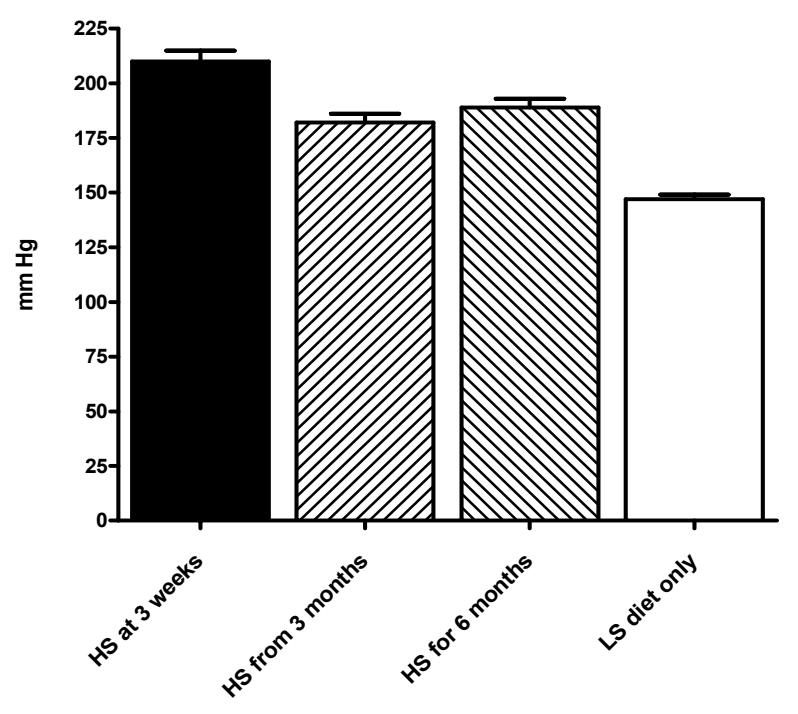

B

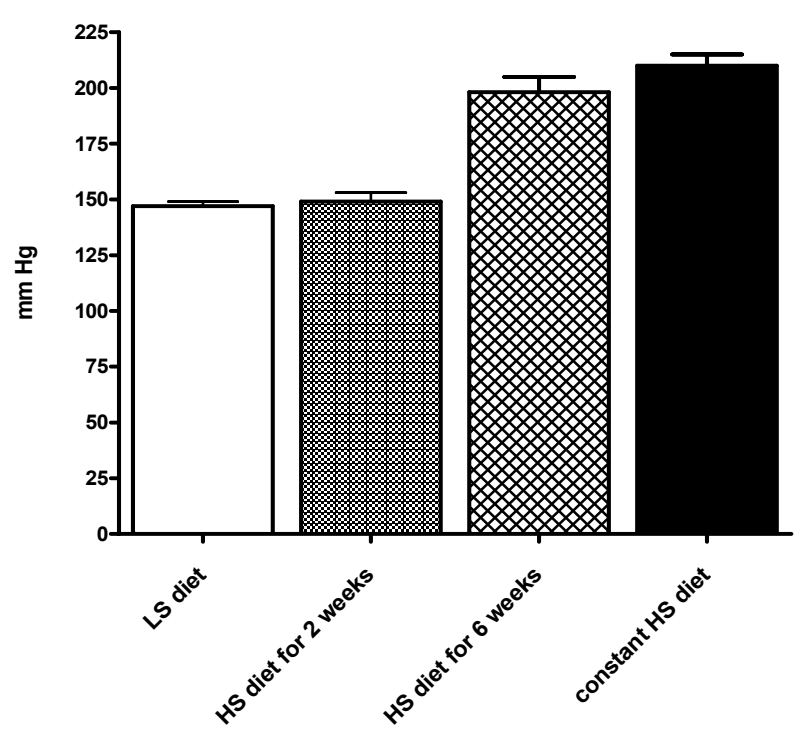

Fig. 1. Blood pressure response of DS rats to high salt intake which started at the age of 3 weeks, 4 or 7 months (A), blood pressure response of DS rats to a transient elevation of salt intake in prepuberty (B). Data modified from Dahl et al. (1968).

The enhanced development of salt hypertension in young (weanling or prepubertal) salt-sensitive Dahl rats was first demonstrated by Dahl et al. (1968) and this finding has been later confirmed by many authors (Iwai et al. 1977, Zicha et al. 1987a, Zicha and Duhm 1990, Dobešová et al. 1995, 2002, Yoneda et al. 2003, Kawarazaki et al. 2010). Using DS animals Dahl et al. (1968) described the basic differences in the response of young and adult rats to $8 \% \mathrm{NaCl}$ diet in terms of $\mathrm{BP}$ rise, survival rate, end-organ damage etc. They have also shown that high salt intake applied for 6 weeks (but not for 2 weeks) after weaning was capable to induce lifelong self-sustaining severe hypertension in DS rats (Fig. 1).

Iwai et al. (1977) studied the long-term effects of chronic administration of thiazide diuretics in DS and DR rats. If chlorothiazide was added to a low-salt diet consumed from the age of 6 weeks, no major BP effects occurred in either rat strain. This early diuretic treatment had also no effect on moderate BP response of adult DS animals to high salt intake which started after the withdrawal of diuretics at the age of 31 weeks (Fig. 2A). If young 6-week-old DS rats were fed a highsalt diet containing chlorothiazide, their blood pressure rose initially to the same level as that of DS rats untreated with diuretics. Thereafter, blood pressure of chlorothiazide-treated DS rats dropped again to normotensive values (Fig. 2B). When chlorothiazide was omitted from high-salt diet at the age of 31 weeks, thiazide-pretreated DS rats developed a moderate salt hypertension characteristic for adult DS animals (Iwai et al. 1977). Thus, the early diuretic treatment of adolescent animals had no protective effects against the development of salt hypertension in adult animals (Fig. 2). The occurrence of early BP response to high salt intake in DS rats treated with diuretics might be related to the fact that thiazide diuretics do not affect sympathetic nerve activity in salt-loaded DS rats (Sasaki and Bunag 1983). Indeed, the guanethidine-induced sympathectomy prevented better the early than the late phase of salt hypertension (Křeček et al. 1987). This is in line with our observation that the early phase of salt hypertension depended solely on high salt intake, whereas the late phase was related to renal damage (Dlouhá et al. 1979, Zicha et al. 1982).

The most interesting data on early pharmacological interventions in salt-sensitive Dahl rats were obtained by Japanese authors. Nakaya et al. (2002) reported that chronic blockade of angiotensin type 1 $\left(\mathrm{AT}_{1}\right)$ receptors by candesartan at the age of 3-10 weeks prevented BP rise in salt-sensitive Dahl rats fed a highsalt diet and blood pressure remained normotensive for 


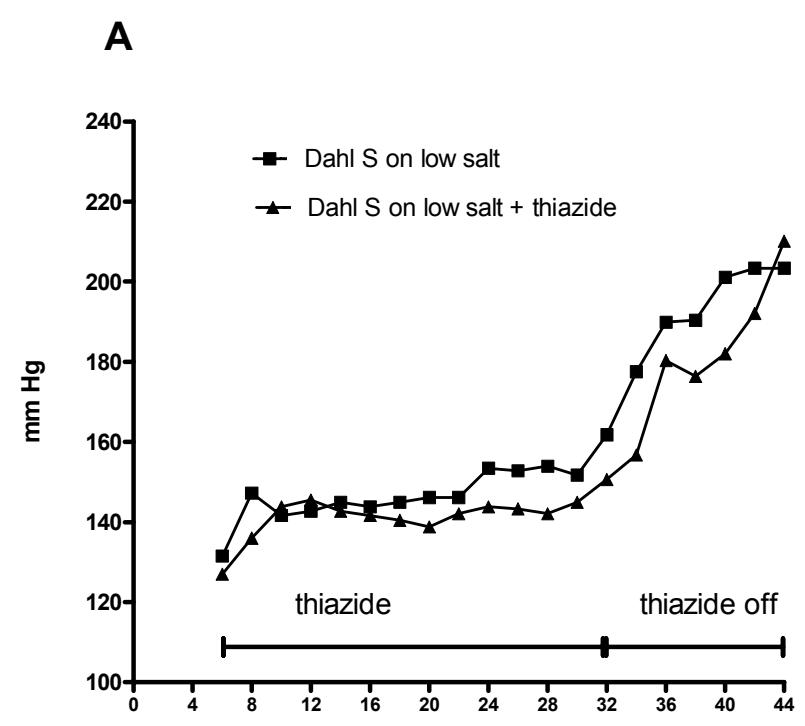

\section{B}

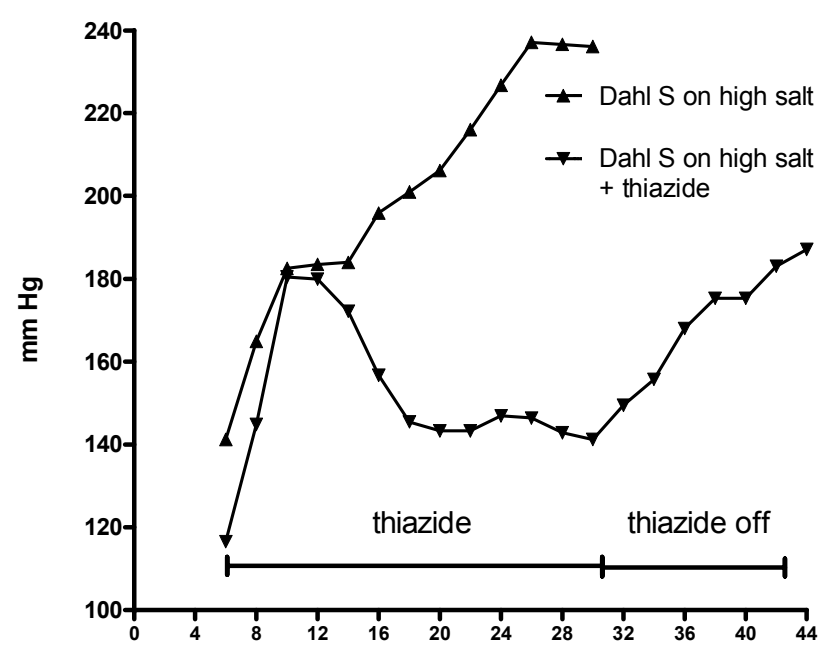

Fig. 2. Blood pressure response of young DS rats to a low-salt diet with or without thiazide diuretics $(\mathbf{A})$, to a high-salt diet with or without thiazide diuretics (B). Data modified from Iwai et al. (1977).

additional 6 weeks when candesartan treatment was withdrawn. Similar results were obtained in olmesartantreated DIS rats (Dejima et al. 2011). They ascribed these beneficial effects of transient blockade of $\mathrm{AT}_{1}$ receptors by olmesartan to the enhanced expression of ATRAP ( $\mathrm{AT}_{1}$ receptor-associated protein), which promotes $\mathrm{AT}_{1}$ receptor internalization and attenuates $\mathrm{AT}_{1}$ receptormediated pathological processes. Finally, prepubertal blockade of mineralocorticoid receptors (MR) by eplerenone attenuated salt hypertension development in DIS rats and these BP effects persisted after drug withdrawal (Kawarazaki et al. 2010).

There is a fascinating story about the research whether the early interventions in Dahl rats during gestation and lactation periods can modify later development of blood pressure and/or salt hypertension. At the beginning of this effort there are two excellent studies by Dene and Rapp (1985a,b) who studied the impact of embryo transfer between $\mathrm{SS} / \mathrm{Jr}$ and $\mathrm{SR} / \mathrm{Jr}$ mothers, cross-fostering of newborns between $\mathrm{SS} / \mathrm{Jr}$ and $\mathrm{SR} / \mathrm{Jr}$ dams, litter size manipulations as well as the influence of high salt intake of mothers during pregnancy or lactation. In fact, none of these early interventions affected BP rise elicited by feeding the SS/Jr offspring by $8 \% \mathrm{NaCl}$ diet since weaning, but we must keep in mind that Dene and Rapp (1985a,b) have used a protocol which always elicited a severe salt hypertension in young $\mathrm{SS} / \mathrm{Jr}$ rats within four weeks. Although the early interventions had no effects on salt hypertension development, some of them (embryo transfer, litter size manipulation) lowered the mortality of SS/Jr rats exposed to this very high salt intake (Dene and Rapp 1985a,b).

There is a question what would happen if the $\mathrm{SS} / \mathrm{Jr}$ offspring subjected to the above mentioned early interventions would be exposed to a moderate increase of salt intake after weaning or if the onset of high salt intake would be postponed to the adulthood. Fortunately, two laboratories did such experiments several years later. Both research groups evaluated the impact of either embryo transfer (Kubisch et al. 1998) or cross-fostering (Murphy and McCarty 1989) on spontaneous BP development which ultimately led to the occurrence of a moderate hypertension in salt-sensitive Dahl rats fed a low-salt diet (Kurtz and Morris 1985).

Under the conditions of low salt intake $(0.3 \%$ $\mathrm{NaCl}$ diet) the embryo transfer between $\mathrm{SS} / \mathrm{Jr}$ and $\mathrm{SR} / \mathrm{Jr}$ mothers considerably delayed and attenuated the spontaneous BP increase in those male $\mathrm{SS} / \mathrm{Jr}$ offspring which were transferred to SR/Jr mothers. It also attenuated salt hypertension development if they were given $0.9 \%$ saline to drink at the age of 11 weeks (Kubisch et al. 1998). Hypertension, which developed in SS/Jr rats fed $0.3 \% \mathrm{NaCl}$ diet, was almost completely abolished by intracerebroventricular administration of mineralocorticoid receptor antagonist and this antihypertensive effect was fully reversible. The same effects of MR antagonist were also found in the attenuated hypertension of $\mathrm{SS} / \mathrm{Jr}$ rats subjected to embryo transfer to $\mathrm{SR} / \mathrm{Jr}$ mothers (Kubisch et al. 1998). The attenuation of spontaneous BP elevation was also observed in $\mathrm{SS} / \mathrm{Jr}$ females transferred as embryos to $\mathrm{SR} / \mathrm{Jr}$ mothers. In contrast, no BP effect was induced by the transfer of SR/Jr embryos to SS/Jr mothers (Kubisch et al. 1998). 
Murphy and McCarty (1989) evaluated the impact of cross-fostering on the future BP development under the conditions of normal salt intake $(0.7 \% \mathrm{NaCl}$ diet). They reported that blood pressure of SS/Jr pups cross-fostered to $\mathrm{SR} / \mathrm{Jr}$ dams was significantly decreased at the age of 60 and 100 days, although it was still elevated compared to $\mathrm{SR} / \mathrm{Jr}$ rats. Cross-fostering of $\mathrm{SR} / \mathrm{Jr}$ pups to SS/Jr dams had no influence on BP development. It should be mentioned that BP development in $\mathrm{SS} / \mathrm{Jr}$ rats was not influenced by in-fostering to other SS/Jr mothers or cross-fostering to SHR mothers (Murphy et al. 1992). Thus hypertensive maternal environment is necessary for the full development of high blood pressure in saltsensitive Dahl rats.

McCaughran et al. (1986a) paid a considerable attention to various ontogenetic aspects of hypertension development in $\mathrm{SS} / \mathrm{Jr}$ rats. They reported a similar BP level in 25-day-old $\mathrm{SS} / \mathrm{Jr}$ and $\mathrm{SR} / \mathrm{Jr}$ pups, but in $\mathrm{SS} / \mathrm{Jr}$ rats there was a stepwise BP increase in the next 20 weeks of life so that these animals developed a considerable hypertension even if they were fed $0.15 \% \mathrm{NaCl}$ diet only. There was a pronounced increase in the density of renal $\alpha_{2}$-adrenoceptors in $\mathrm{SS} / \mathrm{Jr}$ rats between days 25 and 50 of age (McCaughran et al. 1986a). The density of renal $\alpha_{2}$-adrenoceptors was always higher in $\mathrm{SS} / \mathrm{Jr}$ rats compared to SR/Jr animals, regardless of the postweaning diet or hypertension development. The only exceptions were the rats born to the mothers which were exposed to high salt intake during gestation. In these animals there was no significant difference in the density of renal $\alpha_{2}$-adrenoceptors between $\mathrm{SS} / \mathrm{Jr}$ and $\mathrm{SR} / \mathrm{Jr}$ rats (McCaughran and Juno 1986). The density of $\alpha_{2}$-adrenergic receptors remained elevated in saltsensitive Dahl rats throughout their whole life and was further increased by high salt intake (Pettinger et al. 1982a,b). On the contrary, the density of renal $\alpha_{1}$-adrenoceptors was similar in all age groups of Dahl rats of either genotype (McCaughran et al. 1986a). Not only $\alpha_{2}$-adrenoceptors but also $\beta$-adrenoceptors were increased in the kidneys of SS/Jr rats aged 60 days which were studied under the conditions of high salt intake. The increased density of these adrenergic receptors was not affected by verapamil-induced attenuation of salt hypertension development (McCaughran and Juno 1988). Further studies (McCaughran et al. 1986b, McCaughran and Juno 1986) confirmed that high salt intake of dams during gestation did not influence the postnatal BP development in $\mathrm{SS} / \mathrm{Jr}$ rats under the conditions of either low or high salt intake $(0.4 \%$ and $8 \% \mathrm{NaCl}$ diet, respectively). Nevertheless, if $\mathrm{SS} / \mathrm{Jr}$ rats were weaned to a $2 \% \mathrm{NaCl}$ diet, a considerable late augmentation of salt hypertension development appeared in the rats whose mothers were exposed to high-salt diet during the pregnancy (McCaughran et al. 1986c).

Plasma renin activity (PRA) was also not affected by increased salt intake during gestation, but it became considerably suppressed by high salt intake after day 15 of postnatal age (Wilson et al. 1986). It means that the effect of high salt intake on PRA appears only in the weaning period when the rat pups start to consume solid food (Babický et al. 1973). Finally, high salt intake of rat mothers during lactation $(2 \% \mathrm{NaCl}$ diet) retarded body growth of both $\mathrm{SS} / \mathrm{Jr}$ and $\mathrm{SR} / \mathrm{Jr}$ rats (Hua et al. 1990). At the age of 3 weeks this growth retardation was accompanied by a significant BP reduction in pups of both genotypes. However, renal blood flow (RBF), glomerular filtration rate (GFR) and fractional sodium excretion $\left(\mathrm{FE}_{\mathrm{Na}}\right)$ were decreased in immature $\mathrm{SS} / \mathrm{Jr}$ rats only. At the age of 8-9 weeks blood pressure was already elevated in salt-loaded mature SS/Jr rats in which $\mathrm{RBF}$ and GFR were still reduced. The acute volume expansion, which increased $\mathrm{RBF}$, GFR and $\mathrm{FE}_{\mathrm{Na}}$ in mature rats, failed to induce such changes in immature Dahl rats, namely in SS/Jr ones (Hua et al. 1990). The failure of immature Dahl rats to respond to volume expansion by renal vasodilatation, GRF increase and adequate natriuresis corresponds to the fundamental difference in the renal response of young and adult rats to volume expansion (Bengele and Solomon 1974, Misanko et al. 1979).

This chapter on the ontogenetic aspects of salt hypertension illustrates which difficulties can be encountered in the experiments designed to reveal the consequences of early interventions on later BP development. The careful choice of hypertensive stimuli of appropriate strength, which are applied in the adequate age period, might facilitate the demonstration of late effects of early interventions in critical developmental periods.

\section{The effects of potassium or calcium intake on salt hypertension development}

It is well known that dietary potassium supplementation prevents or considerably attenuates the development of salt hypertension (Meneely et al. 1957, Dahl et al. 1972, Manger et al. 2003). On the contrary, potassium deficiency exaggerated salt hypertension, 

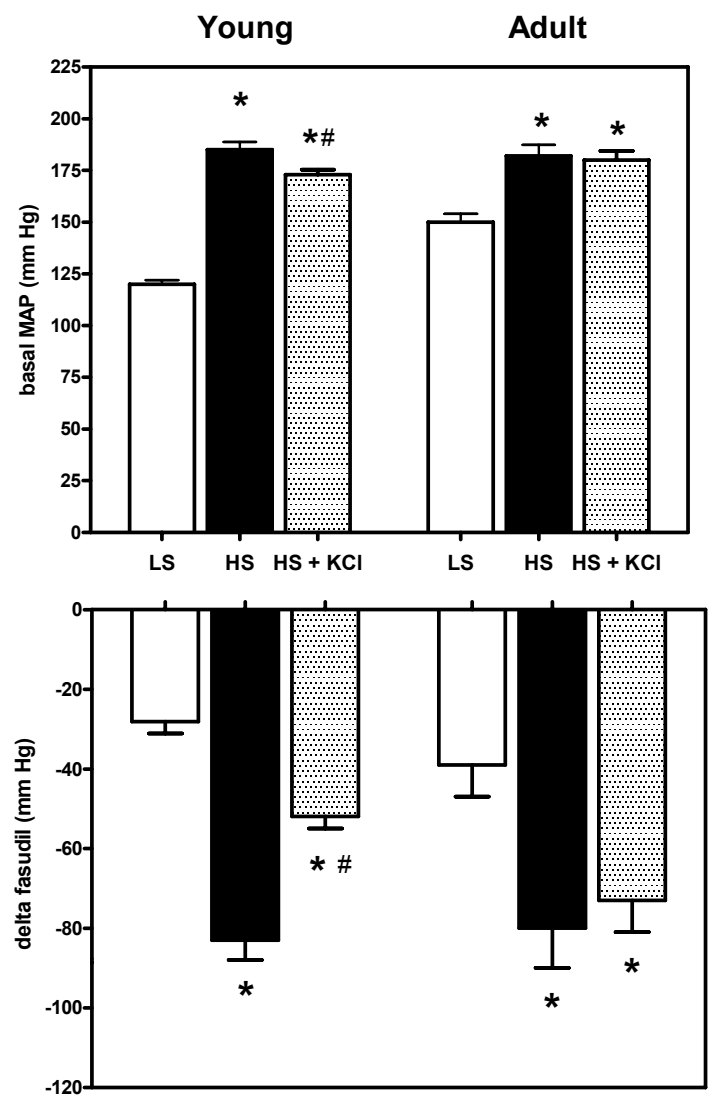

Fig. 3. The age-dependent effects of preventive dietary potassium supplementation in young and adult SS/Jr female rats on basal MAP values (top panels) and on MAP response to acute cumulative administration of fasudil (11 mg/kg b.w.) (bottom panels). Young rats were fed either low-salt diet (LS, $0.3 \%$ $\mathrm{NaCl})$, high-salt diet (HS, $5 \% \mathrm{NaCl})$ or potassium-supplemented high-salt diet ( $\mathrm{HS}+\mathrm{KCl}, 5 \% \mathrm{NaCl}$ plus $3 \% \mathrm{KCl}$ ) for 4 weeks from the age of 4 weeks, whereas the adult animals were fed the same diets for 9 weeks from the age of 20 weeks. Data are means \pm S.E.M. Significantly different $(p<0.05)$ from: * agematched LS animals, " age-matched HS animals.

sympathetic vasoconstriction and renal damage in $\mathrm{SS} / \mathrm{Jr}$ rats (Wu et al. 1996, 1998). Surprisingly, no major BP reduction was achieved by therapeutic dietary potassium supplementation in $\mathrm{SS} / \mathrm{Jr}$ rats with established hypertension (Zicha et al. 2011).

The modification of potassium intake is a characteristic example of a dietary intervention which has typical age-dependent consequences because the preventive antihypertensive effects of high potassium intake can be observed only in young but not in adult SS/Jr rats (Zicha et al. 2011). Potassium supplementation had no beneficial BP effects in adult animals even in the case that a pronounced salt hypertension was elicited in adult $\mathrm{SS} / \mathrm{Jr}$ rats by the prolonged exposure to high salt intake (Fig. 3). To our knowledge, the reason for such a fundamental age difference is not known.
The exact mechanisms of beneficial action of high potassium intake are still not fully understood. Although enhanced sympathetic activity is responsible for salt hypertension in Dahl rats (Takeshita and Mark 1978, Friedman et al. 1979, Huang and Leenen 1994, Zicha et al. 2001b), surprisingly little attention was paid to the influence of increased potassium intake on the activity of this important vasoconstrictor system in Dahl rats (Goto et al. 1981). Our recent study (Zicha et al. 2011) clearly demonstrated that the attenuation of sympathetic vasoconstriction was responsible for BP reduction induced by preventive dietary potassium supplementation in salt-loaded $\mathrm{SS} / \mathrm{Jr}$ rats. Diminished sympathetic BP component in potassium-supplemented rats was accompanied by decreased $\mathrm{BP}$ response to acute nifedipine administration, suggesting the decisive role of norepinephrine-induced L-VDCC opening for the development and/or maintenance of high blood pressure in Dahl rats (Zicha et al. 2011).

On the contrary, several investigators proposed that dietary potassium supplementation improved endothelial dysfunction in salt hypertensive Dahl rats (Raij et al. 1988, Sudhir et al. 1993, Zhou et al. 1999a, Zhou et al. 2000). Decreased NO bioavailability might be a consequence of enhanced superoxide formation in hypertensive animals (Swei et al. 1997, Zicha et al. 2001b, Bayorh et al. 2004). One of the superoxide sources is NADPH oxidase which had an increased activity and/or expression in salt hypertensive Dahl rats and was lowered by dietary potassium supplementation (Fujii et al. 2003, Matsui et al. 2006, Kido et al. 2008). Nevertheless, our data do not support the above assumption because we did not observe any improvement of NO-dependent vasodilatation in young $\mathrm{SS} / \mathrm{Jr}$ rats fed a $5 \% \mathrm{NaCl}$ diet supplemented with $3 \% \mathrm{KCl}$. Moreover, vasodilatation mediated by $\mathrm{PGI}_{2}$ or $\mathrm{BK}_{\mathrm{Ca}}$ channels was also not enhanced by potassium supplementation in young salt-loaded SS/Jr rats (Zicha et al. 2011).

Dietary calcium intake is another example of age-dependent intervention because the increased calcium intake exerted just the opposite influence on salt hypertension development if it was applied to young or adult Dahl rats (Kuneš et al. 1988). High calcium intake from weaning attenuated the development of salt hypertension in young SS/Jr rats, whereas the same highcalcium diet enhanced salt hypertension development in adult animals. In contrast, increased calcium intake had no effects on blood pressure of SR/Jr rats of either age (Kuneš et al. 1988). The attenuation of hypertension 
development by high calcium intake was observed not only in young salt-sensitive Dahl rats (Peuler et al. 1987) but also in immature SHR (Ayachi 1979, McCarron et al. 1981, Hatton et al. 1988). Multiple cellular and humoral mechanisms (calcium regulating hormones, calcitonin gene-related peptide, atrial natriuretic factor as well as RAS and SNS) were proposed to explain BP-lowering effects of supplemental dietary calcium (for review see Hatton and McCarron 1994). One of the interesting mechanisms, which was suggested to mediate these effects of dietary calcium on blood pressure, is based upon putative parathyroid hypertensive factor (PHF), the secretion of which was reduced by increased calcium intake and increased by calcium restriction (Lewanczuk et al. 1990).

\section{Red blood cell ion transport - altered Na,K- pump activity}

Our initial studies in Dahl rats were focused on ion transport, namely on the function of $\mathrm{Na}, \mathrm{K}-$ pump (Zicha et al. 1987a) because we have reported a greater importance of circulating digoxin-like factor (DLF) in young than in adult DOCA-salt hypertensive rats (Zicha et al. 1984, Kuneš et al. 1985, Zicha et al. 1985). We therefore proposed a major role of DLF in the enhanced BP response of young animals to high salt intake (Zicha et al. 1986). To our surprise, Na,K-ATPase activity was suppressed in the heart and kidneys of young salt hypertensive $\mathrm{SS} / \mathrm{Jr}$ rats but ouabain-sensitive (OS) $\mathrm{Rb}^{+}\left(\mathrm{K}^{+}\right)$uptake (mediated by the Na,K-pump) was increased in erythrocytes of these animals (Zicha et al. 1987a). The latter finding was in a good agreement with the report of Overbeck et al. (1981) who found increased $\mathrm{Na}, \mathrm{K}$-pump activity in arteries of salt hypertensive $\mathrm{SS} / \mathrm{Jr}$ rats. Our later studies carried out in Munich (Zicha and Duhm 1990) revealed different alterations in the transport kinetics of the Na,K-pump in erythrocytes of young and old $\mathrm{SS} / \mathrm{Jr}$ rats. Figure 4 shows that chronic high salt intake increased the affinity of the Na,K-pump to internal $\mathrm{Na}^{+}$content $\left(\mathrm{Na}^{+}{ }_{\mathrm{i}}\right)$, but decreased the maximal velocity of $\mathrm{OS} \mathrm{Rb}^{+}$uptake in erythrocytes of young animals, whereas the opposite changes were seen in erythrocytes of old rats (Zicha and Duhm 1990). Thus the measurement of ion transport in intact erythrocytes, which is carried out at 5-10 mmol Na ${ }_{i}^{+} / 1$, disclosed the acceleration of $\mathrm{OS} \mathrm{Rb}^{+}$ uptake, reflecting the increased affinity of the $\mathrm{Na}, \mathrm{K}-$ pump to $\mathrm{Na}^{+}{ }_{\mathrm{i}}$ which was elevated due to enhanced passive $\mathrm{Na}^{+}$ entry into the red blood cells of young salt hypertensive
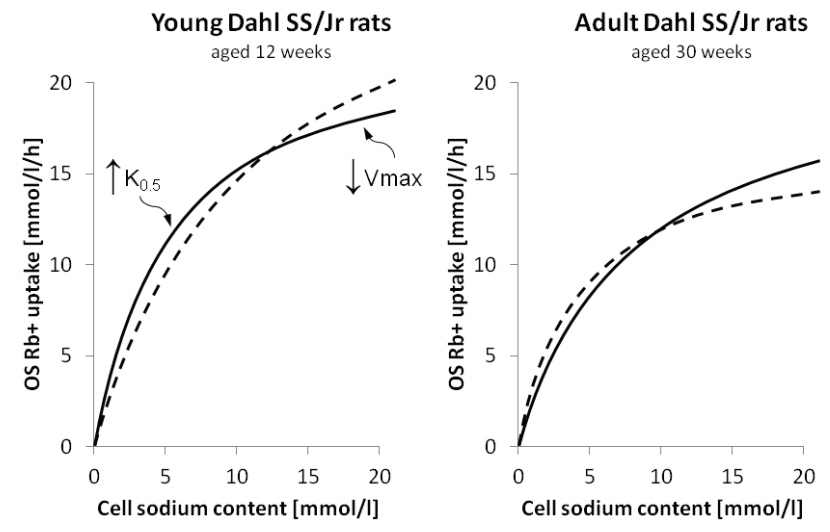

Fig. 4. Kinetic alterations of ouabain-sensitive $\mathrm{Rb}^{+}$uptake mediated by the $\mathrm{Na}$,K-pump in erythrocytes of young and old $\mathrm{SS} / \mathrm{Jr}$ male rats fed either low-salt diet (LS, $0.06 \% \mathrm{NaCl}$, broken lines) or high-salt diet (HS, $8 \% \mathrm{NaCl}$, full lines) for 7 weeks from the ages of 5 weeks and 23 weeks, respectively (data modified from Zicha and Duhm 1990). $\mathrm{V}_{\max }$ - maximal transport rate, $\mathrm{K}_{0.5}-$ internal sodium concentration at half-maximal velocity of the $\mathrm{Na}$,K-pump.

rats. The same was probably true for $\mathrm{OS} \mathrm{Rb}^{+}$uptake measured in non-homogenized arteries of Dahl rats (Overbeck et al. 1981). On the contrary, Na,K-ATPase activity is determined in tissue homogenates at high saturating $\mathrm{NaCl}$ concentrations $(100 \mathrm{mmol} / \mathrm{l})$ in the incubation media so that this measurement reflects the maximal velocity rather than the actual activity of this enzyme. This might explain why Zicha et al. (1987a) observed the attenuation of renal Na,K-ATPase activity in young salt hypertensive $\mathrm{SS} / \mathrm{Jr}$ rats, whereas the activity of this enzyme was reduced in adult animals. Thus the changes in renal $\mathrm{Na}, \mathrm{K}$-ATPase activity induced by high salt intake in young and adult $\mathrm{SS} / \mathrm{Jr}$ rats (Zicha et al. 1987a) corresponded to the changes in the maximal velocity of the $\mathrm{Na}, \mathrm{K}$-pump in erythrocytes of these two age groups (Zicha and Duhm 1990). Enhanced passive $\mathrm{Na}^{+}$entry and increased Na,K-pump activity in erythrocytes of young salt hypertensive animals are also in line with the findings of Vasdev et al. (1988, 1990a, 1990b) who reported the increase of both amiloridesensitive $\mathrm{Na}^{+}$uptake and ouabain-sensitive $\mathrm{Rb}^{+}$uptake in aortas of young salt hypertensive Dahl rats. It is also interesting to mention that McCormick et al. (1989) reported elevated plasma levels of ouabain-like compound and increased red blood cell $\mathrm{Na}^{+}$content but unchanged $\mathrm{OS} \mathrm{Rb}^{+}$uptake in the erythrocytes of 5-weekold DS rats which were fed a low-salt diet. In their experiments erythrocyte $\mathrm{Na}^{+}$i correlated with both blood pressure and $\mathrm{Na}, \mathrm{K}$-pump activity in erythrocytes of these immature Dahl rats. 
We have further tried to elucidate the role of the tentative mutation in $\alpha 1$ subunit of the Na,K-pump which was reported in salt-sensitive Dahl rats by Herrera and Ruiz-Opazo (1990) or Herrera et al. (1998). Unfortunately, our experiments failed to disclose any significant relationship of Atplal locus to either blood pressure or red blood cell OS Na${ }^{+}$and $\mathrm{Rb}^{+}\left(\mathrm{K}^{+}\right)$transport in $\mathrm{F}_{2}$ hybrids of SS/Jr x SR/Jr rats (Zicha et al. 2001a). This negative findings was confirmed by many other investigators (for overview see Mokry and Cuppen 2008). However, functional abnormalities of the $\mathrm{Na}, \mathrm{K}$ pump in erythrocytes of SS/Jr rats were closely related to plasma cholesterol levels (Zicha et al. 2001a) which are elevated in salt hypertensive Dahl rats (Dahl 1960, Zicha et al. 2001a,b). It should be noted that blood pressure of Dahl $F_{2}$ hybrids correlated not only with plasma cholesterol but also with plasma triglycerides (Zicha et al. 2001a, Vokurková et al. 2003), but plasma triglycerides had no significant relationship to red blood cell ion transport (Vokurková et al. 2003), indicating thus a dissociation between ion transport alterations and metabolic syndrome features described in salt-sensitive Dahl rats (Reaven et al. 1991a,b, Kotchen et al. 1991a). On the basis of these findings we studied membrane lipid composition in erythrocytes of Dahl rats (Vokurková et al. 2005a). Our data indicated that the total cholesterol content of erythrocyte membrane was an important determinant of ion transport mediated by the $\mathrm{Na}, \mathrm{K}$-pump, $\mathrm{Na}, \mathrm{K}$ cotransport and cation leaks, but surprisingly erythrocyte membrane cholesterol did not correlate with blood pressure. Further analysis of membrane phospholipid composition suggested that membrane sphingomyelins as well as phosphatidylserines and/or phosphatidylinositols play an important role in the control of red blood cell ion transport (Vokurková et al. 2005a). The induced changes in membrane content of cholesterol or phospholipids are known to modify the activity of the Na,K-pump and $\mathrm{Na}, \mathrm{K}$-cotransport in human erythrocytes (Claret et al. 1978, Engelmann et al. 1990a).

In the above studies we have repeatedly observed that the erythrocytes of some salt hypertensive $\mathrm{SS} / \mathrm{Jr}$ rats were characterized by decreased mean cell hemoglobin content (MCHC), enhanced $\mathrm{Na}, \mathrm{K}-$ pump activity and augmented $\mathrm{Na}^{+}$leak (Zicha and Duhm 1990). This seems to be related to the occurrence of immature cells during chronic anemia described in these animals (Overbeck et al. 1981, Luckhaus et al. 1982). In our studies MCHC correlated significantly with multiple parameters of erythrocyte ion transport in salt hypertensive SS/Jr rats (Vokurková et al. 2005a). Low $\mathrm{MCHC}$ is typical for immature human erythrocytes which are also characterized by enhanced Na,K-pump activity and augmented $\mathrm{Na}^{+}$leak but decreased $\mathrm{Na}, \mathrm{K}$-cotransport activity (Furukawa et al. 1981, Engelmann et al. 1990b). We have therefore studied the erythrocytes of Wistar rats subjected to repeated hemorrhage (Vokurková et al. 2005b). The erythrocytes were divided by repeated centrifugation into immature (light, $34 \%$ reticulocytes) and mature cells (dense, $7 \%$ reticulocytes). These immature red blood cells exhibited lower MCHC, elevated activity of the Na,K-pump, reduced activity of the $\mathrm{Na}, \mathrm{K}$-cotransport and increased cation leak as well as higher concentrations of total cholesterol and total phosholipids in their cell membrane (Vokurková et al. 2005b).

Thus, ion transport abnormalities could be related more closely to the immaturity of the cells rather than to hypertension, reflecting a well-known faster proliferation of various cell types (vascular smooth muscle cells, fibroblasts, blood cells etc) in SHR (Sen et al. 1972, Hadrava et al. 1989, Marche et al. 1995, Bačáková and Kuneš 2000). It would be desirable to consider ion transport alterations in hypertension always in terms of their dependence on the age of animals and/or the maturity of their cells (for review see Zicha and Kuneš 1999b).

\section{Endogenous Na,K-pump inhibitors}

There are several endogenous inhibitors of the Na,K-pump - brain and adrenal ouabain-like compound(s) (OLC) and tissue marinobufagenin which differ by their specificity to $\alpha 3$ and $\alpha 1 \mathrm{Na}, \mathrm{K}$-ATPase isoforms. Gomez-Sanchez et al. (1994) were the first who demonstrated a possible pathogenetic role of OLC in Dahl rats because they attenuated salt-hypertension development by immunization of $\mathrm{SS} / \mathrm{Jr}$ rats against ouabain. In parallel, Leenen et al. (1994) demonstrated that high salt intake increased both plasma and central nervous OLC levels to a greater extent in salt-sensitive than salt-resistant Dahl rats. Brain OLC, which is involved in the central nervous pathways responsible for sympathoexcitation, plays an important role in various salt-dependent forms of experimental hypertension (for review see van Huysse 2007 and Leenen 2010). OLC is released following mineralocorticoid receptor activation and opening of epithelial $\mathrm{Na}^{+}$channels. This compound 
lowers membrane potential by inhibiting Na,K-pump, augmenting thus the activity of angiotensinergic sympathoexcitatory pathway which is primarily stimulated by increased cerebrospinal $\mathrm{Na}^{+}$concentration (Leenen 2010). Adrenal OLC was also proposed to participate in the pathogenesis of DOCA-salt or ACTHinduced hypertension (for review see Blaustein and Hamlyn 2010).

Marinobufagenin (MBG), which can be isolated not only from toad skin but also from rat adrenals or pituitary tissue, is a preferential inhibitor of the $\alpha 1$ isoform of $\mathrm{Na}, \mathrm{K}$-pump which is located on the basolateral membrane of renal tubules. In a series of consecutive papers Bagrov and Fedorova have demonstrated that both OLC and MBG can be detected in salt-sensitive and salt-resistant Dahl rats. Tissue and plasma levels as well as urinary excretion of both compounds are elevated following acute salt loading, but MBG increase is long-lasting in contrast with a short-term OLC rise (Fedorova et al. 2000). Chronic increase of salt intake caused a major elevation of urinary $\mathrm{MBG}$ excretion in $\mathrm{SS} / \mathrm{Jr}$ but not in $\mathrm{SR} / \mathrm{Jr}$ rats, whereas OLC excretion was not changed in either rat strain (Fedorova et al. 2001). A detailed follow-up of urinary excretion of these two $\mathrm{Na}, \mathrm{K}$-pump inhibitors in young $\mathrm{SS} / \mathrm{Jr}$ rats subjected to high salt intake revealed that there was a progressive increase of MBG excretion throughout salt hypertension development, while only a transient increase of OLC excretion can be seen in the first week of high-salt diet feeding (Fedorova et al. 2002). One of the most interesting findings was that brain OLC stimulated adrenocortical MBG levels through angiotensin type 1 receptor pathway (Fedorova et al. 2005). Furthermore, not only the rise of brain OLC in salt-loaded animals but also intrahippocampal administration of low ouabain doses stimulated adrenocortical levels and urinary excretion of MBG (Fedorova et al. 2007). Finally, Bagrov et al. (2009) have shown that acute salt loading elicited a smaller increase of OLC excretion but a greater increase of MBG excretion in $\mathrm{SS} / \mathrm{Jr}$ rats compared to Sprague Dawley animals. This was accompanied by a smaller inhibition of $\mathrm{Na}, \mathrm{K}$-pump in the renal medulla but a greater one in the aorta of $\mathrm{SS} / \mathrm{Jr}$ rats.

Despite three decades of intensive research the exact role of endogenous $\mathrm{Na}, \mathrm{K}$-pump inhibitors in salt hypertension is still not fully understood, namely their action on the vasculature and peripheral SNS (for details see Blaustein et al. 2012).

\section{Abnormal lipid metabolism and cell membrane function}

Abnormalities of lipid metabolism have a crucial importance for functional and structural alterations of cell membrane in both dyslipidemia and/or hypertension (for review see Zicha et al. 1999a). During our long-term cooperation with Marie-Aude Devynck we have studied membrane microviscosity as well as the regulation of cytosolic calcium and $\mathrm{pH}$ in platelets and erythrocytes of rats with various forms of experimental hypertension including Prague hypertriglyceridemic rats (Zicha et al. 1996a, Kuneš et al. 1997, Devynck et al. 1998, Kuneš et al. 2000, Pernollet et al. 2001), Lyon hypertensive rats (Le Quan Sang et al. 1994a, Zicha et al. 1995), Sabra hypertension-prone rats (Pernollet et al. 1994, Le Quan Sang et al. 1994b, Zicha et al. 1996b) and Dahl saltsensitive rats (Zicha et al. 1997, 1999b).

The microviscosity of membrane lipid core, which is reflected by steady-state diphenylhexatriene (DPH) fluorescence anisotropy, was increasing with age in platelets of SS/Jr rats fed a low-salt diet. The changes of membrane microviscosity did not precede BP rise because DPH anisotropy in platelets of SS/Jr (but not $\mathrm{SR} / \mathrm{Jr}$ ) rats was substantially increased after 10 weeks (but not after 5 weeks) of high salt intake (Zicha et al. 1999b). Platelet DPH anisotropy was positively related to both blood pressure and plasma triglycerides, whereas it had an inverse relation to cytosolic $\mathrm{pH}$ which was significantly decreased in platelets of salt hypertensive SS/Jr rats (Zicha et al. 1997, 1999b). Surprisingly, DPH fluorescence anisotropy was significantly decreased in erythrocytes of salt-sensitive ( $\mathrm{SS} / \mathrm{Jr}$ ) rats compared to $\mathrm{SR} / \mathrm{Jr}$ animals, but there was no significant influence of high salt intake or hypertension on this membrane parameter (Kuneš et al. 1994, Zicha et al. 1999b). Unfortunately, we do not have any data about the influence of red blood cell maturity on the microviscosity of their cell membranes.

In contrast to SHR, cytosolic calcium level $\left(\left[\mathrm{Ca}^{2+}\right]_{\mathrm{i}}\right)$ was not elevated in platelets of salt hypertensive $\mathrm{SS} / \mathrm{Jr}$ rats fed $4 \% \mathrm{NaCl}$ diet (Zicha et al. 1996c, 1997). The absence of $\left[\mathrm{Ca}^{2+}\right]_{\mathrm{i}}$ elevation was earlier reported in platelets of DOCA-salt hypertensive rats (Murakawa et al. 1986, Baba et al. 1987, Ishida et al. 1994) or salt hypertensive DIS rats (Ishida et al. 1995, Otsuka et al. 1997). Although platelet $\left[\mathrm{Ca}^{2+}\right]_{\mathrm{i}}$ was not significantly altered in Dahl rats, its value correlated positively with systolic BP but not with diastolic BP. The correlation of 
$\left[\mathrm{Ca}^{2+}\right]_{\mathrm{i}}$ with pulse pressure was especially strong. Similar relationships were also disclosed in platelets of Sabra or Lyon rats (Zicha et al. 1996c). Interestingly, in saltsensitive rats high salt intake was associated with a decreased rate of thrombin-induced $\mathrm{Ca}^{2+}$ entry (Ishida et al. 1995) or $\mathrm{Mn}^{2+}$ entry through receptor-operated $\mathrm{Ca}^{2+}$ channels into the platelets of Sabra or Dahl rats (Zicha et al. 1996c) and this attenuation was independent of basal BP level. Thus, salt hypertensive Dahl rats or Sabra hypertension-prone rats differed substantially from genetically hypertensive Lyon rats in which $\mathrm{Mn}^{2+}$ entry was accelerated (Zicha et al. 1996c). A decrease in thrombin-induced $\mathrm{Ca}^{2+}$ entry into the platelets of salt hypertensive Dahl rats was confirmed by Li et al. (2001) who also demonstrated increased intracellular $\mathrm{Ca}^{2+}$ stores and enhanced SERCA-dependent $\mathrm{Ca}^{2+}$ uptake in platelets of these animals. It should also be noted that we did not find any significant relationship between plasma lipids and platelet $\mathrm{Ca}^{2+}$ handling in Dahl rats (Zicha et al. 1997).

\section{Insulin resistance, inflammation and organ damage}

Distinct features of metabolic syndrome (such as insulin resistance, hyperinsulinemia, hypertriglyceridemia or abdominal obesity) can be disclosed in salt-sensitive Dahl rats and these symptoms are exacerbated by high salt intake (Reaven et al. 1991a). Decreased glucose uptake and utilization were reported in salt hypertensive Dahl rats both at the whole-body level and in particular tissues such as adipocytes or skeletal muscle (Ogihara et al. 2002). Despite the insulin resistance of these rats, the early steps of insulin signaling are augmented. Since tyrosine phosphorylation of the insulin receptor and insulin receptor substrates, the activation of phosphatidylinositol 3-kinase (PI3K) and phosphorylation of Akt (protein kinase B) were enhanced in saltsensitive Dahl rats fed a high-salt diet, the defect of insulin signaling, which is responsible for insulin resistance in these rats, must be located downstream of PI3K and Akt activation (Ogihara et al. 2002). Indeed, the number of insulin receptors, their affinity and binding parameters as well as their mRNA levels or tissue distribution in liver, muscle or kidney were similar in $\mathrm{SS} / \mathrm{Jr}$ and SR/Jr rats (Sechi et al. 1997). It could be supposed that chronic administration of PPAR $\gamma$ agonists as insulin sensitizers would attenuate salt hypertension development or at least mitigate its progression.
Nevertheless, both preventive (Sartori-Valinotti et al. 2010) or therapeutic (Bolten et al. 2007) effects of rosiglitazone treatment on blood pressure were relatively weak and they were not directly related to metabolic action of PPAR $\gamma$ activators (Bolten et al. 2007). Surprisingly, insulin sensitivity of $\mathrm{SS} / \mathrm{Jr}$ rats was improved more effectively by ACE inhibitor quinapril rather than by $\mathrm{AT}_{1}$ receptor blocker losartan, indicating a substantial role of endogenous kinins (Nakagawa et al. 1999).

Recently, Leopoldo Raij and his colleagues documented the link between metabolic and cardiovascular alterations in salt hypertension which involves vascular inflammation. It seems that angiotensin II-induced superoxide overproduction interferes not only with insulin signaling pathways leading to a decreased production of nitric oxide (NO) in metabolic and cardiovascular tissues (Zhou et al. 2009), but it also activates nuclear factor $\mathrm{\kappa B}$ (NF- $\mathrm{\kappa B}$ ) pathway leading to a low-grade inflammation of renal vessels (Zhou et al. 2010). NF- $\mathrm{KB}$ activation in salt hypertensive Dahl rats can be blocked by chronic treatment with either tempol (superoxide dismutase mimetic) or candesartan $\left(\mathrm{AT}_{1}\right.$ receptor blocker) (Zhou et al. 2010). Both treatments attenuated salt hypertension development and improved insulin sensitivity in these rats (Zhou et al. 2009).

Renal inflammation accompanied by increased formation of reactive oxygen species (ROS), NF- $\mathrm{kB}$ activation and tumor necrosis factor- $\alpha$ (TNF- $\alpha$ ) upregulation has been repeatedly reported in salt hypertensive Dahl rats (Gu et al. 2006, Chandramohan et al. 2008). Chronic administration of interferon $\gamma$, a potent immunomodulator, ameliorated renal injury in salt hypertensive DIS rats (Ishimitsu et al. 1992). Preventive administration of interleukin-2, which stimulates the proliferation and maturation of thymus-derived lymphocytes, also attenuated salt hypertension development, reduced cardiac hypertrophy and improved glomerular filtration rate in DIS rats (Ishimitsu et al. 1994). Immunosuppressive therapy attenuated the progression of malignant arteritis in the kidneys of salt hypertensive DIS rats (Uehara et al. 1997). Chronic antiimmune therapy with mycophenolate mofetil (Tian et al. 2007a), chronic antioxidant administration (Tian et al. 2007b) or chronic fish oil supplementation (Diaz Encarnacion et al. 2008) reduced ROS formation, decreased NF- $\mathrm{kB}$ activation, ameliorated renal inflammatory injury and lowered blood pressure in salt hypertensive Dahl rats. Vascular inflammation and 
altered function of regulatory $\mathrm{T}$ lymphocytes in blood vessels of salt-sensitive Dahl rats were also reported by Viel et al. (2010).

The process of glomerular injury and renal fibrosis is associated with an increased expression of transforming growth factor- $\beta$ (TGF- $\beta$ ). Renal levels of TGF- $\beta$ mRNA were markedly elevated in salt hypertensive Dahl rats (Tamaki et al. 1996) and this elevation could be reduced by chronic $\mathrm{AT}_{1}$ receptor blockade (Otsuka et al. 1998, Dejima et al. 2010), statin treatment (Zhou et al. 2008a) or eplerenone administration (Onozato et al. 2007). Dahly et al. (2002) demonstrated that chronic administration of antibody against TGF- $\beta$ reduced blood pressure, proteinuria and renal injury in SS/Jr rats fed a high-salt diet. Ying and Sanders (2003) reported that the aortic production of TGF- $\beta_{1}$ and NO correlated linearly in both $\mathrm{SS} / \mathrm{Jr}$ and SR/Jr, but TGF- $\beta_{1}$ production was always considerably higher in $\mathrm{SS} / \mathrm{Jr}$ rats at any level of NO production. High salt intake augmented TGF- $\beta_{1}$ production in SS/Jr rats only. It seems that the inhibitory effect of NO on TGF- $\beta_{1}$ production was reduced in SS/Jr animals. Thus, the augmented vascular and glomerular production of TGF- $\beta_{1}$ and the diminished NO formation might contribute to the development of hypertensive nephrosclerosis (Ying and Sanders 2003). Indeed, gene silencing of TGF- $\beta_{1}$ promoter lowered not only TGF- $\beta_{1}$ expression but also proteinuria and glomerulosclerosis in salt hypertensive Dahl rats, suggesting a new approach for the treatment of progressive renal disease (Matsuda et al. 2006, 2011). Similar beneficial effects on hypertensive glomerulosclerosis was achieved by the reduction of TGF- $\beta_{1}$ mRNA expression (Tahira et al. 2007).

The suppression of TGF- $\beta$ expression by chronic administration of statins could explain their influence on blood pressure and proteinuria in salt hypertensive Dahl rats (Wilson et al. 1998, Zhou et al. 2004, Kido et al. 2005). Statin treatment lowered ROS production, prevented the downregulation of endothelial NO synthase (eNOS), increased NO bioavailability, improved NOdependent endothelial relaxation and reduced renal damage in salt hypertensive Dahl animals (Zhou et al. 2008a, for review see Schulman et al. 2006). It should be mentioned that atorvastatin exerted these beneficial effects in both preventive and therapeutic experiments (Zhou et al. 2004). Statin-induced inhibition of Rho kinase pathway helps to explain the increase of endothelial NOS-mediated NO production (Rikitake and Liao 2005).

It has been demonstrated that not only TGF- $\beta_{1}$ but also proinflammatory cytokines such as monocyte chemoattractant protein-1 (MCP-1) and lectin-like oxidized LDL receptor-1 (LOX-1) play an important role in hypertensive nephropathy (Nagase et al. 2000, Chiba et al. 2002, Dahly et al. 2002, Ueno et al. 2003). Zhou et al. (2006) observed increased ROS production, impaired endothelium-dependent vasodilatation and enhanced expression of LOX-1 and MCP-1 in salt hypertensive Dahl rats and these changes could be abolished by the inactivation of NADPH oxidase (the inhibition of the assembly of $\mathrm{p} 47^{\text {phox }}$ subunit with gp9 $1^{\text {phox }}$ ), although this intervention had no significant effects on blood pressure. Furthermore, Zhou et al. (2008a) reported that chronic atorvastatin treatment attenuated proteinuria and glomerulosclerosis, normalized oxidative stress, TGF- $\beta_{1}$, LOX-1 and MCP-1 expression as well as restored eNOS activity, but it had only modest BP lowering effects. On the contrary, the administration of thiazide diuretics effectively reduced blood pressure and proteinuria, but it did not affect oxidative stress, LOX-1 and MCP-1 expression or endothelial dysfunction (Zhou et al. 2008b). Chronic administration of low doses of eplerenone reduced proteinuria and glomerulosclerosis as well as the expression of LOX-1-mediated adhesion molecules, inhibited PKCE-MAPK-p90RSK pathway and improved endothelial dysfunction but again without BP reduction (Kobayashi et al. 2005). The inhibition of p38MAPK had also no effect on high blood pressure of salt hypertensive DIS rats, but it suppressed renal NADPH oxidase expression and superoxide formation, increased eNOS and iNOS expression in the kidney, enhanced NO bioavailability and attenuated renal TNF- $\alpha$ and interleukin- $1 \beta$ production, leading thus to the amelioration of renal damage (Tojo et al. 2005). These data suggest that the complex activation of TGF- $\beta_{1}$, LOX-1, adhesion molecules, protein kinase $\mathrm{C} \varepsilon(\mathrm{PKC} \varepsilon$ ), mitogen-activated protein kinase (MAPK) and Rho kinase pathways in salt hypertensive Dahl rats is involved in pathogenetic processes leading to organ damage rather than in the mechanisms directly regulating blood pressure. Further evidence for this assumption was brought by Hiroaki Matsuoka and his colleagues who studied cardiac dysfunction and/or heart failure in salt hypertensive DIS rats. The blockade of particular steps of the above mentioned cascade by subdepressor doses of $\beta$-blocker betaxolol (Kobayashi et al. 2004), Rho kinase inhibitor Y-27632 (Mita et al. 2005), mineralocorticoid receptor inhibitor eplerenone (Kobayashi et al. 2006a), ACE inhibitor quinapril or NADPH oxidase inhibitor apocynin (Kobayashi et al. 2006b) exerted major 
cardioprotective effects without significant BP reduction.

On the basis of the sophisticated experimental data (Shibata et al. 2008) an alternative pathway for the activation of mineralocorticoid receptors (MR) was proposed by Fujita (2010). Rac1, a small GTP-binding protein, which is a member of the Rho family of GTPases, is involved in numerous biological processes, including cytoskeletal organization, cell migration or NADPH oxidase activation. High salt intake activates renal Rac1 in salt-sensitive animals and Rac1 induces MR activation. Hyperglycemia as a part of metabolic syndrome activates MR through Rac1 activation. It is evident that not only MR inhibition by eplerenone but also Rac1 inhibition attenuates proteinuria and renal injury. Thus the abnormal activation of the aldosterone/MR pathway plays a key role in the development of salt-sensitive hypertension and renal injury in metabolic syndrome (Fujita 2010). This seems to be pertinent even for salt hypertension of Dahl rats.

11ß-hydroxysteroid dehydrogenase type 1 (11ß-HSD 1) is one of the factors important for the regulation of insulin sensitivity in salt hypertensive animals (Usukura et al. 2009). High salt intake increased significantly corticosterone concentration, 11 $\beta$-HSD 1 expression and activity as well as the expression of glucocorticoid receptors and TNF- $\alpha$ in adipose tissue of DIS compared to DIR rats. These changes of

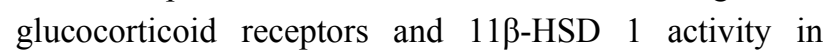
adipose tissue contribute to the decreased insulin sensitivity in salt hypertensive Dahl rats (Usukura et al.

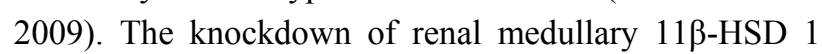
with small-interfering RNA attenuated the early phase of salt hypertension in $\mathrm{SS} / \mathrm{Jr}$ rats (Liu et al. 2008).

Salt hypertension in Dahl rats is associated with numerous metabolic abnormalities (insulin resistance), vascular inflammation of renal vessels and renal injury (glomerulosclerosis, fibrosis). The underlying complex alterations of intracellular signaling might explain why the above abnormalities can be partly dissociated from BP elevation so that some therapeutic interventions can ameliorate end-organ damage without major BP reduction, while the other lower blood pressure without major improvement of renal and cardiac injury.

\section{Sodium and water retention, body fluids,} systemic hemodynamics and kidney function

The theory of Arthur C. Guyton (1992) on the regulation of circulatory homeostasis presumes the important involvement of body fluid expansion in the pathogenesis of salt hypertension. Indeed, blood volume expansion has been reported in salt hypertensive Dahl rats (Overbeck et al. 1981, Simchon et al. 1989), but this is true only for $\mathrm{SS} / \mathrm{Jr}$ animals exposed to high salt intake from youth but not for those subjected to the same stimulus solely in adulthood (Zicha et al. 1987a, Dobešová et al. 1995). Salt hypertension induced by feeding of adult $\mathrm{SS} / \mathrm{Jr}$ rats with $8 \% \mathrm{NaCl}$ diet is accompanied even by the reduction of plasma and blood volumes (Dobešová et al. 1995). Moreover, we observed that the expansion of blood volume and extracellular fluid volume appears relatively late in the development of salt hypertension, i.e. several weeks after a major BP rise (Dobešová et al. 1995). Nevertheless, Simchon et al. (1991) reported that blood volume expansion and increased cardiac output preceded the elevation of systemic resistance in the early stages of salt hypertension development in young Dahl rats. This would be in agreement with the importance of increased cardiac output in very young SHR which is followed by a later increase of systemic resistance (Smith and Hutchins 1979, Lundin and Hallbäck-Nordlander 1980, Evenwel et al. 1983). However, Ganguli et al. (1979) demonstrated the early increase of cardiac output not only in DS but also in DR rats and the rise in systemic resistance was decisive for BP elevation elicited by high salt intake in DS rats. Finally, He et al. (1997) observed that L-arginine supplementation of young salt-loaded DIS rats increased cardiac output but lowered their blood pressure due to a decrease in systemic resistance.

In the course of salt hypertension development there is a gradual impairment of autoregulatory control of renal blood flow in $\mathrm{SS} / \mathrm{Jr}$ rats. $\mathrm{RBF}$ autoregulation was abolished if high salt intake started at weaning, whereas the later onset of high-salt diet feeding was associated with a partially preserved autoregulation (Karlsen et al. 1997). Since renal morphological changes develop before the loss of dynamic autoregulation, the impaired autoregulation appears to be the result but not the cause of the process leading to renal failure in salt hypertensive Dahl rats (Karlsen et al. 1997). The loss of RBF autoregulation in hypertensive animals seems to be due to a compromised myogenic response, whereas there was no evidence of decreased tubuloglerular feedback (TGF) responsiveness in salt hypertensive $\mathrm{SS} / \mathrm{Jr}$ rats (Karlsen et al. 1998). When Wilcox and Welch (1996) compared TGF response in SS/Jr and Sprague Dawley rats, they reported blunted TGF response in $\mathrm{SS} / \mathrm{Jr}$ rats during low salt intake but not during high salt intake. They ascribed 
these findings to a defective regulation of nephron $\mathrm{NO}$ release in $\mathrm{SS} / \mathrm{Jr}$ rats subjected to high salt intake.

The study of renal structural properties in maximally vasodilated perfused kidneys of Dahl rats fed a low-salt diet revealed hypertrophic remodeling of interlobular arteries (without narrowing of preglomerular resistance vessel) as well as a glomerular permeability defect which is responsible for the attenuation of GFR in prehypertensive SS/Jr rats (Tomoda et al. 2000). High perfusion pressure accelerates the development of glomerular injury and interstitial fibrosis in the kidneys of SS/Jr rats (Mori et al. 2008).

Salt hypertensive Dahl rats are characterized by abnormal pressure-natriuresis (Tobian et al. 1978, Roman 1986, Roman and Kaldunski 1991, Patel et al. 1993, Hu and Manning 1995) which results from altered intrarenal generation of angiotensin II (Ang II) and 20-hydroxyeicosatetraenoic acid (20-HETE), enhanced ROS formation and low NO bioavailability (for review see Zou and Cowley 1999, Roman 2002). Lower sodium excretion by DS than by DR kidneys at any renal perfusion pressure was attributed to abnormal $\mathrm{NaCl}$ transport in particular nephron segments, e.g. increased chloride transport in the thick ascending limb of loop of Henle (TALH) (Kirchner 1990). NO was found to inhibit chloride reabsorption in TALH and this inhibition was attenuated in DS compared to DR rats (Garcia et al. 1999), explaining thus the increased $\mathrm{NaCl}$ reabsorption in salt-sensitive animals. Furthermore, the impaired renal NO formation facilitates Ang II-induced vasoconstriction in renal medulla (Szentivanyi et al. 2002). Under the condition of high salt intake, NO production was reduced in salt-sensitive animals, whereas it was increased in saltresistant rats (Chen and Sanders 1993, Hu and Manning 1995, Simchon et al. 1996). One of the possible explanation for reduced NO formation might be higher levels of circulating endogenous NOS inhibitor asymmetrical dimethyl-L-arginine - in $\mathrm{SS} / \mathrm{Jr}$ rats compared to SR/Jr rats fed a high-salt diet (Matsuoka et al. 1997). The supplementation of salt-sensitive Dahl rats with L-arginine improved renal hemodynamics, reversed NADPH oxidase upregulation and attenuated the development of salt hypertension (Chen and Sanders 1991, Patel et al. 1993, Hu and Manning 1995, He et al. 1997, Miyata and Cowley 1999, Mattson and Wu 2000, Fujii et al. 2003). Increased renal vascular resistance, impaired renal vasodilatation and attenuated urinary cGMP excretion are characteristic features of young saltsensitive Dahl rats fed a high-salt diet. This is not only due to their decreased NO production but also due to their hyporesponsiveness to vasodilators such as atrial natriuretic peptide or sodium nitroprusside as it was demonstrated by Simchon et al. $(1989,1992,1996)$.

A molecular basis for decreased renal guanylate cyclase activity was described by Gupta et al. (1997). The importance of impaired cGMP formation for salt hypertension development in Dahl rats was recently confirmed by Geschka et al. (2011). They reported that chronic administration of riociguat (BAY 63-2521), which sensitizes soluble guanylate cyclase to endogenous NO and also directly stimulates cGMP production, attenuated salt hypertension development, improved rat survival and their heart function and prevented fibrotic tissue remodeling.

Although no abnormality of sodium or water transport was disclosed in the cortical collecting duct of SS/Jr rats (Hawk and Schafer 1991), the cells of inner medullary collecting duct (IMCD) from $\mathrm{SS} / \mathrm{Jr}$ rats transported more sodium than IMCD cells from SR/Jr rats (Husted et al. 1996). Higher IMCD Na ${ }^{+}$transport in $\mathrm{SS} / \mathrm{Jr}$ rats was not due to a higher number of $\mathrm{Na}, \mathrm{K}$-pump sites but they operated at a higher fraction of their maximum capacity (Husted et al. 1997). The main reason for a higher rate of $\mathrm{Na}^{+}$transport in IMCD cells of SS/Jr rats was a primary increase in the conductive permeability of the apical membrane for $\mathrm{Na}^{+}$(Husted et al. 1997) which is mediated by epithelial $\mathrm{Na}^{+}$channels $(\mathrm{ENaC})$. Although these channels are not different in $\mathrm{SS} / \mathrm{Jr}$ and SR/Jr rats (Shehata et al. 2007), the regulation of these channels by aldosterone or high salt intake seems to be altered in salt hypertensive Dahl rats (Aoi et al. 2006,2007 ). The mRNA expression of $\alpha, \beta$ and $\gamma \mathrm{ENaC}$ subunits was abnormally increased by high salt intake in salt-sensitive Dahl rats (Aoi et al. 2007). This abnormal $\mathrm{ENaC}$ activation occurred despite the suppression of both plasma and kidney aldosterone levels in these animals and it was clearly enhanced in salt hypertensive Dahl rats (Kakizoe et al. 2009). Serum- and glucocorticoid-induced serine/threonine kinase 1 (SGK1) stimulates the activity and expression of renal ENaC. SGK1 expression was enhanced by high salt intake in the kidneys of saltsensitive rats but suppressed in the kidneys of saltresistant Dahl rats or Sprague Dawley rats (Farjah et al. 2003, Aoi et al. 2007). In addition, both strains of Dahl rats also differed in aldosterone-induced regulation of $\mathrm{ENaC}$ and SGK1 because aldosterone application decreased mRNA expression of $\beta$ and $\gamma \mathrm{ENaC}$ subunits in the kidneys of salt-sensitive but not salt-resistant rats, 
whereas it increased the expression of $\alpha \mathrm{ENaC}$ subunits in both strains. Furthermore, aldosterone increased SGK1 expression in salt-resistant rats only (Aoi et al. 2006). Prostasin, a glycosylphosphatidyl-inositol-anchored serine protease, seems to play a pivotal role in $\mathrm{ENaC}$ activation. Chronic inhibition of this enzyme reduced the development of salt hypertension, proteinuria and renal injury in salt-sensitive Dahl rats (Maekawa et al. 2009).

TALH of salt-sensitive Dahl rats is also characterized by additional abnormalities of ion transport systems such as the overexpression of chloride channels (CLC-K2) (Castrop et al. 2000) or the increased activity of $\mathrm{Na}, \mathrm{K}, 2 \mathrm{Cl}$ cotransporter (NKCC2) (Alvarez-Guerra and Garay 2002). O'Connor et al. (2008, 2009) described enhanced amiloride-sensitive superoxide production in TALH of SS/Jr rats which was not mediated by $\mathrm{Na}^{+} / \mathrm{H}^{+}$ exchanger.

Metabolites of arachidonic acid are also important players in the control of renal function in salt hypertensive Dahl rats. 20-hydroxyeicosatetraenoic acid is known to inhibit the activity of $\mathrm{Na}, \mathrm{K}, 2 \mathrm{Cl}$-cotransporter in TALH and renal outer medullary $\mathrm{K}^{+}$channel, both of them being important for sodium and chloride excretion (for review see Roman 2002). The formation of 20-HETE by cytochrome P450-4A $\omega$ hydrolase in the renal outer medulla is reduced in SS/Jr rats (Ma et al. 1994), predisposing these rats to the enhanced sodium and chloride reabsorption and salt retention when exposed to high salt intake (Stec et al. 1996, Hoagland et al. 2004). The induction of cytochrome P450-4A (CYP4A) activity by fibrates improved pressure-natriuresis relationship in SS/Jr rats (Alonso-Galicia et al. 1998) and attenuated salt hypertension development in this rat strain (Roman et al. 1993, Wilson et al. 1998). On the other hand, the inhibition of medullary 20-HETE synthesis induced salt sensitivity in Sprague Dawley and Lewis rats (Stec et al. 1997, Hoagland et al. 2003). CYP4A is located on rat chromosome 5 and the respective chromosomal region cosegregated with blood pressure in $\mathrm{F}_{2}$ hybrids of $\mathrm{SS} / \mathrm{Jr} \mathrm{x}$ Lewis rats (Stec et al. 2006). The transfer of this region from Lewis into $\mathrm{SS} / \mathrm{Jr}$ rats improved pressure-natriuresis and attenuated the development of salt hypertension and renal injury (Roman et al. 2006, Williams et al. 2008).

Further important metabolites of arachidonic acid such as epoxyeicosatrienoic acids (EETs) also exert an important role in salt hypertension development. Liclican et al. (2009) induced the salt sensitivity in saltresistant Dahl rats through the inhibition of cytochrome P450 epoxygenase, leading to a decreased formation of vasodilator and natriuretic EETs.

Although increased systemic resistance is a dominant hemodynamic abnormality in salt hypertensive Dahl rats, the importance of early blood volume expansion and the increase of cardiac output cannot be excluded. Impaired renal sodium and water excretion in salt-sensitive Dahl rats has been recognized a long time ago. The central role of kidney in this hypertensive model is manifested by abnormal pressure-natriuresis relationship due to the altered intrarenal formation of Ang II, 20-HETE, ROS, NO and EETs. A special attention should be paid to the changes in blood flow and ion transport in the inner renal medulla (with a special respect to the function of TALH) in salt hypertensive animals.

\section{Balance of vasoconstrictor and vasodilator systems}

Hypertensive effects of high salt intake exerted by the changes in the balance of vasoconstrictor and vasodilator systems seem to be more important than those caused by the increase of hemodynamically active intravascular volume. As far as the altered balance of vasoactive systems in salt-dependent hypertension is concerned, our initial studies in young and adult DOCAsalt hypertensive rats indicated that sympathetic nervous system is responsible for the maintenance of high blood pressure in young animals, whereas pressor effects of angiotensin II and vasopressin play a more important role in adult rats (Zicha et al. 1987b, 1989).

The contribution of vasoconstrictor effects of endogenous angiotensin II to the maintenance of high blood pressure in young salt hypertensive SS/Jr Dahl rats was almost negligible, whereas the acute captopril administration to adult salt hypertensive $\mathrm{SS} / \mathrm{Jr}$ rats lowered their blood pressure by $10-15 \mathrm{~mm} \mathrm{Hg}$ (Table 2). The association of captopril-induced BP changes with basal blood pressure is also more significant in adult than in young Dahl animals (Table 3). This absence of actual pressor action of circulating Ang II contrasts with the fact that chronic blockade of renin-angiotensin system (RAS) by either ACE inhibitors (Fernandez et al. 1988, Hirawa et al. 1994, Quaschning et al. 2001) or $\mathrm{AT}_{1}$ receptor blockers (Maitland et al. 2006, Takeda et al. 2007, Liang and Leenen 2008) considerably attenuated salt hypertension development and/or renal damage occurrence. However, our experiments revealed that the mild BP reduction induced by chronic preventive 
Table 2. Basal and residual values of mean arterial pressure (MAP) as well as its particular components mediated by sympathetic vasoconstriction (pentolinum-induced BP fall) and NO-dependent vasodilatation (L-NAME-induced BP rise) in young and adult Dahl female rats subjected to $8 \% \mathrm{NaCl}$ diet feeding for 4 weeks from the age of 4 or 12 weeks, respectively.

\begin{tabular}{|c|c|c|c|c|c|c|c|c|c|}
\hline & \multicolumn{4}{|c|}{ Young } & \multicolumn{5}{|c|}{ Adult } \\
\hline & $\begin{array}{l}\text { SR/Jr } \\
\text { LS }\end{array}$ & $\begin{array}{l}\text { SR/Jr } \\
\text { HS }\end{array}$ & $\begin{array}{l}\text { SS/Jr } \\
\text { LS }\end{array}$ & $\begin{array}{l}\text { SS/Jr } \\
\text { HS }\end{array}$ & $\begin{array}{l}\text { SR/Jr } \\
\mathbf{L S}\end{array}$ & $\begin{array}{l}\text { SR/Jr } \\
\text { HS }\end{array}$ & $\begin{array}{l}\text { SS/Jr } \\
\text { LS }\end{array}$ & $\begin{array}{l}\text { SS/Jr } \\
\text { HS }\end{array}$ & \\
\hline$n$ & 12 & 20 & 11 & 17 & 18 & 20 & 16 & 21 & LSD \\
\hline $\begin{array}{l}\text { Basal MAP } \\
\text { (mm Hg) }\end{array}$ & $114 \pm 3$ & $113 \pm 3$ & $121 \pm 5$ & $201 \pm 6^{* \#}$ & $114 \pm 3$ & $115 \pm 2$ & $141 \pm 4^{+\S}$ & $176 \pm 5 * \# \S$ & 12 \\
\hline $\begin{array}{l}\text { Residual MAP } \\
(\mathrm{mm} \mathrm{Hg})\end{array}$ & $54 \pm 2$ & $54 \pm 2$ & $62 \pm 2^{+}$ & $104 \pm 7 *^{\#}$ & $52 \pm 3$ & $57 \pm 7$ & $76 \pm 4^{+\S}$ & $90 \pm 5^{* \# \S}$ & 14 \\
\hline $\begin{array}{l}\Delta \text { captopril } \\
(\mathrm{mm} \mathrm{Hg})\end{array}$ & $-3.8 \pm 0.9$ & $-3.1 \pm 0.9$ & $-4.1 \pm 1.5$ & $-6.2 \pm 2.6$ & $-6.3 \pm 1.0$ & $-1.5 \pm 1.2$ & $-8.5 \pm 1.2$ & $-12 \pm 2.5^{\# \S}$ & 4.9 \\
\hline $\begin{array}{l}\Delta \text { pentolinium } \\
(\mathrm{mm} \mathrm{Hg})\end{array}$ & $-63 \pm 3$ & $-59 \pm 3$ & $-63 \pm 5$ & $-106 \pm 5^{* \#}$ & $-63 \pm 2$ & $-67 \pm 2$ & $-77 \pm 4^{+\S}$ & $-96 \pm 4 * \# \S$ & 10 \\
\hline $\begin{array}{l}\triangle L-N A M E \\
(m m H g)\end{array}$ & $57 \pm 3$ & $51 \pm 3$ & $71 \pm 5^{+}$ & $72 \pm 5^{\#}$ & $53 \pm 2$ & $49 \pm 3$ & $78 \pm 4^{+}$ & $84 \pm 5^{\# \S}$ & 11 \\
\hline$\% \Delta$ captopril & $-3.4 \pm 0.8$ & $-2.7 \pm 0.9$ & $-3.3 \pm 1.2$ & $-3.0 \pm 1.2$ & $-5.4 \pm 0.8$ & $-1.3 \pm 1.1^{+}$ & $-6.1 \pm 0.9$ & $-6.7 \pm 1.4^{\# \S}$ & 3.2 \\
\hline$\% \Delta$ pentolinium & $-55 \pm 1$ & $-52 \pm 2$ & $-52 \pm 3$ & $-53 \pm 2$ & $-56 \pm 1$ & $-59 \pm 1$ & $-54 \pm 2$ & $-55 \pm 2$ & NS \\
\hline$\% \Delta L-N A M E$ & $50 \pm 3$ & $46 \pm 3$ & $60 \pm 4$ & $37 \pm 3 * \#$ & $48 \pm 3$ & $43 \pm 2$ & $56 \pm 3$ & $49 \pm 3^{\S}$ & 8.5 \\
\hline
\end{tabular}

Data are mean \pm S.E.M. BP changes are shown either as absolute values $(\Delta)$ or they are expressed as relative values (\% $\Delta)$, i.e. in percentages of their basal BP values. LSD - least significant difference at $\mathrm{p}<0.05$ level. Significant differences: $*$ vs. SS-LS, \# vs. SR-HS, + vs. SR-LS, $\S$ vs. young rats. NS - not significant on the basis of ANOVA test. These data were modified from Zicha et al. (2001b), Dobešová et al. (2002) and Zicha et al. (2012).

Table 3. The relationships between basal mean arterial pressure (MAP) and its particular components representing angiotensin II-dependent vasoconstriction ( $\Delta$ captopril), sympathetic vasoconstriction ( $\Delta$ pentolinium) and NO-dependent vasodilatation $(\Delta$ L-NAME) in young and adult SS/Jr and SR/Jr Dahl female rats as well as in SS/Jr x SR/Jr $F_{2}$ hybrids.

\begin{tabular}{|c|c|c|c|c|c|c|c|c|}
\hline & \multicolumn{2}{|c|}{ Young } & \multicolumn{2}{|c|}{ Adult } & \multicolumn{2}{|c|}{ All $(n=135)$} & \multicolumn{2}{|c|}{$F_{2}$ hybrids } \\
\hline Number of rats & \multicolumn{2}{|c|}{60} & \multicolumn{2}{|c|}{75} & \multicolumn{2}{|c|}{135} & \multicolumn{2}{|c|}{122} \\
\hline & & & & & & & & \\
\hline$\Delta$ captopril & -0.251 & $\mathrm{p}=0.06$ & -0.479 & $\mathrm{p}<0.001$ & -0.347 & $\mathrm{p}<0.001$ & -0.339 & $\mathrm{p}<0.001$ \\
\hline$\Delta$ pentolinium & -0.869 & $\mathrm{p}<0.0001$ & -0.847 & $\mathrm{p}<0.0001$ & -0.856 & $\mathrm{p}<0.0001$ & -0.772 & $\mathrm{p}<0.0001$ \\
\hline$\triangle L-N A M E$ & 0.301 & $\mathrm{p}<0.05$ & 0.506 & $\mathrm{p}<0.0005$ & 0.390 & $\mathrm{p}<0.0005$ & 0.339 & $\mathrm{p}<0.001$ \\
\hline Residual MAP & 0.770 & $\mathrm{p}<0.0001$ & 0.707 & $\mathrm{p}<0.0001$ & 0.734 & $\mathrm{p}<0.0001$ & 0.569 & $\mathrm{p}<0.0001$ \\
\hline$\% \Delta$ captopril & -0.035 & NS & -0.315 & $\mathrm{p}<0.01$ & -0.169 & $\mathrm{p}=0.05$ & -0.285 & $\mathrm{p}<0.005$ \\
\hline$\% \Delta$ pentolinium & -0.020 & NS & 0.171 & NS & 0.068 & NS & -0.277 & $\mathrm{p}<0.01$ \\
\hline$\% \triangle L-N A M E$ & -0.545 & $\mathrm{p}<0.001$ & -0.150 & NS & -0.359 & $\mathrm{p}<0.001$ & -0.139 & NS \\
\hline
\end{tabular}

Data represent correlation coefficients r. Residual MAP was recorded after the combined blockade of renin-angiotensin system by captopril and sympathetic nervous system by pentolinium. Relative MAP changes ( $\% \Delta$ ) were expressed in percentage of basal MAP values.

treatment of salt hypertensive $\mathrm{SS} / \mathrm{Jr}$ rats with $\mathrm{ACE}$ inhibitor captopril lowered their blood pressure by the attenuation of sympathetic vasoconstriction but not by the reduction of Ang II-dependent vasoconstriction (Dobešová and Zicha, unpublished data). Similarly, our earlier studies in rats with spontaneous or NO-deficient hypertension indicated that chronic captopril treatment prevented BP rise mainly by the attenuation of the sympathetic BP component (Zicha et al. 2006, Paulis et al. 2007). This is in agreement with the important 
participation of angiotensin II in the central nervous mechanisms controlling sympathetic outflow (for review see Leenen 2010). Although there is no doubt on the importance of RAS in the pathogenesis of salt hypertension, the peripheral vasoconstrictor effects of Ang II seem to be of minimal significance.

Rapp et al. $(1989,1990)$ were the first who demonstrated the cosegregation of $\mathrm{S}$ allele of the polymorphic renin gene with blood pressure in different sets of $F_{2}$ hybrids. Further evidence for the importance of renin gene was obtained in congenic or consomic strains in which renin gene from $\mathrm{SR} / \mathrm{Jr}$ or $\mathrm{BN}$ rats was introgressed into SS/Jr background (Amaral et al. 2001, Cowley et al. 2001, Hoagland et al. 2004, Taylor et al. 2006a, Bugenhagen et al. 2010). Actually these strains are often used to confirm or exclude the participation of renin gene in particular phenotypes of salt hypertensive Dahl rats. The overwhelming majority of positive results obtained in SS. $13^{\mathrm{BN}}$ rats might indicate either the extreme importance of RAS in multiple regulatory systems essential for the development of salt hypertension in Dahl rats or the considerable fragility of the polygenic system which is disrupted if a single component is missing. Vascular reactivity is one of the promising areas of research in which these special rat strains are very useful. The introgression of either renin gene region from SR/Jr rats (Drenjancevic-Peric et al. 2004) or chromosome 13 from $\mathrm{BN}$ rats into $\mathrm{SS} / \mathrm{Jr}$ background $\left(\mathrm{SS} .13^{\mathrm{BN}}\right)$ (Drenjancevic-Peric et al. 2003) restored the impaired acetylcholine-induced vasodilatation in cremaster muscle of SS/Jr rats fed a high-salt diet. Furthermore, the reduced acetylcholine-induced or hypoxia-induced relaxations of middle cerebral artery from $\mathrm{SS} / \mathrm{Jr}$ rats fed a low-salt diet were also caused by an abnormal RAS regulation because they were restored by renin gene transfer from $\mathrm{BN}$ or $\mathrm{SR} / \mathrm{Jr}$ rats (Drenjancevic-Peric et al. 2005, 2010). Moreover, the attenuation of RAS regulatory mechanisms by chronic high salt intake or chronic losartan treatment of SS.13 ${ }^{\mathrm{BN}}$ rats abolished these relaxations restored by the renin gene transfer (Drenjancevic-Peric and Lombard 2004, 2005). Durand and Lombard (2011) ascribed the attenuation of NO-dependent vasodilatation in cerebral arteries of $\mathrm{SS} / \mathrm{Jr}$ to the increased levels of superoxide which were lowered by the enhanced expression of $\mathrm{Cu} / \mathrm{Zn}$ superoxide dismutase in the respective congenic strain possessing BN renin gene.

The dysbalance between sympathetic nervous system (SNS) and nitric oxide, as principle vasoactive systems, plays a major role in the maintenance of salt hypertension. Enhanced sympathetic vasoconstriction (Mark 1991, Huang and Leenen 1998) together with enhanced norepinephrine turnover (Kotchen et al. 1991b, Kuneš et al. 1991) in salt hypertensive Dahl rats are accompanied by a reduced production of vasodilator and natriuretic nitric oxide (Lüscher et al. 1987, Chen and Sanders 1991, Hu and Manning 1995, Simchon et al. 1996, He et al. 1997). Our studies on vasoactive balance carried out in young salt hypertensive $\mathrm{SS} / \mathrm{Jr}$ rats (Zicha et al. 2001b) confirmed the decisive role of sympathetic hyperactivity and suggested that NO-dependent vasodilatation was attenuated by enhanced production of superoxide anions interacting with the available NO at the vascular level.

Sympathetic hyperactivity in salt hypertensive Dahl rats results from the increased sympathoexcitation and/or decreased sympathoinhibition mediated by complex central nervous mechanisms (for review see Leenen 2010, Huang and Leenen 2011, Blaustein et al. 2012, Oki et al. 2012). The increased sympathoexcitation in salt hypertensive Dahl rats seems to result from the enhanced response of vasomotor neurons of rostral ventrolateral medulla (RVLM) to excitatory amino acids (Ito et al. 2001), although Tsuchihashi et al. (1997) did not observe any difference in the effects of these amino acids in DIS and DIR rats. The injection of Ang II into RVLM or in the vicinity of the hypothalamic paraventricular nucleus elicited a greater tonic activation of vasomotor neurons in salt hypertensive Dahl rats which can be prevented by $\mathrm{AT}_{1}$ receptor antagonists (Ito et al. 2003).

This Ang II-dependent excitatory process is further amplified by the central nervous pathway(s) involving endogenous brain aldosterone and mineralocorticoid receptors (Gomez-Sanchez et al. 1992, 2005), epithelial sodium channels (Gomez-Sanchez and Gomez-Sanchez 1995) and endogenous brain ouabainlike compound (Huang and Leenen 1994, Huang et al. 2009). Sympathetic hyperactivity of salt hypertensive Dahl rats is triggered by the increased $\mathrm{Na}^{+}$concentration in the cerebrospinal fluid (CSF) (Nakamura and Cowley 1989, Simchon et al. 1999, Huang et al. 2004). The underlying mechanisms of the enhanced sympathoexcitation in salt hypertensive animals seem to involve the reduced NO release in paraventricular nucleus (Gabor and Leenen 2011) and angiotensin II-induced activation of glutamate receptors in this nucleus (Gabor and Leenen 2012).

There are several fundamental findings 
concerning the above mentioned central nervous mechanisms. First of all, the increase of CSF $\mathrm{Na}^{+}$ concentration precedes BP increase (Huang et al. 2004). Second, the increase of CSF $\mathrm{Na}^{+}$concentration elicits a more pronounced sympathetic activation and a greater BP rise in young than in adult salt-sensitive Dahl rats (Huang et al. 2001). Third, intracerebroventricular infusion of aldosterone to $\mathrm{SS} / \mathrm{Jr}$ rats causes a similar response as high salt intake, i.e. brain ouabain-like compound increase, sympathetic hyperactivity and hypertension (Huang et al. 2005). Finally, high salt intake increases brain RAS preferentially in SS/Jr rats, i.e. ACE activity, Ang II levels and $\mathrm{AT}_{1}$ receptor density (Zhao et al. 2001, Wang et al. 2003a).

The possible role of brain aldosterone in the pathogenesis of salt hypertension has attracted the attention since the demonstration that intracerebroventricular but not subcutaneous infusion of selective MR antagonist RU28318 blocked the development of salt hypertension in SS/Jr rats (Gomez-Sanchez et al. 1992). The same effect was achieved by the blockade of brain steroidogenesis in salt-sensitive Dahl rats using the

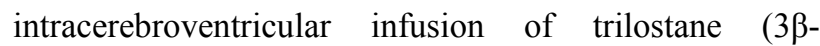
hydroxysteroid dehydrogenase inhibitor) (GomezSanchez et al. 2005). Aldosterone synthase mRNA expression was found to be enhanced in the brain of SS/Jr rats, whereas no significant changes in mRNA expression of mineralocorticoid receptors, $11 \beta$-hydroxylase or $11 \beta$ hydroxysteroid dehydrogenase type 1 or 2 were detected in the brainstem, hypothalamus or hippocampus of $\mathrm{SS} / \mathrm{Jr}$ rats (Gomez-Sanchez et al. 2010). Central infusion of aldosterone synthase inhibitor FAD286 prevented sympathetic hyperactivity and hypertension elicited by the elevation of cerebrospinal $\mathrm{Na}^{+}$concentration in Wistar rats (Huang et al. 2008). Indeed, a chronic intracerebroventricular infusion of aldosterone synthase inhibitor FAD286 or MR antagonist spironolactone prevented salt hypertension development in $\mathrm{SS} / \mathrm{Jr}$ rats (Huang et al. 2009, Gomez-Sanchez et al. 2010).

It should be noted that MR can be activated by the surplus of glucocorticoids which are normally inactivated by $11 \beta$-hydroxysteroid dehydrogenase type 2 (11 $\beta$-HSD 2). The expression and/or activity of this enzyme was decreased in blood vessels of salt-sensitive Dahl rats (Takeda et al. 1994, Mazancová et al. 2003b) and the reduced $11 \beta$-HSD 2 activity in mesenteric arteries of salt hypertensive Dahl rats was accompanied by their enhanced vasoconstrictor response to norepinephrine (Takeda et al. 1994). On the other hand, Fenton et al.
(2003) observed that under the conditions of low salt intake 11 $\beta$-HSD 2 levels were increased in inner medullary collecting duct of $\mathrm{SS} / \mathrm{Jr}$ rats compared to $\mathrm{SR} / \mathrm{Jr}$ ones. This abnormality, which leads to decreased local corticosterone concentrations, was associated with a decreased expression of $\alpha$ subunit of $\mathrm{ENaC}$ that was normalized by the chronic inhibition of $11 \beta$-hydroxysteroid dehydrogenase in $\mathrm{SS} / \mathrm{Jr}$ rats using carbenoxolone infusion (Fenton et al. 2003). In fact, Pohlová et al. (2000) observed a higher activity of 11ß-HSD 2 in the renal medulla and cortex of $\mathrm{SS} / \mathrm{Jr}$ rats fed a low-salt diet, but chronic elevation of salt intake increased $11 \beta$-HSD 2 activity in the kidney of SR/Jr rats only, abolishing thus the strain difference in the activity of this enzyme. This might also be associated with a decreased corticosterone inactivation in salt hypertensive Dahl rats. Moreover, Mazancová et al. (2003a) reported a significantly lower net activity of 11ß-hydroxysteroid dehydrogenase in placental tissue of $\mathrm{SS} / \mathrm{Jr}$ rats leading to lower corticosterone inactivation and less efficient placental protection of SS/Jr fetuses from the deleterious effects of intrauterine glucocorticoid surplus. Indeed, chronic inhibition of $11 \beta$-hydroxysteroid dehydrogenase in pregnant rats by carbenoxolone increased blood pressure in their offspring (Lindsay et al. 1996).

Increased brain oxidative stress can also participate in the central sympathoexcitation which mediates BP elevation in young salt hypertensive Dahl rats (Fujita et al. 2007) or Sprague Dawley rats (Fujita et al. 2012). In fact, chronic administration of antioxidants such as $\mathrm{N}$-acetylcysteine attenuated the development of salt hypertension in $\mathrm{SS} / \mathrm{Jr}$ rats by a reduction of sympathetic vasoconstriction (Kuneš et al. 2004b). Not only central but also peripheral mechanisms contribute to the increased sympathetic nerve activity because high salt intake can suppress catechol-O-methyltransferase activity via blunting $\alpha_{2}$-adrenoceptor signaling (Hirano et al. 2007).

Finally, decreased baroreflex efficiency and resulting attenuation of sympathoinhibition might also contribute to the increased sympathetic nervous activity in salt-sensitive Dahl rats (Gordon et al. 1981, Miyajima and Bunag 1987, Peuler et al. 1989). Baroreflex impairment as a cause of elevated sympathetic tone was recently confirmed by the radiotelemetric study of blood pressure and heart rate in $\mathrm{SS} / \mathrm{Jr}$ and $\mathrm{SS} .13^{\mathrm{BN}}$ rats fed either a low-salt or a high-salt diets (Bugenhagen et al. 2010). Our study on baroreflex control of heart rate (Nedvídek and Zicha 2000) disclosed a major impairment 

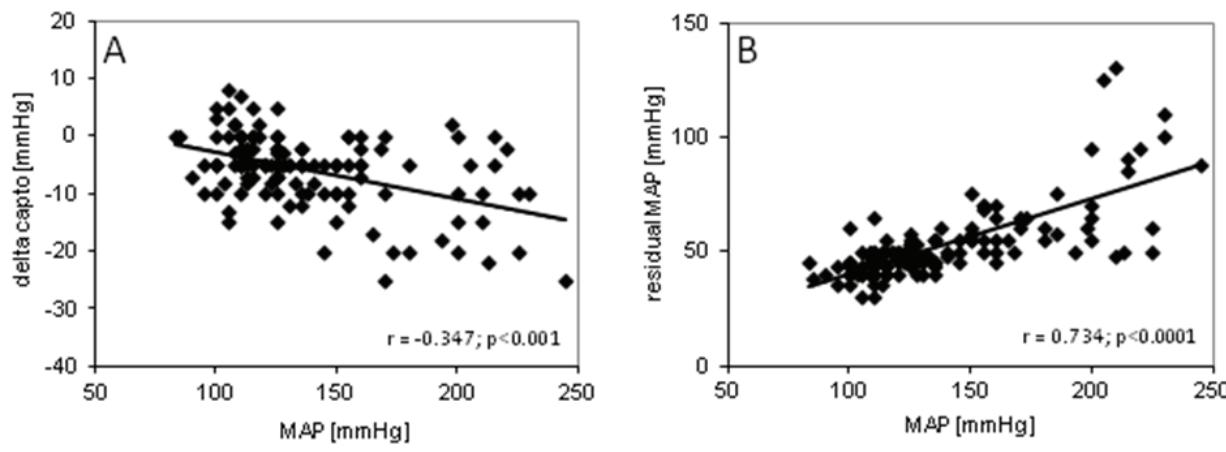

Fig. 5. The relationships between basal MAP values and captoprilinduced MAP changes (A), residual MAP (B), pentoliniuminduced (C) or L-NAME-induced MAP changes (D) in the whole population of Dahl female rats $(n=135)$ listed in Table 2. BP changes are shown either as absolute values (A-D) or expressed in percentage of basal $B P$ values $(\mathbf{E}, \mathbf{F})$ (data modified from Zicha et al. 2001b and
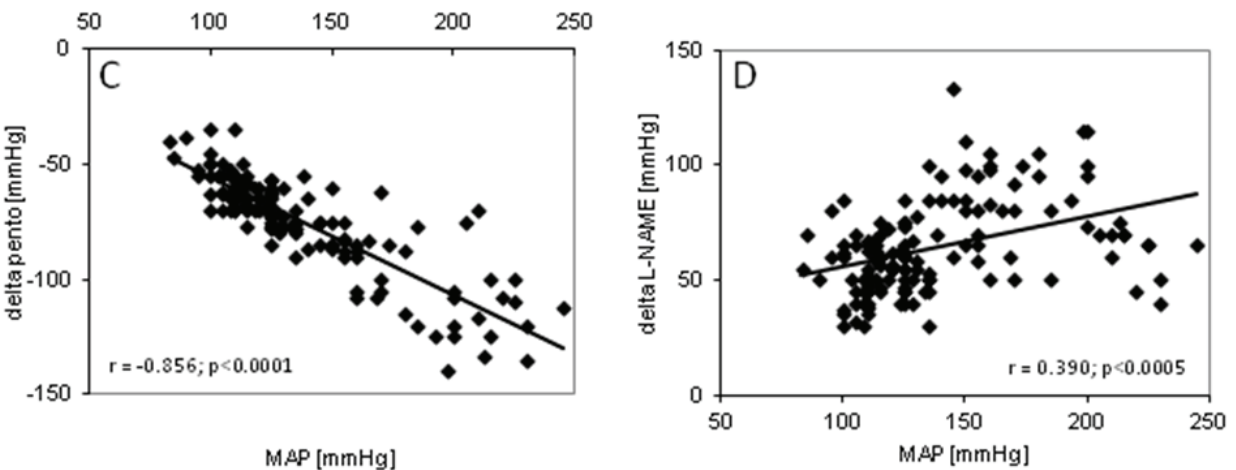

Dobešová et al. 2002).

$M A P[\mathrm{mmHg}]$

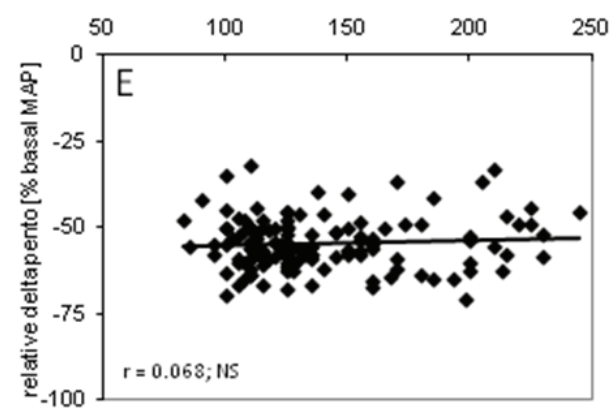

$M A P[m m H g]$

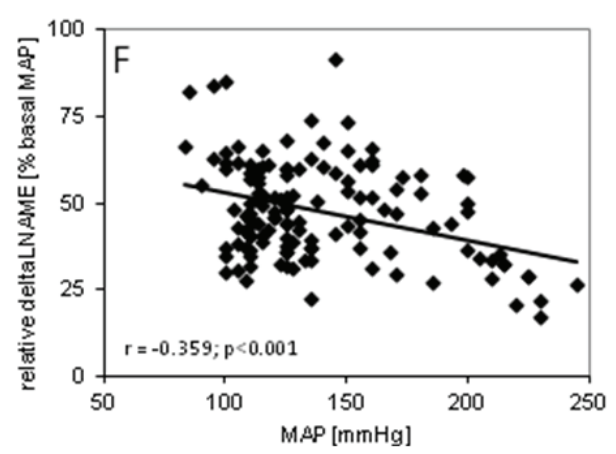

of the baroreflex efficiency in young salt hypertensive $\mathrm{SS} / \mathrm{Jr}$ rats, whereas there were only marginal changes in adult animals. This is in agreement with a less pronounced sympathetic hyperactivity in adult salt hypertensive SS/Jr rats in which smaller amounts of superoxide anions and no signs of NO deficiency were demonstrated (Dobešová et al. 2002). A comparison of the balance between sympathetic vasoconstriction and NO-dependent vasodilatation in young and adult salt hypertensive SS/Jr rats is summarized in Table 2.

A subsequent detailed phenotypic analysis of $\mathrm{SS} / \mathrm{Jr} \times \mathrm{SR} / \mathrm{Jr} \mathrm{F}_{2}$ hybrids subjected to high salt intake in youth (Dobešová et al. 2002) confirmed our conclusions on the major importance of sympathetic hyperactivity for BP maintenance. Moreover, we have clearly demonstrated that NO-dependent vasodilatation in salt hypertensive Dahl animals is attenuated only relatively as compared to the magnitude of BP rise and/or elevation of sympathetic vasoconstriction (Table 3). When we analyzed the relationships of sympathetic vasoconstriction (pentolinium-induced BP changes) or NOdependent vasodilatation (L-NAME-induced BP changes) to basal $\mathrm{BP}$ values, it was clear that in both $\mathrm{F}_{2}$ hybrids (Dobešová et al. 2002) and progenitor rats (Fig. 5) the slope of the relationship of sympathetic BP component (pentolinium-induced BP fall) was much steeper than that of NO-dependent BP component (L-NAME-induced BP rise). It is thus evident that NO-dependent vasodilatation can hardly compensate for BP elevation driven by the enhanced sympathetic vasoconstriction in salt hypertensive Dahl rats. Moreover, the presence of relative NO deficiency in young rats is clearly evident if BP changes are expressed in the percentage of basal blood pressure (Table 2, Fig. 5). A similar role of sympathetic hyperactivity and relative NO deficiency in BP maintenance was also observed in other forms of genetic 
hypertension such as Prague hereditary hypertriglyceridemic rats (Kuneš et al. 2002) or SHR (Zicha et al., to be published).

The adrenergic vasoconstriction in SS/Jr rats fed a high-salt diet was enhanced by 20-HETE (Raffai et al. 2010) which also increased resting tone of resistance vessels in salt hypertensive animals (Wang et al. 2009). In fact, 20-HETE production tended to be increased by high salt intake in small resistance vessels of $\mathrm{SS} / \mathrm{Jr}$ rats (Wang et al. 2009, Raffai et al. 2010). This is in contrast with suppressed 20-HETE production in renal medulla of these animals (Ma et al. 1994). In fact, myogenic activation of resistance vessels in skeletal muscle of salt hypertensive SS/Jr rats is partly a function of 20-HETE production, whereas this is not the case for myogenic activation of resistance vessels in normotensive $\mathrm{SS} / \mathrm{Jr}$ rats fed a low-salt diet (Frisbee et al. 2001). The underlying mechanisms of 20-HETE-induced vasoconstriction, which include the increase of calcium conductance through L-VDCC channels and the inhibition of calciumactivated $\mathrm{K}^{+}$channels $\left(\mathrm{BK}_{\mathrm{Ca}}\right.$ channels), are reviewed by Roman (2002).

There is also the evidence that calcium-activated chloride channels participate in $\alpha$-adrenergic vasoconstriction. The in vivo and in vitro study on mesenteric vascular bed of Dahl rats indicated that the inhibition of these channels with niflumic acid attenuated $\alpha$-adrenergic vasoconstriction less in salt hypertensive $\mathrm{SS} / \mathrm{Jr}$ rats than in normotensive $\mathrm{SR} / \mathrm{Jr}$ animals (Parai and Tabrizchi 2005a, b).

Since the enhanced $\alpha$-adrenergic activity is associated with the opening of L-type voltage-dependent calcium channels (L-VDCC), whereas NO contributes to their closure (Pintérová et al. 2009), it is not surprising that salt hypertension in Dahl rats was associated with augmented BP response to acute administration of nifedipine or other calcium antagonists (Sharma et al. 1984, Kuneš et al. 2004a). The magnitude of nifedipineinduced BP reduction was always proportional to the basal BP level (Kuneš et al. 2004a, Pintérová et al. 2009, Zicha et al. 2011).

A comparison of young and adult salt hypertensive $\mathrm{SS} / \mathrm{Jr}$ rats also revealed a major agedependent difference in the residual blood pressure which is recorded as minimal blood pressure at maximal NOinduced vasodilatation following the acute blockade of both RAS and SNS. This parameter reflects structural remodeling and/or changes in basal tone of resistance vessels. Residual blood pressure was elevated more in young than in adult salt hypertensive animals (Dobešová et al. 2002), confirming a major structural remodeling of resistance vessels in young salt hypertensive Dahl rats reported by Lee and Triggle (1986). There was also a positive correlation between basal and residual BP values in our set of Dahl $F_{2}$ hybrids as well as in young and adult Dahl rats, indicating the importance of structural and/or functional alterations of resistance vasculature for the severity of salt hypertension (Table 3).

Recently, we have compared the efficacy of three major vasodilator systems - prostacyclin $\left(\mathrm{PGI}_{2}\right)$, $\mathrm{Ca}^{2+}$-activated $\mathrm{K}^{+}$channels of large conductance $\left(\mathrm{BK}_{\mathrm{Ca}}\right)$ and nitric oxide - in Dahl rats (Behuliak et al. 2011). It was demonstrated that $\mathrm{PGI}_{2}$ and to a certain extent also $\mathrm{BK}_{\mathrm{Ca}}$ channels are able to enhance their vasodilator action in young salt hypertensive $\mathrm{SS} / \mathrm{Jr}$ rats, whereas this was not the case of NO. BP response to acute NO synthase inhibition by L-NAME tended to be decreased in salt hypertensive animals compared to $\mathrm{SS} / \mathrm{Jr}$ rats fed a low-salt diet and there was a clear-cut evidence of relative NO deficiency in these hypertensive rats. Furthermore, the different adaptation of these three vasodilator systems can be documented by the absence of a significant correlation between basal blood pressure and L-NAME-induced BP elevation which contrasted with positive correlations of basal blood pressure with BP changes induced by the acute inhibition of $\mathrm{PGI}_{2}$ formation by indomethacin or acute blockade of $\mathrm{BK}_{\mathrm{Ca}}$ channels by tetraethylammonium (Behuliak et al. 2011).

In contrast with the studies showing larger effects of various pharmacological interventions in young salt hypertensive Dahl rats, some vasoactive systems play a more important role in adult than in young animals, endothelin-1 (ET-1) being a typical example. The acute blockade of its $\mathrm{ET}_{\mathrm{A}}$ receptors by ambrisentan (BSF 208075) caused only a moderate BP decrease which was similar in both age groups of salt hypertensive $\mathrm{SS} / \mathrm{Jr}$ rats (Zicha et al. 2012). However, chronic ambrisentan administration attenuated salt hypertension development only in adult but not in young animals and this BP reduction was due to the attenuation of sympathetic BP component (Zicha et al. 2012). Our finding suggests ET-1 involvement in the central nervous mechanisms regulating sympathetic tone as it was proposed by Rossi et al. (2004).

There is a similar age-dependent involvement of superoxide anions in the pathogenesis of salt hypertension in Dahl rats. Chronic administration of 
tempol (superoxide dismutase mimetic) attenuated salt hypertension development only in adult but not in young $\mathrm{SS} / \mathrm{Jr}$ rats (Vaněčková et al., to be published). The underlying mechanism of this tempol-induced chronic BP reduction was again a decrease in sympathetic BP component. It is possible that both endothelin-1 and superoxide anions are involved in the same central nervous mechanisms regulating sympathetic tone as it was suggested by D'Angelo et al. (2010).

There is no doubt about the dysbalance of vasoconstrictor and vasodilator systems (namely SNS and NO) in salt hypertension. Neither central nor peripheral BP-lowering action of NO (or other vasodilators) can effectively counterbalance the enhancement of centrally driven sympathetic outflow. The major role of SNS in BP maintenance of young salt hypertensive Dahl rats becomes partially attenuated in adult animals in which other pressor systems (Ang II, ET-1 etc) also participate in the maintenance of elevated blood pressure.

\section{Superoxide formation, NO synthesis and NO-dependent vasodilatation}

Oxidative stress is enhanced in salt hypertensive Dahl rats in which higher ROS production was demonstrated in blood vessels (Swei et al. 1997, Bayorh et al. 2004) and kidneys (Trolliet et al. 2001, Meng et al. 2002). Plasma levels of hydrogen peroxide (Swei et al. 1997, Yamamoto et al. 2007) and 8-isoprostane (Trolliet et al. 2001, Forde et al. 2003, Bayorh et al. 2004) were elevated in these animals in which increased urinary excretion of 8-isoprostane and decreased urinary excretion of NO metabolites and cGMP were also reported (Trolliet et al. 2001, Forde et al. 2003, Zhang et al. 2004). Acute intravenous tempol administration caused a more pronounced transient BP reduction in salt hypertensive $\mathrm{SS} / \mathrm{Jr}$ rats as compared to normotensive animals (Zicha et al. 2001b).

The sources of superoxide anions in hypertensive animals seem to be xanthine oxidase (Swei et al. 1999), mitochondrial oxidative processes (Taylor et al. 2006a), uncoupled NO synthase (Taylor et al. 2006b, Satoh et al. 2010) and especially NADPH oxidase (Tojo et al. 2002, Zhang et al. 2004, Taylor et al. 2006a). The latter enzyme is known to be activated by Ang II (Hitomi et al. 2006, Schulman et al. 2006). This is a reason why ROS production in salt hypertensive Dahl rats can be lowered by the chronic treatment with either ACE inhibitors (Tsutsui et al. 2001, Tojo et al. 2002) or $\mathrm{AT}_{1}$ receptor blockers (Bayorh et al. 2005, Satoh et al. 2010). Similarly, the chronic mineralocorticoid receptor blockade by eplerenone decreased blood pressure, oxidative stress and NADPH protein expression in the kidney (Bayorh et al. 2011). Chronic administration of various antioxidants such as $\alpha$-tocopherol (Forde et al. 2003), vitamins C and E (Tian et al. 2005), tempol (Nishiyama et al. 2004, Ozawa et al. 2004, Hisaki et al. 2005) or apocynin (Taylor et al. 2006, Tian et al. 2008) not only attenuated oxidative stress, but also improved vascular relaxation, reduced renal damage and lowered blood pressure of salt-sensitive Dahl rats subjected to high salt intake.

Meng et al. (2002) demonstrated an increased oxidative stress and the attenuation of superoxide dismutase activity in the kidney of SS/Jr rats fed a highsalt diet. Their later study (Meng et al. 2003) revealed that intravenous tempol infusion lasting three weeks attenuated salt hypertension development in $\mathrm{SS} / \mathrm{Jr}$ rats aged 8-10 weeks and this BP reduction was achieved without any increase in sodium or water excretion. Major attenuation of renal medullary superoxide release and salt hypertension development was also induced by the addition of $\mathrm{N}$-acetylcysteine into the high-salt diet (Tian et al. 2006). Similar but less pronounced BP effects were observed in $\mathrm{SS} / \mathrm{Jr}$ rats chronically supplemented with vitamins $\mathrm{C}$ and $\mathrm{E}$ (Tian et al. 2007b) or in animals subjected to chronic inhibition of NADPH oxidase by apocynin (Tian et al. 2008). These antioxidants ameliorated all the changes elicited by high salt intake in the kidneys of $\mathrm{SS} / \mathrm{Jr}$ rats aged 8-10 weeks, i.e. the upregulation of gp91 $1^{\text {phox }}$ and $\mathrm{p} 47^{\text {phox }}$ subunits of NADPH oxidase, augmented the activity of NADPH oxidase, enhanced superoxide release and increased hydrogen peroxide content as well as elevated vascular resistance as it was reported by Tian et al. (2005, 2007b, 2008). NADPH oxidase seems to be a major source of superoxide production in the renal medulla of $\mathrm{SS} / \mathrm{Jr}$ rats. The disruption of its $\mathrm{p} 67^{\text {phox }}$ subunit in $\mathrm{SS} / \mathrm{Jr}$ rats significantly attenuated salt hypertension development, lowered renal medullary oxidative stress and ameliorated renal injury (Feng et al. 2012). Apocynin infusion into the medullary interstitium lowered not only superoxide production but also attenuated initial BP elevation induced by high salt intake in 10-week-old animals (Taylor et al. 2006a). Enhanced superoxide and hydrogen peroxide production in renal outer medulla, which is stimulated by Ang II, reduced NO-mediated tubularvascular cross-talk between the thick ascending limb of 
loop of Henle and the contractile pericytes of surrounding vasa recta (Taylor and Cowley 2005, Mori et al. 2007).

Concerning BP effects of superoxide scavenging by tempol, there is a considerable difference between our acute and chronic studies. The acute administration of tempol lowered blood pressure significantly more in young than in adult salt hypertensive $\mathrm{SS} / \mathrm{Jr}$ rats and this BP reduction was ascribed to the augmented NOdependent vasodilatation (Zicha et al. 2001b, Dobešová et al. 2002). On the contrary, chronic preventive tempol treatment attenuated the development of salt hypertension only in adult (but not in young) $\mathrm{SS} / \mathrm{Jr}$ rats and this was due to the reduction of sympathetic vasoconstriction. The results of our chronic experiments are in line with the age-dependent difference in superoxide levels in the aorta of salt hypertensive $\mathrm{SS} / \mathrm{Jr}$ rats which were more elevated in adult than in young animals (Vaněčková et al., to be published). The relationships between blood pressure and vascular superoxide production or levels of conjugated dienes (indicators of oxidative stress) in Dahl rats were similar to those which we described in rats with NOdeficient L-NAME-induced hypertension (Rauchová et al. 2005). It would be desirable to compare the effects of preventive and therapeutic administration of antioxidants in both age groups as we did with $\mathrm{N}$-acetylcysteine in young and adult SHR (Pecháňová et al. 2006, 2007). $\mathrm{N}$-acetylcysteine might be a very useful drug because it combines ROS scavenging with NO storage in the form of S-nitrosothiols.

Our earlier studies on NO synthase (NOS) activity in the kidneys of young and adult Dahl rats fed high-salt diet disclosed that high salt intake lowered NOS activity in both young and adult animals (Pecháňová et al., to be published). We were also interested in the expression of particular NOS isoforms in Dahl rats. Some abnormalities of the gene for inducible NOS isoform (Nos2) were reported in salt-sensitive Dahl rats (Deng and Rapp 1995, Chen et al. 1998). Unfortunately, we did not confirm the occurrence of any of the above reported Nos 2 gene polymorphisms in our colony of $\mathrm{SS} / \mathrm{Jr}$ rats (Hojná et al. 2005). Our later study, which was focused on protein expression of all three NOS isoforms in the brain and kidneys (Hojná et al. 2010), revealed the suppressed expression of neuronal (nNOS) and inducible (iNOS) isoforms in the diencephalon and brainstem of young salt hypertensive $\mathrm{SS} / \mathrm{Jr}$ rats. In addition, under the conditions of low salt intake the protein expression of endothelial (eNOS) isoform was decreased in the kidneys of $\mathrm{SS} / \mathrm{Jr}$ rats compared to $\mathrm{SR} / \mathrm{Jr}$ rats and this suppression of eNOS expression was further augmented in $\mathrm{SS} / \mathrm{Jr}$ rats subjected to high salt intake from weaning (Hojná et al. 2010). Similar findings on protein expression of particular NOS isoforms were earlier reported in adult salt hypertensive DS rats (Ni and Vaziri 2001). Although both above mentioned papers disclosed a decreased nNOS expression in the brain of salt hypertensive Dahl rats, Tandai-Hiruma et al. (2005) reported higher nNOS expression and NOS activity in the brainstem of salt hypertensive animals as well as a more pronounced BP elevation and a greater rise of renal sympathetic nerve activity after the acute intracerebroventricular administration of S-methyl-L-thiocitrulline which is a rather selective inhibitor of nNOS. These data are in line with the findings of Serino et al. (2001) on hypothalamic expression of nNOS in Dahl/Rapp rats. Using in situ hybridization they found that high salt intake increased nNOS mRNA more in SS/Jr rats than in SR/Jr rats. On the basis of these results they suggested that the increased NOS activity in the hypothalamus of hypertensive $\mathrm{SS} / \mathrm{Jr}$ rats may be insufficient to prevent the increased sympathetic nervous activity, vasopressin release and salt hypertension development. The acute intraperitoneal administration of another "selective" nNOS inhibitor 7-nitroindazole also increased renal sympathetic nerve activity more in salt hypertensive $\mathrm{SS} / \mathrm{Jr}$ rats than in other normotensive groups, indicating that neuronal NOmediated suppression of sympathetic outflow was greatly enhanced in salt hypertension (Nishida et al. 2001).

On the other hand, chronic inhibition of nNOS by intravenous infusion of 7-nitroindazole did not affect blood pressure of salt-loaded SS/Jr rats, but it abolished the salt resistance of $\mathrm{SR} / \mathrm{Jr}$ rats (Tan et al. 1999). Similarly, Rudd et al. (1999) reported that chronic administration of three different iNOS inhibitors also enabled $\mathrm{BP}$ rise in salt-loaded $\mathrm{SR} / \mathrm{Jr}$ rats. Tan et al. (2000) demonstrated that intravenous infusion of aminoguanidine (another "selective" iNOS inhibitor) induced a considerable BP rise in both $\mathrm{SS} / \mathrm{Jr}$ and $\mathrm{SR} / \mathrm{Jr}$ rats subjected to high salt intake, whereas renal medullary aminoguanidine infusion elicited a moderate BP increase in SS/Jr animals only (Tian et al. 2003). These important changes in salt sensitivity induced by chronic blockade of nNOS or iNOS always occurred without any major alterations of renal hemodynamics or water and sodium excretion.

Salt hypertensive DS rats are characterized by a downregulation of eNOS and impaired NO bioavailability in blood vessels and kidneys (Hayakawa 
and Raij 1997, Hayakawa and Raij 1998). The increased superoxide production by NADPH oxidase was linked to the functional upregulation of Ang II and was accompanied by insufficient NO bioavailability (Zhou et al. 2003).

Formerly, Lüscher et al. (1987) and Nishida et al. (1998) demonstrated that vascular contractions to norepinephrine are increased but vascular relaxation to acetylcholine are attenuated in salt hypertensive Dahl rats. These differences between hypertensive animals and their normotensive controls were abolished by pretreatment of vessels with NOS inhibitors. On the contrary, L-arginine pretreatment augmented this difference because norepinephrine-induced contraction was attenuated more in normotensive than in hypertensive vessels (Nishida et al. 1998). Impaired acetylcholine-induced relaxation was also observed in norepinephrine-precontracted afferent arterioles in the kidney of salt hypertensive Dahl rats and this attenuated vasodilatation was improved by acute or chronic tempol treatment which augmented both NO-dependent and EDHF-mediated component of acetylcholine-induced vasodilatation (Ozawa et al. 2004), although the former component seemed to be more important in salt-sensitive Dahl rats (Hayakawa et al. 1993).

A detailed research on microvascular structure and function has been performed in skeletal muscle of salt hypertensive Dahl rats (for review see Boegehold 2002). The dissipation of intraluminal pressure across particular segments of vascular bed in exteriorized spinotrapezius muscle of salt hypertensive $\mathrm{SS} / \mathrm{Jr}$ rats demonstrated that the increased luminal pressure can be detected up to the level of proximal resistance arterioles which effectively protect capillary network from abnormally high hydrostatic pressure (Boegehold 1991). Resting arteriolar diameters in spinotrapezius muscle were already diminished in SS/Jr rats fed a low-salt diet and these changes were even more pronounced in salt hypertensive animals (Boegehold 1993a). These alterations were due to the increased vascular tone rather than due to the remodeling of the vascular wall because all these changes were entirely eliminated at the maximal vasodilatation induced by adenosine (Boegehold and Kotchen 1990). The resting diameters of distal (downstream located) resistance arterioles were not reduced and no arteriolar rarefaction has been detected in spinotrapezius muscle of salt hypertensive Dahl rats (Boegehold 1993a, Boegehold and Kotchen 1990).

About $50 \%$ of increased vascular resistance was due to arteriolar constriction, whereas the changes in small feed arteries were responsible for the remaining increase of systemic resistance (Boegehold 1991, Boegehold et al. 1991). Sympathetic hyperactivity caused about $50 \%$ of increased vascular resistance in isolated hindquarters of salt hypertensive Dahl rats (Takeshita and Mark 1978). Reduced NO bioavailability in salt hypertensive animals accounted for a considerable part of non-neurogenic mechanisms of increased vascular tone in salt hypertensive SS/Jr rats (Boegehold 1992, Boegehold 1993b). It was found that the acute blockade of NO synthesis by L-NAME application caused arteriolar constriction, while L-arginine application induced arteriolar dilatation in normotensive $\mathrm{SS} / \mathrm{Jr}$ rats, whereas both interventions had negligible effects on arteriolar diameter in salt hypertensive animals. Since acetylcholine- or nitroprusside-induced vasodilatations were not altered in skeletal muscle arterioles of salt hypertensive Dahl rats, high salt intake seems to suppress basal NO release from the endothelium (Boegehold 1992). Later studies in SR/Jr or Sprague Dawley rats confirmed that high salt intake can attenuate flowdependent arteriolar dilation in skeletal muscle just through the suppression of NO formation (Boegehold 1993c, Boegehold 1995) and/or through enhanced NO inactivation by high ROS levels (Lenda et al. 2000). Decreased $\mathrm{Cu} / \mathrm{Zn}$ superoxide dismutase activity (Lenda and Boegehold 2002a) together with elevated activities of NADPH oxidase and xanthine oxidase (Lenda and Boegehold 2002b) were responsible for a decrease in NO bioavailability in salt hypertensive Dahl rats.

There are two important factors which were suggested to contribute to the decreased NO bioavailability in salt hypertensive Dahl rats. The first one concerns arginase activity which might reduce substrate levels for NO synthase because L-arginine is metabolized to L-ornithine instead of L-citrulline. Johnson et al. (2005) observed attenuated acetylcholineinduced or flow-mediated vasodilatation in gracilis muscle arterioles of salt hypertensive $\mathrm{SS} / \mathrm{Jr}$ rats which was restored either by arginase inhibition or by L-arginine pretreatment. Another factor contributing to the endothelial dysfunction in salt hypertensive $\mathrm{SS} / \mathrm{Jr}$ rats is endogenous carbon monoxide which is produced by vascular heme oxygenase (HO). The formation HOderived carbon monoxide, an established inhibitor of endothelial NO production, was increased and aortic HO was upregulated in salt hypertensive animals (Johnson et al. 2003, Teran et al. 2005). Progressive BP rise was 
accompanied by a gradual impairment of endotheliumdependent vasodilatation which was restored by acute pretreatment of blood vessels with $\mathrm{HO}$ inhibitor. Beneficial effects of $\mathrm{HO}$ inhibition on flow-mediated vasodilatation in gracilis muscle arterioles of salt hypertensive $\mathrm{SS} / \mathrm{Jr}$ rats were abolished by exogenous carbon monoxide. It should also be noted that acute in vivo HO inhibition lowered considerably high blood pressure of salt hypertensive animals (Teran et al. 2005).

Using young male $\mathrm{SS} / \mathrm{Jr}$ and $\mathrm{SR} / \mathrm{Jr}$ rats subjected to high salt intake from weaning Chen and Sanders (1991) demonstrated the importance of NO deficiency for the development of salt hypertension. Their acute experiments in anesthetized animals revealed a slightly greater BP rise following NOS inhibition by $\mathrm{N}^{\mathrm{G}}$-monomethyl-L-arginine (L-NMMA) but normal BP fall after L-arginine infusion in salt hypertensive $\mathrm{SS} / \mathrm{Jr}$ rats. Chronic L-arginine or L-citrulline administration enhanced urinary cGMP excretion and fully prevented salt hypertension development. Later Chen and Sanders (1993) ascribed the attenuation of NO production in salt hypertensive $\mathrm{SS} / \mathrm{Jr}$ rats to the defect in the activity of dexamethasone-suppressible inducible NOS which was considered to be based upon the mutation of Nos 2 gene in vascular smooth muscle of SS/Jr rats (Chen et al. 1998). However, this mutation of iNOS was absent not only in our colony of SS/Jr animals (Hojná et al. 2005) but also in the original Brookhaven DS rats (Chen et al. 1998).

Thus, the role of nitric oxide and ractive oxygen species in the maintenance of increased systemic resistance of salt hypertensive $\mathrm{SS} / \mathrm{Jr}$ rats is not simple. Using our in vivo approach to estimate the whole-body NO-dependent vasodilatation (Zicha et al. 2001b, Dobešová etal. 2002) we have always observed a moderate augmentation of BP response to acute L-NAME administration in $\mathrm{SS} / \mathrm{Jr}$ rats compared to $\mathrm{SR} / \mathrm{Jr}$ ones. High salt intake never significantly enhanced this BP response in young or adult animals of either Dahl strain so that the relative NO deficiency was disclosed in young severely hypertensive $\mathrm{SS} / \mathrm{Jr}$ rats. Surprisingly, chronic ROS scavenging by tempol attenuated salt hypertension development only in adult but not in young $\mathrm{SS} / \mathrm{Jr}$ rats, although young salt hypertensive $\mathrm{SS} / \mathrm{Jr}$ rats were characterized by greater BP response to acute tempol administration and by smaller $\mathrm{BP}$ response to acute L-NAME administration compared to adult salt hypertensive animals (Table 2). Perhaps the involvement of ROS and NO might differ in severe and moderate forms of salt hypertension which are typical for young and adult Dahl rats, respectively.

\section{Other vasodilator and natriuretic systems}

Decreased urinary kallikrein excretion was one of the first abnormal phenotypes described in saltsensitive Dahl rats (Carretero et al. 1978, Rapp et al. 1984, Arbeit and Serra 1985, Bouhnik et al. 1992). High salt intake decreased BP response to the infusion of bradykinin antagonist only in $\mathrm{SS} / \mathrm{Jr}$ but not in $\mathrm{SR} / \mathrm{Jr}$ rats (Benetos et al. 1993). Ideishi et al. (1994) reported that chronic taurine administration, which activated renal kallikrein, retarded salt hypertension development in $\mathrm{SS} / \mathrm{Jr}$ rats. Chronic blockade of bradykinin $\mathrm{B}_{2}$ receptor had no BP effect in salt-loaded SS/Jr rats (Ideishi et al. 1994), but it permitted salt-induced BP rise in SR/Jr rats (Mukai et al. 1998). Polymorphism in Klkl gene for kallikrein 1 cosegregated with blood pressure in DS $\mathrm{x}$ LEW $\mathrm{F}_{2}$ hybrids and was associated with reduced mRNA and protein kallikrein expression in the kidneys of DS rats (Iwai et al. 2005).

High salt intake upregulated kininogen but downregulated tissue kallikrein expression in saltsensitive Dahl rats (Wang et al. 1996). The preventive delivery of human tissue kallikrein gene moderately attenuated salt hypertension development but considerably ameliorated cardiac hypertrophy and renal injury in salt-sensitive Dahl rats. The lowering of high blood pressure was ascribed to the enhanced cGMP formation (Chao et al. 1998a). The therapeutic delivery of human tissue kallikrein gene to Dahl rats with established salt hypertension also lowered their blood pressure and partially reversed the organ damage (Chao et al. 1998b). Similar effects were achieved by chronic bradykinin infusion to salt-sensitive Dahl rats fed a highsalt diet, although bradykinin infusion did not influence their blood pressure. Kinin-induced protection against renal injury was associated with increased renal $\mathrm{NO}$ production, reduced NADPH oxidase activity and decreased superoxide generation. Lower oxidative stress was accompanied by reduced TGF- $\beta_{1}$ expression and decreased phosphorylation of MAPK (Chao et al. 2007). Therapeutic administration of human tissue kallikrein gene caused similar changes of cell signaling as bradykinin infusion (Zhang et al. 2004), but there was a moderate BP reduction. These beneficial effects could be abolished by the treatment with bradykinin $\mathrm{B}_{2}$ receptor antagonist icatibant (Bledsoe et al. 2006). Similarly, bradykinin $\mathrm{B}_{2}$ receptor antagonist prevented the 
therapeutic effects of long-term infusion of subdepressor doses of rat urinary kallikrein on renal injury in salt hypertensive DIS rats (Hirawa et al. 1999). Further studies demonstrated that the activation of bradykinin $\mathrm{B}_{2}$ receptors and a subsequent enhanced NO formation by eNOS were involved in the renoprotective and cardioprotective effects of chronic $\mathrm{AT}_{1}$ receptor blockade in salt hypertensive DIS rats (Yokota et al. 2003, Yoshida et al. 2007).

Atrial natriuretic peptide (ANP) exerts numerous effects on circulatory homeostasis ranging from the control of renal sodium reabsorption over the influence on aldosterone secretion control up to the vasorelaxation. Some of its effects were not altered in salt-sensitive Dahl rats because ANP-induced attenuation of aldosterone secretion (Racz et al. 1986) or ANP-induced relaxation of non-renal vessels (Snajdar and Rapp 1985, Simchon et al. 1992) were similar in both rat strains. Thus, ANP administration induced similar reduction of systemic resistance in salt-sensitive and salt-resistant Dahl rats (Simchon et al. 1989, 1992) and ANP-induced BP reduction was proportional to basal BP level, i.e. BP change induced by ANP was greater in hypertensive than normotensive rats (Sonnenberg et al. 1987).

However, one of the main abnormalities of saltsensitive Dahl rats is the blunted renal natriuretic response to ANP (Hirata et al. 1984, Steele and Challoner-Hue 1988a), although some investigators failed to confirm this defect (Sonnenberg et al. 1987, Sterzel et al. 1987, Brier et al. 1995). In contrast to salt-resistant Dahl rats fed $1 \% \mathrm{NaCl}$ diet, the infusion of ANP did not cause any significant rise in renal blood flow and glomerular filtration rate in salt-sensitive rats in which no major ANP-induced rise of urinary sodium excretion was observed (Simchon et al. 1989). The absence of ANPinduced attenuation of renal vascular resistance in saltsensitive Dahl rats was accompanied by the hypersensitivity of renal vascular bed to norepinephrine and angiotensin II. In addition, endothelin-1 increased renal vascular resistance in salt-sensitive rats but lowered it in salt-resistant Dahl rats (Simchon et al. 1992). ANP elicited much smaller rise in renal papillary blood flow in DS than in DR rats (Hirata et al. 1984) and there was also a reduced sensitivity of inner medullary collecting duct to ANP in terms of cGMP formation (Appel and Dunn 1987). This is in line with the decreased urinary cGMP excretion in salt hypertensive Dahl rats, although the attenuation of NO bioavailability might also contribute to this phenotype (Simchon et al. 1996, Trolliet et al. 2001).
Increased atrial content of ANP, enhanced ANP release and elevated plasma ANP levels were reported in adult salt-sensitive Dahl rats (Hirata et al. 1984, Snajdar and Rapp 1985, Snajdar and Rapp 1986, Tanaka and Inagami 1986, Gutkowska et al. 1986). It should be kept in mind that ANP content in the atria is increasing during postnatal development (Wilson et al. 1988) and ANP release from the atria is enhanced in adult hypertensive but not in prehypertensive SS/Jr rats (Onwochei et al. 1987, Onwochei and Rapp 1989). The development of hypertension in aging $\mathrm{SS} / \mathrm{Jr}$ rats fed $1 \% \mathrm{NaCl}$ diet was associated with the increase of ANP content in both atria and ventricles (Dene and Rapp 1987). Chronic salt loading increased plasma ANP levels and brainstem ANP content in DS but not in DR rats (John and Morich 1990), whereas no significant changes of ANP content were induced by high salt intake in atria of young DS rats (Hirata et al. 1984, John and Morich 1990). Both preventive and therapeutic administration of L-VDCC blocker nisoldipine lowered blood pressure, attenuated cardiac hypertrophy and decreased plasma ANP levels in young salt hypertensive SS/Jr rats (Stasch et al. 1990). This suggests that ANP production is increasing with the progression of hypertensive cardiac dysfunction as a part of compensatory mechanisms. In fact, ANP gene delivery attenuated salt hypertension development, cardiac hypertrophy and renal injury in salt-sensitive Dahl rats (Lin et al. 1998).

The number of ANP binding sites detected in zona glomerulosa of adrenal gland, renal glomeruli and subfornical organ was increased in young $\mathrm{SS} / \mathrm{Jr}$ rats compared to age-matched SR/Jr animals (Stewart et al. 1987, 1988). ANP receptor, which is coupled to guanylate cyclase (NPR-A), was considered to be a strong candidate gene for salt hypertension because it cosegregated with blood pressure in two sets of $F_{2}$ hybrids (SS/Jr x MNS and SS/Jr x WKY) fed a high-salt diet from the 5th week of age (Deng and Rapp 1992). Nagase et al. (1997) described the exaggerated reduction of NPR-C receptor expression induced by high salt intake in the kidneys of DIS rats and suggested that the abnormality of this "clearance" ANP receptor, which is, however, not coupled to guanylate cyclase, might be related to the impaired renal sodium excretion.

High-salt diet feeding of SS/Jr rats elevated plasma, cardiac and renal levels of adrenomedullin which is a hypotensive peptide (Shimokubo et al. 1996, Yoshihara et al. 2005). Chronic adrenomedullin infusion in salt hypertensive Dahl rats had partial preventive but 
no therapeutic effects on salt hypertension, but in both cases the adrenomedullin infusion improved renal function, reduced proteinuria, restored renal NOS activity, lowered RAS activity in plasma and kidney and decreased TGF- $\beta$ expression (Nishikimi et al. 2002, Yoshihara et al. 2005). Similar effects were achieved by a single delivery of human adrenomedullin gene to saltloaded SS/Jr rats which increased cAMP levels, improved renal function, lowered blood pressure and ameliorated both renal injury and cardiac hypertrophy (Zhang et al. 2000). The effects of human adrenomedullin gene delivery resembled to those of human tissue kallikrein gene delivery except for the difference in cyclic nucleotides involved (cAMP for adrenomedullin vs. cGMP for kallikrein).

The role of renal dopaminergic system in genetic and salt hypertension has been reviewed in details by Zeng et al. (2004). Earlier studies suggested increased dopamine levels in the adrenals (Saavedra et al. 1983) as well as lower renal dopamine content and reduced urinary dopamine excretion (Racz et al. 1987, Sakamoto et al. 1994) in salt hypertensive Dahl rats. However, the latter findings were not confirmed by DeFeo et al. (1987) or Grossman et al. (1991). The main defect of renal dopaminergic system in $\mathrm{SS} / \mathrm{Jr}$ rats is the impaired ability of renal dopamine $\mathrm{D}_{1}$-like receptors to stimulate cAMP production and to inhibit sodium transport in particular segments of the nephron (Nishi et al. 1993, Hansell 1995, Ohbu et al. 1995). This defect seems to be due to the uncoupling of $D_{1}$-like receptors from $G$ protein/effector complex (José et al. 1996). One of the consequences of such a defect is the inability to inhibit the Na,K-ATPase activity in the thick ascending limb of loop of Henle and proximal tubule of SS/Jr rats (Nishi et al. 1993). This explains why high salt intake downregulated the $\mathrm{Na}, \mathrm{K}$ ATPase activity only in proximal tubule of SR/Jr but not $\mathrm{SS} / \mathrm{Jr}$ rats (Nishi et al. 1992). Although $\mathrm{D}_{1}$-like receptors were altered in $\mathrm{SS} / \mathrm{Jr}$ rats, their natriuretic response to acute volume expansion was normal at least in prehypertensive animals fed a low-salt diet (Hansell 1995, Möller and Hansell 1995), indicating the replacement of the defective dopaminergic system by other natriuretic mechanisms. Besides the above mentioned alterations in the function of $\mathrm{D}_{1}$-like receptors, Luippold et al. (2001) described a defect of renal dopamine $\mathrm{D}_{3}$ receptors in $\mathrm{SS} / \mathrm{Jr}$ rats and they succeeded to elicit considerable BP elevation in $\mathrm{SR} / \mathrm{Jr}$ rats fed a high-salt diet if these animals were subjected to a chronic $\mathrm{D}_{3}$ receptor blockade.
Less attention has been paid to prostacyclin $\left(\mathrm{PGI}_{2}\right)$ in Dahl rats. The initial studies reported impaired vascular $\mathrm{PGI}_{2}$ generation in prehypertensive DIS rats but this was not the case of salt hypertensive animals (Uehara et al. 1987). Prostacyclin synthase activity and $\mathrm{PGI}_{2}$ release from mesenteric artery were similar in DIS and DIR rats fed a low-salt diet, but these parameters were increased by high salt intake in DIS rats only (Uehara et al. 1990). A similar enhancement of $\mathrm{PGI}_{2}$ formation by high salt intake was also observed in the aorta of DIS rats (Ishimitsu et al. 1991). On the contrary, Falardeau and Martineau (1983) reported that high salt intake increased $\mathrm{PGI}_{2}$ production only in DR rats. Later study (Bayorh et al. 2004) disclosed higher plasma $\mathrm{PGI}_{2}$ levels in $\mathrm{SR} / \mathrm{Jr}$ than in SS/Jr rats, but high salt intake suppressed plasma $\mathrm{PGI}_{2}$ levels only in $\mathrm{SR} / \mathrm{Jr}$ but not in $\mathrm{SS} / \mathrm{Jr}$ male rats. In fact, high salt intake had quite opposite effects on $\mathrm{PGI}_{2}$ than on NO metabolism in $\mathrm{SS} / \mathrm{Jr}$ rats because it lowered plasma NO levels but did not modify plasma $\mathrm{PGI}_{2}$ levels in this rat strain (Bayorh et al. 2004). This is in line with the acute blockade of $\mathrm{PGI}_{2}$ and/or NO formation by indomethacin and/or L-NAME administration which revealed greater suppression of NO-dependent vasodilatation than $\mathrm{PGI}_{2}$-dependent vasodilatation in salt hypertensive SS/Jr rats (Behuliak et al. 2011).

Attenuated $\beta$-adrenergic vasodilatation in salt hypertensive DS rats was described by Soltis and Katovich (1991), who observed a reduction of isoprenaline-induced relaxation of the aortic smooth muscle from hypertensive rats, whereas the relaxation response to sodium nitrate was unaltered. Since contractile response to $\mathrm{KCl}$ and $\alpha_{1}$ - or $\alpha_{2}$-adrenergic stimulation were also unchanged in aorta of salt hypertensive Dahl rats, the enhanced smooth muscle responsiveness to norepinephrine in hypertensive rats was ascribed to a decreased $\beta$-adrenergic responsiveness (Soltis and Katovich 1991). The desensitization of adenylyl cyclase in the heart of salt hypertensive $\mathrm{SS} / \mathrm{Jr}$ rats seems to be caused by the upregulation of inhibitory $\mathrm{G}$ (Gi) proteins as well as by a decreased activity of adenylyl cyclase (Böhm et al. 1993). On the other hand, Gros et al. (2000) reported that the impaired $\beta$-adrenergic responsiveness in lymphocytes and vascular smooth muscle of hypertensive rats was due to a defect in receptor/Gs protein coupling which was related to the increased expression of $\mathrm{G}$ protein-coupled receptor kinase 2 (GRK-2). This abnormality was also found in aortas of salt hypertensive SS/Jr rats. Another reason for reduced $\beta$-adrenergic signaling in the kidney of salt 
hypertensive $\mathrm{SS} / \mathrm{Jr}$ rats might be the increased activity of renal phosphodiesterase 4B4 which lowers cAMPinduced relaxation of renal resistance vessels (Tawar et al. 2008).

Recently, Toshiro Fujita and coworkers proposed that $\beta$-adrenergic mechanisms might be involved in the pathogenesis of salt hypertension through the modulation of WNK4 kinase pathway which plays a key role in the control of renal tubular sodium reabsorption (Mu et al. 2011). Thus the stimulation of $\beta_{2}$-adrenoceptors as a part of increased renal sympathetic activity in the hypertensive rats (DOCA-salt or DIS) downregulates WNK4 kinase expression which leads to the activation of $\mathrm{Na}^{+}-\mathrm{Cl}^{-}$cotransporter $(\mathrm{NCC})$ and epithelial $\mathrm{Na}^{+}$channels $(\mathrm{ENaC})$ resulting in enhanced renal tubular sodium reabsorption and salt hypertension development. On the contrary, chronic salt loading of normotensive rats (Sprague Dawley, DIR) reduced renal sympathetic nerve activity and renal norepinephrine turnover, which through a decreased $\beta_{2}$-adrenoceptor stimulation increased renal WNK4 kinase expression. These observations were further confirmed by the effects of renal denervation and/or $\beta$-adrenoceptor blockade $(\mathrm{Mu}$ et al. 2011).

Recent studies (Wang and Wang 2006, Gao and Wang 2010) disclosed the important role of transient receptor potential vanilloid type 1 and type 4 channels (TRPV1 and TRPV4) in salt hypertension of Dahl rats. These channels are upregulated by high salt intake in the kidneys and mesenteric arteries of salt-resistant rats, but they are suppressed by high salt intake in salt-sensitive rats. Consequently, this abnormality in salt hypertensive Dahl rats impairs their compensatory mechanisms facing salt load because BP-lowering effects of these channels are reduced. Of course, there is a considerable difference in the vasodilator action of these two TRPV channels because TRPV1-mediated vasodilatation is largely dependent on calcitonin gene-related peptide, whereas TRPV4-dependent vasodilatation is mediated by the activation of calcium-activated $\mathrm{K}^{+}$channels (Wang and Wang 2006, Gao and Wang 2010).

It is rather difficult to evaluate the complex role of numerous vasodilator and natriuretic systems in the pathogenesis of salt hypertension in Dahl rats because our conclusions will be highly dependent on the experimental approaches used. Some of these systems are enhanced in salt hypertensive rats (ANP, adrenomedullin, $\mathrm{PGI}_{2}$ ), while the others (kallikrein, NO, dopamine, TRPV1 or TRPV4) seem to be absolutely or relatively downregulated. However, the ultimate impact of these systems on BP regulation depends on vascular and renal responsiveness to their mediators. Attenuated $\beta$-adrenergic vasodilatation and reduced natriuretic responses to ANP, NO or dopamine are characteristic examples of impaired action of these systems in salt hypertensive Dahl rats.

\section{Cell calcium handling in salt hypertension - calcium influx and calcium sensitization}

The altered influence of the above mentioned vasoconstrictor and vasodilator systems on BP regulation in salt hypertensive Dahl rats might result not only from the abnormal function of these systems but also from the alterations of cell signaling in resistance vessels. Cell calcium handling was therefore often studied in arterial smooth muscle of Dahl rats. It is always rather difficult to separate so-called primary defects of cell signaling from the changes induced by abnormal stimulation of vascular smooth muscle by various endogenous agents and/or from the consequences of high blood pressure.

Blood vessels of salt hypertensive Dahl rats were characterized by enhanced calcium uptake (Rapp et al. 1986, Vasdev et al. 1989) which was associated with augmented hypotensive response to acute nifedipine injection (Sharma et al. 1984). Increased vascular calcium uptake was reported to be mediated by a humoral factor present in the plasma of salt hypertensive Dahl rats (Vasdev et al. 1989). The relationship of this circulating factor to parathyroid hypertensive factor which is enhanced by high salt intake in plasma of salt-sensitive Dahl rats (Lewanczuk and Pang 1993) is still unclear. Vascular calcium uptake in salt-sensitive Dahl rats could be normalized by various interventions preventing the development of salt hypertension (Vasdev et al. 1990b, 1992).

Kazda et al. (1982, 1986), Fleckenstein et al. (1989) as well as McCaughran and Juno (1988) were the first to demonstrate the long-term beneficial effects of calcium antagonists (nifedipine, nitrendipine, amlodipine, verapamil) in salt hypertensive Dahl rats. Both preventive and therapeutic administration of these L-VDCC blockers was effective in salt-sensitive rats fed a high-salt diet, whereas no significant BP effects were induced in normotensive control groups (Kazda 1986). On the other hand, chronic administration of BAY K8644, which is a dihydropyridine agonist of L-VDCC channels, accelerated the development of fulminant salt 
hypertension in SS/Jr rats, whereas no BP effects of BAY K8644 were observed in salt-loaded SR/Jr rats (Garthoff et al. 1984, Kazda et al. 1986).

Calcium antagonists (L-VDCC blockers) such as verapamil or nitrendipine increased glomerular filtration rate if the renal vascular resistance (RVR) was increased by norepinephrine pretreatment. This GFR rise was greater in the kidneys of DS rats, although RVR decrease elicited by calcium antagonists was similar in both rat strains. Nevertheless, GFR increase in DS kidney was not accompanied by the appropriate rise of $\mathrm{Na}^{+}$excretion which was observed in DR kidney (Steele and ChallonerHue 1987). Similar results were obtained using in situ kidneys by Takenaka et al. (1994) who found that nicardipine enhanced renal plasma flow and GFR, improving thus the pressure-natriuresis relationship in salt hypertensive Dahl rats. The application of L-VDCC agonist BAY K-8644 increased RVR only in DS kidneys, irrespective of salt intake. This RVR increase was augmented by the 6-hydroxydopamine-induced sympathectomy of salt-loaded kidney donors, but the effect was greater in DS than in DR kidneys. L-VDCC agonist application reduced GFR in both DS and DR kidneys, but GFR decrease was most pronounced in the kidneys of salt hypertensive DS rats. This effect of BAY K-8644 was further enhanced under the conditions of chronic high salt intake (Steele and Challoner-Hue 1988b).

It is well known that membrane depolarization is responsible for L-VDCC opening, but Abel et al. (1981) reported that membrane potential was not altered in the caudal artery of adult salt hypertensive female DS rats and there were no changes in the contractile sensitivity to norepinephrine and serotonin. On the contrary, Fujii et al. (1997) demonstrated a depolarization of resting cell membrane in superior mesenteric artery of young salt hypertensive male DIS rats. Thus, L-VDCC channels in resistance vessels of these salt hypertensive rats were more available for opening near their altered resting potential (Ohya et al. 2000). Wellman et al. (2001) ascribed the membrane depolarization seen in the cerebral arteries of salt hypertensive Dahl rats to a decreased density of $\mathrm{K}^{+}$ current mediated by voltage-dependent $\mathrm{K}^{+}\left(\mathrm{K}_{\mathrm{V}}\right)$ channels.

The acute nifedipine administration lowered dosedependently blood pressure of salt hypertensive SS/Jr rats and this BP reduction was proportional to basal BP level (Kuneš et al. 2004a, Pintérová et al. 2009, Zicha et al. 2011), suggesting a major contribution of calcium influx to the maintenance of high blood pressure in this form of experimental hypertension. However, vascular smooth muscle contraction is dependent not only on myosin light chain kinase (MLCK) pathway, which is stimulated by calcium entry through L-VDCC, but also on myosin light chain phosphatase (MLCP) pathway, which is dependent on Rho kinase activity stimulated by vasoconstrictors and atenuated by vasodilators (namely $\mathrm{NO}$ ).

\section{Fasudil}

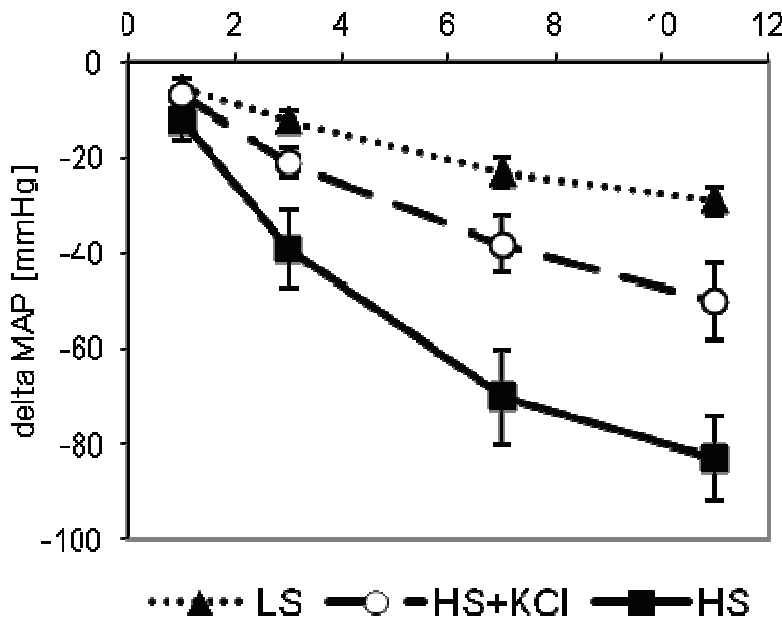

Nifedipine

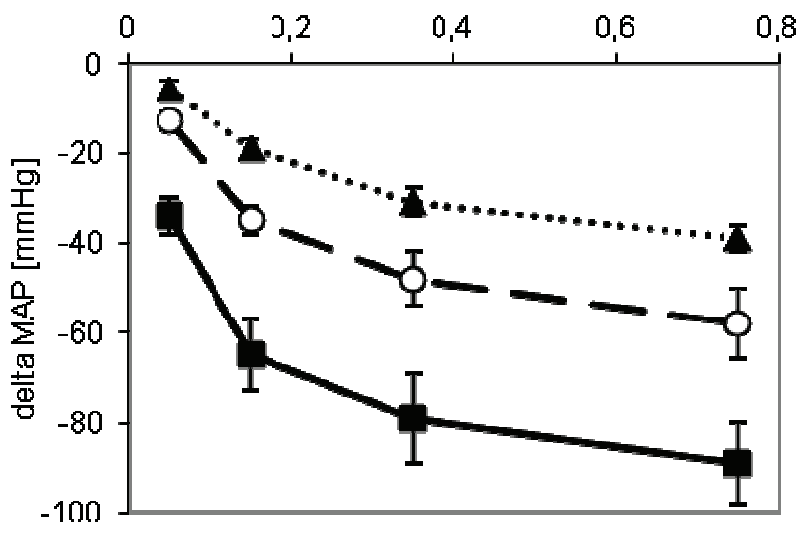

Fig. 6. A comparison of dose-dependent MAP response of young $\mathrm{SS} / \mathrm{Jr}$ female rats to acute blockade of Rho kinase by fasudil (top panel) or L-VDCC by nifedipine (bottom panel). Animals fed a low-salt diet (LS, $0.3 \% \mathrm{NaCl}$ ) were compared with those fed either high-salt diet (HS, $5 \% \mathrm{NaCl}$ ) or potassium-supplemented high-salt diet $(\mathrm{HS}+\mathrm{KCl}, 5 \% \mathrm{NaCl}$ plus $3 \% \mathrm{KCl})$. Data are means \pm S.E.M.

To our surprise, the same was true for the acute inhibition of Rho kinase by fasudil (Fig. 6), indicating the important role of calcium sensitization in salt hypertension. A detailed comparison of dose-dependent BP changes induced by fasudil or nifedipine (Fig. 6) revealed a more pronounced BP reduction at low 
nifedipine doses. Our current explanation is that fasudilinduced BP changes could be attenuated by a compensatory increase of $\mathrm{Ca}^{2+}$ influx. This explanation might also be pertinent for minimal BP effects elicited by chronic administration of various Rho kinase inhibitors in salt hypertensive Dahl rats (fasudil - Nishikimi et al. 2004, Fukui et al. 2008, Takeshima et al. 2012; Y-27632 - Kobayashi et al. 2002, Satoh et al. 2003, Mita et al. 2005), although such treatments attenuated cardiac hypertrophy, heart failure or renal damage in these animals.

Further abnormalities of cell $\mathrm{Ca}^{2+}$ handling in vascular smooth muscle of young male salt hypertensive DIS rats were the reduction of $\mathrm{Ca}^{2+}$ extrusion mediated by the plasma $\mathrm{Ca}^{2+}$ pump and the acceleration of $\mathrm{Ca}^{2+}$ extrusion mediated by the $\mathrm{Na}^{+} / \mathrm{Ca}^{2+}$ exchanger. Both parameters correlated with blood pressure $-\mathrm{Ca}^{2+}$ pump negatively and $\mathrm{Na}^{+} / \mathrm{Ca}^{2+}$ exchanger positively (Ashida et al. 1996). Increased $\mathrm{Ca}^{2+}$ extrusion mediated by the $\mathrm{Na}^{+} / \mathrm{Ca}^{2+}$ exchanger might be a compensation mechanism for increased $\left[\mathrm{Ca}^{2+}\right]_{i}$ resulting from the attenuated $\mathrm{Ca}^{2+}$ pump activity and/or enhanced $\mathrm{Ca}^{2+}$ entry through L-VDCC or non-selective cationic channels. In contrast to the acceleration of $\mathrm{Na}^{+} / \mathrm{Ca}^{2+}$ exchanger in the aorta, the activity of this transport system was attenuated in afferent but not in efferent arterioles of young salt hypertensive $\mathrm{SS} / \mathrm{Jr}$ rats (Nelson et al. 1999), which seems to be related to a defect in protein kinase $\mathrm{C}$ regulation of $\mathrm{Na}^{+} / \mathrm{Ca}^{2+}$ exchanger in mesangial cells of hypertensive animals (Mashburn et al. 1999).

Mesenteric arteries isolated from salt hypertensive DIS rats exhibited increased spontaneous electrical activity which was inhibited not only by $\mathrm{Ca}^{2+}$ free medium or L-VDCC blocker nicardipine but also by cyclooxygenase inhibitor indomethacin or $\mathrm{PGH}_{2} / \mathrm{TXA}_{2}$ receptor antagonist. The latter two drugs did not modify membrane potential or $\mathrm{Ca}^{2+}$ entry through L-VDCC because $\mathrm{PGH}_{2}$ seems to activate non-selective cationic channels in arterial smooth muscle cells of DIS rats (Fujii et al. 1997, Ohya et al. 1997). It should be kept in mind that $\mathrm{PGH}_{2}$ acts as endothelium-derived contracting factor (EDCF) in large conduit arteries but not in small resistance arteries (Paulis et al. 2008) and its potentiation of vasoconstrictor effects of norepinephrine is enhanced with age and in hypertension (Liššvá et al. 2011).

Acetylcholine-induced release of EDCF was demonstrated in the carotid and renal arteries (Zhou et al. 1999b, Zhou et al. 2001) but not in the aorta (Lüscher et al. 1987) of salt hypertensive Dahl rats in which it contributed to endothelium dysfunction. EDCF action can be blocked not only by indomethacin but also by the pretreatment of vessels with thromboxane synthase inhibitor OKY-046 or $\mathrm{PGH}_{2} / \mathrm{TXA}_{2}$ receptor antagonist ONO-3708 (Zhou et al. 1999b). Dietary L-arginine supplementation, which attenuated BP rise in saltsensitive Dahl rats exposed to high salt intake, also abolished EDCF-mediated contraction of their renal arteries (Zhou et al. 2001). However, chronic administration of orally active $\mathrm{PGH}_{2} / \mathrm{TXA}_{2}$ receptor antagonist ONO-8809 neither reduced blood pressure nor improved acetylcholine-induced arterial relaxation in salt hypertensive rats (Zhou et al. 1999b, 2001). On the other hand, acetylcholine-induced EDCF-mediated contraction of renal arteries was also abolished by chronic $\mathrm{ET}_{\mathrm{A}}$ receptor blockade by LU132252, which attenuated not only salt hypertension development in Dahl rats but also improved NO-dependent vasorelaxation and enhanced renal NOS activity (Barton et al. 2001).

It is evident that vascular smooth muscle contraction in salt hypertensive Dahl rats is enhanced due to the alterations in cell calcium handling and/or intracellular signaling. Although the increased $\mathrm{Ca}^{2+}$ entry through L-VDCC seems to be a dominant abnormality in this hypertensive model, further attention should be paid to possible alterations in membrane potential regulation, $\mathrm{Ca}^{2+}$ mobilization from internal stores, $\mathrm{Ca}^{2+}$ entry through other channels and $\mathrm{Ca}^{2+}$ extrusion from VSMC as well as to intracellular signaling via myosin light chain kinase or Rho kinase/myosin light chain phosphatase.

\section{Conclusions and perspectives}

Salt-sensitive Dahl rats are not only a useful model for salt hypertension research, but they also represent a challenge for the scientific mind. There are many unresolved contradictory issues which expect a future scientific effort, although a lot has already been done.

Salt hypertension is a "low-renin" form of hypertension because peripheral activity of the reninangiotensin-aldosterone system (RAAS) is suppressed by high salt intake. Nevertheless, this is not the case of central nervous system in which the enhancement of RAAS system plays a critical role in the pathogenesis of salt hypertension (for review see Leenen 2010, Huang and Leenen 2011, Oki et al. 2012). Although renal epithelial sodium channels $(\mathrm{ENaC})$ contribute to a greater sodium retention in salt-loaded $\mathrm{SS} / \mathrm{Jr}$ rats (Husted et al. 
1997, Amin et al. 2011) and brain $\mathrm{ENaC}$ are the integral part of central pathogenetic mechanisms responsible for sympathoexcitation and high blood pressure in salt hypertensive SS/Jr rats (Wang and Leenen 2002, Wang et al. 2003), the comprehensive sequence analysis of ENaC genes did not reveal any differences between $\mathrm{SS} / \mathrm{Jr}$ and $\mathrm{SR} / \mathrm{Jr}$ rats (Shehata et al. 2007). Both renal tubules and choroid plexus utilize ENaC for $\mathrm{Na}^{+}$influx into the cells and the $\mathrm{Na}, \mathrm{K}$-pump for $\mathrm{Na}^{+}$extrusion from the cells. The increased renal $\mathrm{Na}^{+}$reabsorption in salt hypertensive $\mathrm{SS} / \mathrm{Jr}$ rats is due to the enhanced permeability of the apical membrane for $\mathrm{Na}^{+}$, which is mediated by $\mathrm{ENaC}$ (Husted et al. 1997). In contrast, the increased $\mathrm{Na}^{+}$ concentration in cerebrospinal fluid of these rats does not result from the enhanced $\mathrm{Na}^{+}$influx through $\mathrm{ENaC}$, but it is caused by the failure to inhibit ouabain-sensitive $\mathrm{Na}^{+}$ transport in the choroid plexus of salt hypertensive Dahl rats (Amin et al. 2009), although the increased levels of endogenous brain ouabain (OLC) were observed in both plasma and hypothalamus of salt hypertensive Dahl rats (Leenen et al. 1994).

Another example of such a contradiction is the fact that the acute systemic inhibition of Rho kinase by fasudil elicits similar BP effects as the acute systemic blockade of L-VDCC by nifedipine (Fig. 6). Both fasudil and nifedipine reduce blood pressure dose-dependently and proportionally to the initial BP level. The onset of BP reduction after intravenous administration is similar for both drugs, but the duration of fasudil-induced BP reduction seems to be considerably shorter. Thus high blood pressure in salt hypertensive Dahl rats can be lowered either by the normalization of calcium sensitization of the contractile apparatus by fasudil or by the reduction of calcium influx by nifedipine. Nevertheless, long-term BP reduction can be easily achieved in salt hypertensive Dahl rats by a chronic administration of L-VDCC antagonists but not by a chronic inhibition of Rho kinase. The questions arise whether the increase of $\mathrm{Ca}^{2+}$ entry can compensate for decreased $\mathrm{Ca}^{2+}$ sensitization and why there is no compensation for diminished $\mathrm{Ca}^{2+}$ entry. The interrelationships of MLCK and MLCP in chronic regulation of vascular tone are still not fully resolved.

Further puzzle in hypertension research is the gender difference in the severity of salt hypertension which is less expressed in salt-sensitive female Dahl rats (Dahl et al. 1975, Hinojosa-Laborde et al. 2000, Bayorh et al. 2001, Mazancová et al. 2003b). The influence of gonadal hormones (both testosterone and estradiol) is evident (Dahl et al. 1975, Rowland and Fregly 1992), but sex differences in the involvement of mineralocorticoids and glucocorticoids should also be considered (GomezSanchez and Gomez-Sanchez 1988, Mazancová et al. 2003b). Female sex hormones do not exert their protective effects through renal excretory mechanisms (Hinojosa-Laborde et al. 2000), but they downregulated renal $\mathrm{AT}_{1}$ receptors (Harrison-Bernard et al. 2003), whereas testosterone aggravates salt hypertension development through the upregulation of intrarenal RAS (Yanes et al. 2009). There are only very scarce data on sex differences in the hemodynamics and in the participation of particular vasoactive systems in salt hypertension of Dahl rats. Interestingly, Bayorh et al. (2001) reported much smaller increase of systemic resistance in female than in male salt hypertensive Dahl rats. Surprisingly, renal vascular resistance was increased in male but decreased in female hypertensive rats. As far as vasoconstrictor and vasodilator systems were concerned, the involvement of SNS was augmented in male rats compared to female ones, while no major sex differences were demonstrated in circulating levels of $\mathrm{NO}$ metabolites or vasodilator prostaglandins $\left(\mathrm{PGI}_{2}\right.$ or $\left.\mathrm{PGE}_{2}\right)$ (Bayorh et al. 2001).

These are only three of many questions (local vs. systemic effects of humoral factors, detailed description of abnormalities in intracellular signaling, involvement of local RAAS in the end-organ damage etc.) which must be solved before we shall fully understand the complex pathogenesis of salt hypertension. The possibility to apply the hypertensive stimulus (increased salt intake) as well as the nutritional or pharmacological interventions in different age periods is a great advantage but also a major complication of the use of Dahl rats for hypertension research. The effects and/or consequences of particular stimuli applied within critical periods of development (developmental windows) might considerably differ from those elicited by the same interventions applied in adulthood. The detection of such differences together with the detailed knowledge on the developmental processes might provide desirable clues for better understanding of pathophysiological mechanisms underlying salt hypertension and/or its complications.

\section{Conflict of Interest}

There is no conflict of interest.

\section{Acknowledgements}

Valuable comments of Dr. Jiří Pácha and Dr. Libor 
Kopkan are highly appreciated. This work was supported by grants AV0Z 50110509, 305/09/0336 and 304/12/0259 (Czech Science Foundation) and by grant of MSMT CR 1M0510.

\section{Abreviations}

$\left[\mathrm{Ca}^{2+}\right]_{\mathrm{i}}-$ cytosolic calcium level; 11ß-HSD 1 $11 \beta$-hydroxysteroid dehydrogenase type $1 ; 11 \beta$-HSD 2 11ß-hydroxysteroid dehydrogenase type $2 ; 20$-HETE 20-hydroxyeicosa-tetraenoic acid; ACE angiotensin converting enzyme; ACTH - adrenocorticotropic hormone; Akt - protein kinase B (serine/threoninespecific protein kinase); Ang II - angiotensin II; ANP atrial natriuretic peptide; $\mathrm{AT}_{1}-$ angiotensin type 1 receptor; $\mathrm{BK}_{\mathrm{Ca}}-$ large conductance $\mathrm{Ca}^{2+}$-activated $\mathrm{K}^{+}$ channel; BN - Brown Norway rats; BP - blood pressure; cAMP - cyclic adenosine monophosphate; cGMP cyclic guanosine monophosphate; CSF - cerebrospinal fluid; CYP4A - cytochrome P450-4A; DIS, DIR Dahl/Iwai salt-sensitive and salt-resistant rats; DLF digoxin-like factor; DOCA - deoxycorticosterone acetate; DPH - diphenylhexatriene; DS, DR - Dahl salt-sensitive and salt-resistant rats; EDCF - endothelium-derived contracting factor; EDHF - endothelium-derived hyperpolarizing factor; EETs - epoxyeicosatrienoic acids; $\mathrm{ENaC}-$ epithelial $\mathrm{Na}^{+}$channels; eNOS - endothelial NO synthase (NOS 3); ET-1 - endothelin-1; $\mathrm{ET}_{\mathrm{A}}$ receptor endothelin type $\mathrm{A}$ receptor; $\mathrm{FE}_{\mathrm{Na}}$ - fractional sodium excretion; GFR - glomerular filtration rate; $G_{i}-$ inhibitory $G$ proteins; GRK-2 - G protein-coupled receptor kinase 2; $\mathrm{G}_{\mathrm{s}}$ - stimulatory $\mathrm{G}$ proteins; GTP guanosine triphosphate; $\mathrm{HO}$ - heme oxygenase; IMCD inner medullary collecting duct; iNOS - inducible NO synthase (NOS 2); LEW - Lewis rats; L-NAME $-\mathrm{N}^{\omega}$ nitro-L-arginine methyl ester; L-NMMA $-\mathrm{N}^{\mathrm{G}}$ monomethyl-L-arginine; LOX-1 - lectin-like oxidized LDL receptor-1; L-VDCC - L-type voltage-dependent calcium channel; MAPK - mitogen-activated protein kinase; MBG - marinobufagenin; MCHC - mean cell hemoglobin content; MCP-1 - monocyte chemoattractant protein-1; MLCK - myosin light chain kinase; MLCP myosin light chain phosphatase; MNS - Milan normotensive rats; MR - mineralocorticoid receptors; $\mathrm{Na}, \mathrm{K}-\mathrm{ATPase}$ - sodium, potassium adenosine triphosphatase; NADPH oxidase - nicotineamide adenine dinucleotide phosphate oxidase; NF- $\mathrm{KB}$ - nuclear factor kappa-light-chain-enhancer of activated B cells; nNOS neuronal NO synthase (NOS 1); NO - nitric oxide; NOS - nitric oxide synthase; NPR-A - natriuretic peptide receptor A; NPR-C - natriuretic peptide receptor C (clearance receptor); OLC - ouabain-like compound; OS - ouabain-sensitive; $\mathrm{PGE}_{2}$ - prostaglandin $\mathrm{E}_{2} ; \mathrm{PGH}_{2}$ prostaglandin $\mathrm{H}_{2} ; \mathrm{PGI}_{2}$ - prostacyclin; $\mathrm{PHF}$ - parathyroid hypertensive factor; PI3K - phosphatidylinositol 3-kinase; PKC $\varepsilon$ - protein kinase C epsilon; PPAR $\gamma-$ peroxisome proliferator-activated receptor gamma; PRA - plasma renin activity; RAAS - renin-angiotensinaldosterone system; Rac1 - Ras-related C3 botulinum toxin substrate 1 (G protein); RAS - renin-angiotensin system; RBF - renal blood flow; Rho kinase - Rhoassociated protein kinase (ROCK); ROS - reactive oxygen species; RSK - ribosomal S6 kinase; RVLM rostral ventrolateral medulla; RVR - renal vascular resistance; SERCA - sarco/endoplasmic reticulum $\mathrm{Ca}^{2+}$ ATPase; SGK1 - serum- and glucocorticoid-induced serine/threonine kinase 1; SHR - spontaneously hypertensive rats; SNS - sympathetic nervous system; $\mathrm{SS} / \mathrm{Jr}, \mathrm{SR} / \mathrm{Jr}$ - Dahl/Rapp salt-sensitive and salt-resistant rats; TALH - thick ascending limb of loop of Henle; TGF - tubuloglomerular feedback; TGF- $\beta$ - transforming growth factor beta; TNF- $\alpha$ - tumor necrosis factor alpha; TRPV1, TRPV4 - transient receptor potential vanilloid type 1 and type 4 channels; TXA $A_{2}$ - thromboxane $\mathrm{A}_{2}$; WKY - Wistar-Kyoto rats; WNK4 kinase serine/threonine protein kinase WNK4.

\section{References}

ABEL PW, TRAPANI A, MATSUKI N, INGRAM MJ, INGRAM FD, HERMSMEYER K: Unaltered membrane properties of arterial muscle in Dahl strain genetic hypertension. Am J Physiol 241: H224-H227, 1981.

ALONSO-GALICIA M, FROHLICH B, ROMAN RJ: Induction of P4504A activity improves pressure-natriuresis in Dahl S rats. Hypertension 31: 232-236, 1998.

ALVAREZ-GUERRA M, GARAY RP: Renal Na-K-Cl cotransporter NKCC2 in Dahl salt-sensitive rats. $J$ Hypertens 20: 721-727, 2002.

AMARAL SL, ROMAN RJ, GREENE AS: Renin gene transfer restores angiogenesis and vascular endothelial growth factor expression in Dahl S rats. Hypertension 37: 386-390, 2001. 
AMIN MS, REZA E, WANG H, LEENEN FH: Sodium transport in the choroid plexus and salt-sensitive hypertension. Hypertension 54: 860-867, 2009.

AMIN MS, REZA E, EL-SHAHAT E, WANG HW, TESSON F, LEENEN FH: Enhanced expression of epithelial sodium channels in the renal medulla of Dahl S rats. Can J Physiol Pharmacol 89: 159-168, 2011.

AOI W, NIISATO N, SAWABE Y, MIYAZAKI H, MARUNAKA Y: Aldosterone-induced abnormal regulation of ENaC and SGK1 in Dahl salt-sensitive rat. Biochem Biophys Res Commun 341: 376-381, 2006.

AOI W, NIISATO N, SAWABE Y, MIYAZAKI H, TOKUDA S, NISHIO K, YOSHIKAWA T, MARUNAKA Y: Abnormal expression of ENaC and SGK1 mRNA induced by dietary sodium in Dahl salt-sensitively hypertensive rats. Cell Biol Int 31: 1288-1291, 2007.

APPEL RG, DUNN MJ: Papillary collecting tubule responsiveness to atrial natriuretic factor in Dahl rats. Hypertension 10: 107-114, 1987.

ARBEIT LA, SERRA SR: Decreased total and active urinary kallikrein in normotensive Dahl salt susceptible rats. Kidney Int 28: 440-446, 1985.

ASHIDA T, YOSHIMI H, KAWANO Y, MATSUOKA H, OMAE T: Effects of dietary salt and angiotensin-converting enzyme inhibitor on ATP-driven $\mathrm{Ca}$ pump and $\mathrm{Na} / \mathrm{Ca}$ exchange in aortic rings of Dahl rats. Clin Exp Hypertens 18: 851-871, 1996.

AYACHI S: Increased dietary calcium lowers blood pressure in the spontaneously hypertensive rat. Metabolism 28: 1234-1238, 1979.

BABA A, FUKUDA K, KUCHII M, URA M, YOSHIKAWA H, HAMADA M, HANO T, NISHIO I, MASUYAMA $\mathrm{Y}$ : Intracellular free calcium concentration, $\mathrm{Ca}^{++}$channel and calmodulin level in experimental hypertension in rats. Jpn Circ J 51: 1216-1222, 1987.

BABICKÝ A, PAŘÍZEK J, OŠŤÁDALOVÁ I, KOLÁŘ J: Initial solid food intake and growth of young rats in nests of different sizes. Physiol Bohemoslov 22: 557-566, 1973.

BAČÁKOVÁ L, KUNEŠ J: Gender differences in growth of vascular smooth muscle cells isolated from hypertensive and normotensive rats. Clin Exp Hypertens 22: 33-44, 2000.

BAGROV AY, AGALAKOVA NI, KASHKIN VA, FEDOROVA OV: Endogenous cardiotonic steroids and differential patterns of sodium pump inhibition in NaCl-loaded salt-sensitive and normotensive rats. $\mathrm{Am} J$ Hypertens 22: 559-563, 2009.

BARTON M, VOS I, SHAW S, BOER P, D'USCIO LV, GRÖNE HJ, RABELINK TJ, LATTMANN T, MOREAU P, LÜSCHER TF: Dysfunctional renal nitric oxide synthase as a determinant of salt-sensitive hypertension: mechanisms of renal artery endothelial dysfunction and role of endothelin for vascular hypertrophy and glomerulosclerosis. J Am Soc Nephrol 11: 835-845, 2000.

BAYORH MA, SOCCI RR, EATMAN D, WANG M, THIERRY-PALMER M: The role of gender in salt-induced hypertension. Clin Exp Hypertens 23: 241-255, 2001.

BAYORH MA, GANAFA AA, SOCCI RR, SILVESTROV N, ABUKHALAF IK: The role of oxidative stress in saltinduced hypertension. Am J Hypertens 17: 31-36, 2004.

BAYORH MA, GANAFA AA, EATMAN D, WALTON M, FEUERSTEIN GZ: Simvastatin and losartan enhance nitric oxide and reduce oxidative stress in salt-induced hypertension. Am J Hypertens 18: 1496-1502, 2005.

BAYORH MA, ROLLINS-HAIRSTON A, ADIYIAH J, LYN D, EATMAN D: Eplerenone suppresses aldosterone/salt-induced expression of NOX-4. J Renin Angiotensin Aldosterone Syst 12: 195-201, 2011.

BEHULIAK M, PINTÉROVÁ M, KUNEŠ J, ZICHA J: Vasodilator efficiency of endogenous prostanoids, $\mathrm{Ca}^{2+}$ activated $\mathrm{K}^{+}$channels and nitric oxide in rats with spontaneous, salt-dependent or NO-deficient hypertension. Hypertens Res 34: 968-975, 2011.

BENETOS A, BOUAZIZ H, SAFAR M: Endogenous bradykinin activity in Dahl rats. J Cardiovasc Pharmacol 21: 101-104, 1993.

BENGELE HH, SOLOMON S: Development of renal response to blood volume expansion in the rat. Am J Physiol 227: 364-368, 1974.

BLAUSTEIN MP, HAMLYN JM: Signaling mechanisms that link salt retention to hypertension: endogenous ouabain, the $\mathrm{Na}^{+}$pump, the $\mathrm{Na}^{+} / \mathrm{Ca}^{2+}$ exchanger and TRPC proteins. Biochim Biophys Acta 1802: 1219-1229, 2010. 
BLAUSTEIN MP, LEENEN FH, CHEN L, GOLOVINA VA, HAMLYN JM, PALLONE TL, VAN HUYSSE JW, ZHANG J, WIER WG: How $\mathrm{NaCl}$ raises blood pressure: a new paradigm for the pathogenesis of saltdependent hypertension. Am J Physiol 302: H1031-H1049, 2012.

BLEDSOE G, SHEN B, YAO Y, ZHANG JJ, CHAO L, CHAO J: Reversal of renal fibrosis, inflammation, and glomerular hypertrophy by kallikrein gene delivery. Hum Gene Ther 17: 545-555, 2006.

BOEGEHOLD MA: Effect of salt-induced hypertension on microvascular pressures in skeletal muscle of Dahl rats. $\mathrm{Am}$ J Physiol 260: H1819-H1825, 1991.

BOEGEHOLD MA: Reduced influence of nitric oxide on arteriolar tone in hypertensive Dahl rats. Hypertension 19: 290-295, 1992.

BOEGEHOLD MA: Microvascular changes associated with high salt intake and hypertension in Dahl rats. Int $J$ Microcirc Clin Exp 12: 143-156, 1993a.

BOEGEHOLD MA: Enhanced arteriolar vasomotion in rats with chronic salt-induced hypertension. Microvasc Res 45: 83-94, $1993 \mathrm{~b}$.

BOEGEHOLD MA: Effect of dietary salt on arteriolar nitric oxide in striated muscle of normotensive rats. Am $J$ Physiol 264: H1810-H1816, 1993c.

BOEGEHOLD MA: Flow-dependent arteriolar dilation in normotensive rats fed low-or high-salt diets. Am J Physiol 269: H1407-H1414, 1995.

BOEGEHOLD MA: Microvascular structure and function in salt-sensitive hypertension. Microcirculation 9: 225-241, 2002.

BOEGEHOLD MA, KOTCHEN TA: Effect of dietary salt on the skeletal muscle microvasculature in Dahl rats. Hypertension 15: 420-426, 1990.

BOEGEHOLD MA, HUFFMAN LJ, HEDGE GA: Peripheral vascular resistance and regional blood flows in hypertensive Dahl rats. Am J Physiol 261: R934-R938, 1991.

BÖHM M, GIERSCHIK P, KNORR A, SCHMIDT U, WEISMANN K, ERDMANN E: Cardiac adenylyl cyclase, $\beta$-adrenergic receptors, and $\mathrm{G}$ proteins in salt-sensitive hypertension. Hypertension 22: 715-727, 1993.

BOLTEN CW, PAYNE MA, MCDONALD WG, BLANNER PM, CHOTT RC, GHOSH S, ARHANCET GB, STATEN NR, GULVE EA, SULLIVAN PM, HROMOCKYJ AE, COLCA JR: Thiazolidinediones inhibit the progression of established hypertension in the Dahl salt-sensitive rat. Diab Vasc Dis Res 4: 117-123, 2007.

BOUHNIK J, RICHOUX JP, HUANG H, SAVOIE F, BAUSSANT T, ALHENC-GELAS F, CORVOL P: Hypertension in Dahl salt-sensitive rats: biochemical and immunohistochemical studies. Clin Sci 83: 13-22, 1992.

BRIER ME, LATHON PV, ARONOFF GR, LUFT FC: Pharmacodynamics of atrial natriuretic peptide in isolated perfused Dahl rat kidneys. Hypertens Res 18: 219-225, 1995.

BROWNIE AC, BERNARDIS LL, NIWA T, KAMURA S, SKELTON FR: The influence of age and sex on the development of adrenal regeneration hypertension. Lab Invest 15: 1342-1356, 1966.

BUGENHAGEN SM, COWLEY AW JR, BEARD DA: Identifying physiological origins of baroreflex dysfunction in salt-sensitive hypertension in the Dahl SS rat. Physiol Genomics 42: 23-41, 2010.

CARRETERO OA, AMIN VM, OCHOLIK T, SCICLI AG, KOCH J: Urinary kallikrein in rats bred for their susceptibility and resistance to the hypertensive effect of salt. A new radioimmunoassay for its direct determination. Circ Res 42: 727-731, 1978.

CASTROP H, KRÄMER BK, RIEGGER GA, KURTZ A, WOLF K: Overexpression of chloride channel CLC-K2 mRNA in the renal medulla of Dahl salt-sensitive rats. J Hypertens 18: 1289-1295, 2000.

CHANDRAMOHAN G, BAI Y, NORRIS K, RODRIGUEZ-ITURBE B, VAZIRI ND: Effects of dietary salt on intrarenal angiotensin system, $\mathrm{NAD}(\mathrm{P}) \mathrm{H}$ oxidase, $\mathrm{COX}-2, \mathrm{MCP}-1$ and PAI-1 expressions and NF- $\mathrm{kB}$ activity in salt-sensitive and -resistant rat kidneys. Am J Nephrol 28: 158-167, 2008.

CHAO J, ZHANG JJ, LIN KF, CHAO L: Human kallikrein gene delivery attenuates hypertension, cardiac hypertrophy, and renal injury in Dahl salt-sensitive rats. Hum Gene Ther 9: 21-31, 1998a.

CHAO J, ZHANG JJ, LIN KF, CHAO L: Adenovirus-mediated kallikrein gene delivery reverses salt-induced renal injury in Dahl salt-sensitive rats. Kidney Int 54: 1250-1260, 1998b. 
CHAO J, LI HJ, YAO YY, SHEN B, GAO L, BLEDSOE G, CHAO L: Kinin infusion prevents renal inflammation, apoptosis, and fibrosis via inhibition of oxidative stress and mitogen-activated protein kinase activity. Hypertension 49: 490-497, 2007.

CHEN PY, SANDERS PW: L-arginine abrogates salt-sensitive hypertension in Dahl/Rapp rats. J Clin Invest 88: 1559$1567,1991$.

CHEN PY, SANDERS PW: Role of nitric oxide synthesis in salt-sensitive hypertension in Dahl/Rapp rats. Hypertension 22: 812-818, 1993.

CHEN PY, GLADISH RD, SANDERS PW: Vascular smooth muscle nitric oxide synthase anomalies in Dahl/Rapp salt-sensitive rats. Hypertension 31: 918-924, 1998.

CHERCHOVICH GM, ČAPEK K, JEFREMOVA Z, POHLOVÁ I, JELÍNEK J: High salt intake and blood pressure in lower primates (Papio hamadryas). J Appl Physiol 40: 601-604, 1976.

CHIBA Y, ANDO K, FUJTA T: The protective effects of taurine against renal damage by salt loading in Dahl saltsensitive rats. J Hypertens 20: 2269-2274, 2002.

CLARET M, GARAY R, GIRAUD F: The effect of membrane cholesterol on the sodium pump in red blood cells. J Physiol Lond 274: 247-263, 1978.

COWLEY AW JR: Genomics and homeostasis. Am J Physiol 284: R611-R627, 2003.

COWLEY AW JR, ROMAN RJ, KALDUNSKI ML, DUMAS P, DICKHOUT JG, GREENE AS, JACOB HJ: Brown Norway chromosome 13 confers protection from high salt to consomic Dahl S rat. Hypertension 37: 456-461, 2001.

COWLEY AW JR, LIANG M, ROMAN RJ, GREENE AS, JACOB HJ: Consomic rat model systems for physiological genomics. Acta Physiol Scand 181: 585-592, 2004.

DAHL LK: Effects of chronic excess salt feeding. Elevation of plasma cholesterol in rats and dogs. J Exp Med 112: 635-651, 1960.

DAHL LK, HEINE M, TASSINARI L: Effects of chronia excess salt ingestion. Evidence that genetic factors play an important role in susceptibility to experimental hypertension. J Exp Med 115: 1173-1190, 1962.

DAHL LK, KNUDSEN KD, HEINE MA, LEITL GJ: Effects of chronic excess salt ingestion. Modification of experimental hypertension in the rat by variations in the diet. Circ Res 22: 11-18, 1968.

DAHL LK, LEITL G, HEINE M: Influence of dietary potassium and sodium/potassium molar ratios on the development of salt hypertension. J Exp Med 136: 318-330, 1972.

DAHLY AJ, HOAGLAND KM, FLASCH AK, JHA S, LEDBETTER SR, ROMAN RJ: Antihypertensive effects of chronic anti-TGF- $\beta$ antibody therapy in Dahl S rats. Am J Physiol 283: R757-R767, 2002.

D'ANGELO G, LORIA AS, POLLOCK DM, POLLOCK JS: Endothelin activation of reactive oxygen species mediates stress-induced pressor response in Dahl salt-sensitive prehypertensive rats. Hypertension 56: 282-289, 2010.

DECANO JL, VIERECK JC, MCKEE AC, HAMILTON JA, RUIZ-OPAZO N, HERRERA VLM: Early-life sodium exposure unmasks susceptibility to stroke in hyperlipidemic, hypertensive heterozygous $\mathrm{Tg} 25$ rats transgenic for human cholesteryl ester transfer protein. Circulation 119: 1501-1509, 2009.

DEFEO ML, JADHAV AL, LOKHANDWALA MF: Dietary sodium intake and urinary dopamine and sodium excretion during the course of blood pressure development in Dahl salt-sensitive and salt-resistant rats. Clin Exp Hypertens A 9: 2049-2060, 1987.

DEJIMA T, TAMURA K, WAKUI H, MAEDA A, OHSAWA M, KANAOKA T, HAKU S, KENGO A, MASUDA S, SHIGENAGA A, AZUMA K, MATSUDA M, YABANA M, HIROSE T, UCHINO K, KIMURA K, NAGASHIMA Y, UMEMURA S: Prepubertal angiotensin blockade exerts long-term therapeutic effect through sustained ATRAP activation in salt-sensitive hypertensive rats. J Hypertens 29: 1919-1929, 2011.

DENE H, RAPP JP: Maternal effects on blood pressure and survivability in inbred Dahl salt-sensitive rats. Hypertension 7: 767-774, 1985a.

DENE H, RAPP JP: Lack of effects of maternal salt intake on blood pressure of offspring in Dahl salt-sensitive rats. Clin Exp Hypertens A 7: 1121-1133, 1985b.

DENE H, RAPP JP: Quantification of messenger ribonucleic acid for atrial natriuretic factor in atria and ventricles of Dahl salt-sensitive and salt-resistant rats. Mol Endocrinol 1: 614-620, 1987. 
DENG Y, RAPP JP: Cosegregation of blood pressure with angiotensin converting enzyme and atrial natriuretic peptide receptor genes using Dahl salt-sensitive rats. Nat Genet 1: 267-272, 1992.

DENG AY, RAPP JP: Locus for the inducible, but not a constitutive, nitric oxide synthase cosegregates with blood pressure in the Dahl salt-sensitive rat. J Clin Invest 95: 2170-2177, 1995.

DEVYNCK MA, KUNEŠ J, LE QUAN SANG KH, ZICHA J: Membrane microviscosity and plasma triacylglycerols in the rat. Clin Sci 94: 79-85, 1998.

DIAZ ENCARNACION MM, WARNER GM, GRAY CE, CHENG J, KERYAKOS HK, NATH KA, GRANDE JP: Signaling pathways modulated by fish oil in salt-sensitive hypertension. Am J Physiol 294: F1323-F1335, 2008.

DLOUHÁ H, KŘEČEK J, ZICHA J: Hypertension in rats with hereditary diabetes insipidus. The role of age. Pflügers Arch 369: 177-182, 1977.

DLOUHÁ H, Ǩ̌EČEK J, ZICHA J: Effect of age on hypertensive stimuli and the development of hypertension in Brattleboro rats. Clin Sci 57: 273-275, 1979.

DOBEŠOVÁ Z, KUNEŠ J, ZICHA J: Body fluid alterations and organ hypertrophy in age-dependent salt hypertension of Dahl rats. Physiol Res 44: 377-387, 1995.

DOBEŠOVÁ Z, KUNEŠ J, ZICHA J: The altered balance between sympathetic nervous system and nitric oxide in salt hypertensive Dahl rats: ontogenetic and $\mathrm{F}_{2}$ hybrid studies. J Hypertens 20: 945-955, 2002.

DRENJANCEVIC-PERIC I, LOMBARD JH: Introgression of chromosome 13 in Dahl salt-sensitive genetic background restores cerebral vascular relaxation. Am J Physiol 287: H957-H962, 2005.

DRENJANCEVIC-PERIC I, LOMBARD JH: Reduced angiotensin II and oxidative stress contribute to impaired vasodilation in Dahl salt-sensitive rats on low-salt diet. Hypertension 45: 687-691, 2005.

DRENJANCEVIC-PERIC I, FRISBEE JC, LOMBARD JH: Skeletal muscle arteriolar reactivity in SS.BN13 consomic rats and Dahl salt-sensitive rats. Hypertension 41: 1012-1015, 2003.

DRENJANCEVIC-PERIC I, GREENE AS, KUNERT MP, LOMBARD JH: Arteriolar responses to vasodilator stimuli and elevated $\mathrm{PO}_{2}$ in renin congenic and Dahl salt-sensitive rats. Microcirculation 11: 669-677, 2004.

DRENJANCEVIC-PERIC I, PHILLIPS SA, FALCK JR, LOMBARD JH: Restoration of normal vascular relaxation mechanisms in cerebral arteries by chromosomal substitution in consomic SS.13BN rats. Am J Physiol 289: H188-H195, 2005.

DRENJANCEVIC-PERIC I, WEINBERG BD, GREENE AS, LOMBARD JH: Restoration of cerebral vascular relaxation in renin congenic rats by introgression of the Dahl R renin gene. Am J Hypertens 23: 243-248, 2010.

DURAND MJ, LOMBARD JH: Introgression of the Brown Norway renin allele onto the Dahl salt-sensitive genetic background increases $\mathrm{Cu} / \mathrm{Zn}$ SOD expression in cerebral arteries. Am J Hypertens 24: 563-568, 2011.

ENGELMANN B, OP DEN KAMP JA, ROELOFSEN B: Replacement of molecular species of phosphatidylcholine: influence on erythrocyte Na transport. Am J Physiol 258: C682-C691, 1990a.

ENGELMANN B, GREVERS G, JANKA HU, DUHM J: Alterations in $\mathrm{Na}^{+}, \mathrm{K}^{+}$and $\mathrm{Ca}^{2+}$ transport in erythrocytes of patients with carcinomas of the head and neck: possible role of mild anaemia and cell age. Clin Sci (Lond) 78: $315-320,1990 b$.

EVENWEL RT, KASBERGEN CM, STRUYKER-BOUDIER HA: Central and regional hemodynamics and plasma volume distribution during the development of spontaneous hypertension in rats. Clin Exp Hypertens A 5: 1511-1536, 1983.

FALARDEAU P, MARTINEAU A: In vivo production of prostaglandin $\mathrm{I}_{2}$ in Dahl salt-sensitive and salt-resistant rats. Hypertension 5: 701-705, 1983.

FEDOROVA OV, LAKATTA EG, BAGROV AY: Endogenous Na,K pump ligands are differentially regulated during acute $\mathrm{NaCl}$ loading of Dahl rats. Circulation 102: 3009-3014, 2000.

FEDOROVA OV, KOLODKIN NI, AGALAKOVA NI, LAKATTA EG, BAGROV AY: Marinobufagenin, an endogenous $\alpha_{1}$ sodium pump ligand, in hypertensive Dahl salt-sensitive rats. Hypertension 37: 462-466, 2001.

FEDOROVA OV, TALAN MI, AGALAKOVA NI, LAKATTA EG, BAGROV AY: Endogenous ligand of sodium pump, marinobufagenin, is a novel mediator of sodium chloride-dependent hypertension. Circulation 105: 1122-1127, 2002. 
FEDOROVA OV, AGALAKOVA NI, TALAN MI, LAKATTA EG, BAGROV AY: Brain ouabain stimulates peripheral marinobufagenin via angiotensin II signalling in NaCl-loaded Dahl-S rats. J Hypertens 23: 1515$1523,2005$.

FEDOROVA OV, ZHURAVIN IA, AGALAKOVA NI, YAMOVA LA, TALAN MI, LAKATTA EG, BAGROV AY: Intrahippocampal microinjection of an exquisitely low dose of ouabain mimics $\mathrm{NaCl}$ loading and stimulates a bufadienolide Na/K-ATPase inhibitor. J Hypertens 25: 1834-1844, 2007.

FENG D, YANG C, GEURTS AM, KURTH T, LIANG M, LAZAR J, MATTSON DL, O'CONNOR PM, COWLEY AW JR: Increased expression of $\mathrm{NAD}(\mathrm{P}) \mathrm{H}$ oxidase subunit $\mathrm{p} 67$ (phox) in the renal medulla contributes to excess oxidative stress and salt-sensitive hypertension. Cell Metab 15: 201-208, 2012.

FENTON RA, CHOU CL, AGELOFF S, BRANDT W, STOKES JB, KNEPPER MA: Increased collecting duct urea transporter expression in Dahl salt-sensitive rats. Am J Physiol 285: F143-F151, 2003.

FERNANDEZ D, BOLLI P, SNEDDEN W, VASDEV S, FERNANDEZ PG: Modulation of left ventricular hypertrophy by dietary salt and inhibition of angiotensin converting enzyme. J Hypertens 6 (Suppl 4): S145S147, 1988.

FERRELL F, LANOU A, GRAY SD: Salt level in weaning diet affects saline preference and fluid intake in Dahl rats. Hypertension 8: 1021-1026, 1986.

FLECKENSTEIN A, FREY M, ZORN J, FLECKENSTEIN-GRÜN G: Amlodipine, a new 1,4-dihydropyridine calcium antagonist with a particularly strong antihypertensive profile. Am J Cardiol 64: 21I-34I, 1989.

FORDE P, SCRIBNER AW, DIAL R, LOSCALZO J, TROLLIET MR: Prevention of hypertension and renal dysfunction in Dahl rats by $\alpha$-tocopherol. J Cardiovasc Pharmacol 42: 82-88, 2003.

FRIEDMAN R, TASSINARI LM, HEINE M, IWAI J: Differential development of salt-induced and renal hypertension in Dahl hypertension-sensitive rats after neonatal sympathectomy. Clin Exp Hypertens 1: 779-799, 1979.

FRISBEE JC, ROMAN RJ, KRISHNA UM, FALCK JR, LOMBARD JH: 20-HETE modulates myogenic response of skeletal muscle resistance arteries from hypertensive Dahl-SS rats. Am J Physiol 280: H1066-H1074, 2001.

FUJII K, ONAKA U, OHYA Y, OHMORI S, TOMINAGA M, ABE I, TAKATA Y, FUJISHIMA M: Role of eicosanoids in alteration of membrane electrical properties in isolated mesenteric arteries of salt-loaded, Dahl salt-sensitive rats. Br J Pharmacol 120: 1207-1214, 1997.

FUJII S, ZHANG L, IGARASHI J, KOSAKA H: L-arginine reverses p47phox and gp91phox expression induced by high salt in Dahl rats. Hypertension 42: 1014-1420, 2003.

FUJITA T: Mineralocorticoid receptors, salt-sensitive hypertension, and metabolic syndrome. Hypertension 55: 813$818,2010$.

FUJITA M, ANDO K, NAGAE A, FUJITA T: Sympathoexcitation by oxidative stress in the brain mediates arterial pressure elevation in salt-sensitive hypertension. Hypertension 50: 360-367, 2007.

FUJITA M, ANDO K, KAWARAZAKI H, KAWARASAKI C, MURAOKA K, OHTSU H, SHIMIZU H, FUJITA T: Sympathoexcitation by brain oxidative stress mediates arterial pressure elevation in salt-induced chronic kidney disease. Hypertension 59: 105-112, 2012.

FUKUI S, FUKUMOTO Y, SUZUKI J, SAJI K, NAWATA J, TAWARA S, SHINOZAKI T, KAGAYA Y, SHIMOKAWA H: Long-term inhibition of Rho-kinase ameliorates diastolic heart failure in hypertensive rats. J Cardiovasc Pharmacol 51: 317-326, 2008.

FURUKAWA H, BILEZIKIAN JP, LOEB JN: Potassium fluxes in the rat reticulocyte. Ouabain sensitivity and changes during maturation. Biochim Biophys Acta 649: 625-632, 1981.

GABOR A, LEENEN FH: Mechanisms mediating sodium-induced pressor responses in the PVN of Dahl rats. Am $J$ Physiol 301: R1338-R1349, 2011.

GABOR A, LEENEN FH: Cardiovascular effects of angiotensin II and glutamate in the PVN of Dahl salt-sensitive rats. Brain Res 1447: 28-37, 2012.

GANGULI M, TOBIAN L, IWAI J: Cardiac output and peripheral resistance in strains of rats sensitive and resistant to $\mathrm{NaCl}$ hypertension. Hypertension 1: 3-7, 1979.

GAO F, WANG DH: Impairment in function and expression of transient receptor potential vanilloid type 4 in Dahl saltsensitive rats: significance and mechanism. Hypertension 55: 1018-1025, 2010. 
GARCÍA NH, PLATO CF, STOOS BA, GARVIN JL: Nitric oxide-induced inhibition of transport by thick ascending limbs from Dahl salt-sensitive rats. Hypertension 34: 508-513, 1999.

GARTHOFF B, KAZDA S, LUCKHAUS G: 'Calcium agonist' in salt-dependent hypertension: hints at calciummediated blood pressure increase. J Hypertens 2 (Suppl 3): S503-S505, 1984.

GESCHKA S, KRETSCHMER A, SHARKOVSKA Y, EVGENOV OV, LAWRENZ B, HUCKE A, HOCHER B, STASCH JP: Soluble guanylate cyclase stimulation prevents fibrotic tissue remodeling and improves survival in salt-sensitive Dahl rats. PLoS One 6: e21853, 2011.

GOMEZ-SANCHEZ EP, GOMEZ-SANCHEZ CE: 19-Nordeoxycorticosterone excretion in male and female inbred salt-sensitive (S/JR) and salt-resistant (R/JR) Dahl rats. Endocrinology 122: 1110-1113, 1988.

GOMEZ-SANCHEZ EP, GOMEZ-SANCHEZ CE: Effect of central infusion of benzamil on Dahl S rat hypertension. Am J Physiol 269: H1044-H1047, 1995.

GOMEZ-SANCHEZ EP, FORT C, THWAITES D: Central mineralocorticoid receptor antagonism blocks hypertension in Dahl S/JR rats. Am J Physiol 262: E96-E99, 1992.

GOMEZ-SANCHEZ EP, GOMEZ-SANCHEZ CE, FORT C: Immunization of Dahl SS/jr rats with an ouabain conjugate mitigates hypertension. Am J Hypertens 7: 591-596, 1994.

GOMEZ-SANCHEZ EP, SAMUEL J, VERGARA G, AHMAD N: Effect of 3ß-hydroxysteroid dehydrogenase inhibition by trilostane on blood pressure in the Dahl salt-sensitive rat. Am J Physiol 288: R389-R393, 2005.

GOMEZ-SANCHEZ EP, GOMEZ-SANCHEZ CM, PLOCZYNSKI M, GOMEZ-SANCHEZ CE: Aldosterone synthesis in the brain contributes to Dahl salt-sensitive rat hypertension. Exp Physiol 95: 120-130, 2010.

GORDON FJ, MATSUGUCHI H, MARK AL: Abnormal baroreflex control of heart rate in prehypertensive and hypertensive Dahl genetically salt-sensitive rats. Hypertension 3 (Suppl I): I-135-I-141, 1981.

GOTO A, TOBIAN L, IWAI J: Potassium feeding reduces hyperactive central nervous system pressor responses in Dahl salt-sensitive rats. Hypertension 3 (Suppl I): I-128-I-134, 1981.

GROS R, CHORAZYCZEWSKI J, MEEK MD, BENOVIC JL, FERGUSON SS, FELDMAN RD: G-Protein-coupled receptor kinase activity in hypertension: increased vascular and lymphocyte G-protein receptor kinase-2 protein expression. Hypertension 35: 38-42, 2000.

GROSSMAN E, HOFFMAN A, TAMRAT M, ARMANDO I, KEISER HR, GOLDSTEIN DS: Endogenous dopa and dopamine responses to dietary salt loading in salt-sensitive rats. J Hypertens 9: 259-263, 1991.

GU JW, TIAN N, SHPARAGO M, TAN W, BAILEY AP, MANNING RD JR: Renal NF- $k B$ activation and TNF- $\alpha$ upregulation correlate with salt-sensitive hypertension in Dahl salt-sensitive rats. Am J Physiol 291: R1817R1824, 2006.

GUPTA G, AZAM M, YANG L, DANZIGER RS: The $\beta 2$ subunit inhibits stimulation of the $\alpha 1 / \beta 1$ form of soluble guanylyl cyclase by nitric oxide. Potential relevance to regulation of blood pressure. $J$ Clin Invest 100: 14881492, 1997.

GUTKOWSKA J, KUCHEL O, RACZ K, BUU NT, CANTIN M, GENEST J: Increased plasma immunoreactive atrial natriuretic factor concentrations in salt sensitive Dahl rats. Biochem Biophys Res Commun 136: 411-416, 1986.

GUYTON AC: Kidneys and fluids in pressure regulation. Small volume but large pressure changes. Hypertension 19 (Suppl I): I-2-I-8, 1992.

HADRAVA V, TREMBLAY J, HAMET P: Abnormalities in growth characteristics of aortic smooth muscle cells in spontaneously hypertensive rats. Hypertension 13: 589-597, 1989.

HANSELL P: In vivo evidence for a defect in the dopamine $\mathrm{DA}_{1}$ receptor in the prehypertensive Dahl salt-sensitive rat: Exp Nephrol 3: 15-22, 1995.

HARRISON-BERNARD LM, SCHULMAN IH, RAIJ L: Postovariectomy hypertension is linked to increased renal $\mathrm{AT}_{1}$ receptor and salt sensitivity. Hypertension 42: 1157-1163, 2003.

HATTON DC, MCCARRON DA: Dietary calcium and blood pressure in experimental models of hypertension. A review. Hypertension 23: 513-530, 1994.

HATTON DC, MUNTZEL M, MCCARRON DA, PRESSLEY M, BUKOSKI RD: Early effects of dietary calcium on blood pressure, plasma volume, and vascular reactivity. Kidney Int Suppl 25: S16-S18, 1988.

HAWK CT, SCHAFER JA: Effects of AVP and deoxycorticosterone on $\mathrm{Na}^{+}$and water transport in the Dahl saltsensitive rat CCD. Am J Physiol 260: F471-F478, 1991. 
HAYAKAWA H, RAIJ L: The link among nitric oxide synthase activity, endothelial function, and aortic and ventricular hypertrophy in hypertension. Hypertension 29: 235-241, 1997.

HAYAKAWA H, RAIJ L: Nitric oxide synthase activity and renal injury in genetic hypertension. Hypertension 31: 266-270, 1998.

HE H, KIMURA S, FUJISAWA Y, TOMOHIRO A, KIYOMOTO K, AKI Y, ABE Y: Dietary L-arginine supplementation normalizes regional blood flow in Dahl-Iwai salt-sensitive rats. Am J Hypertens 10 (Suppl): 89S-93S, 1997.

HERRERA VL, RUIZ-OPAZO N: Alteration of $\alpha 1 \mathrm{Na}^{+}, \mathrm{K}^{+}$-ATPase ${ }^{86} \mathrm{Rb}^{+}$influx by a single amino acid substitution. Science 249: 1023-1026, 1990.

HERRERA VL, XIE HX, LOPEZ LV, SCHORK NJ, RUIZ-OPAZO N: The $\alpha 1$ Na,K-ATPase gene is a susceptibility hypertension gene in the Dahl salt-sensitive ${ }^{\mathrm{HSD}}$ rat. J Clin Invest 102: 1102-1111, 1998.

HERRERA VLM, DIDISHVILI T, LOPEZ LV, ZANDER K, TRAVERSE S, GANTZ D, HERSCOVITZ H, RUIZOPAZO N: Hypertension exacerbates coronary artery disease in transgenic hyperlipidemic Dahl salt-sensitive hypertensive rats. Mol Med 7: 831-844, 2001.

HINOJOSA-LABORDE C, LANGE DL, HAYWOOD JR: Role of female sex hormones in the development and reversal of dahl hypertension. Hypertension 35: 484-489, 2000.

HIRANO Y, TSUNODA M, SHIMOSAWA T, MATSUI H, FUJITA T, FUNATSU T: Suppression of catechol-Omethyltransferase activity through blunting of $\alpha_{2}$-adrenoceptor can explain hypertension in Dahl salt-sensitive rats. Hypertens Res 30: 269-278, 2007.

HIRATA Y, GANGULI M, TOBIAN L, IWAI J: Dahl S rats have increased natriuretic factor in atria but are markedly hyporesponsive to it. Hypertension 6 (Suppl I): I-148-I-155, 1984.

HIRAWA N, UEHARA Y, KAWABATA Y, OHSHIMA N, ONO H, NAGATA T, GOMI T, IKEDA T, GOTO A, YAGI S, OMATA M: Mechanistic analysis of renal protection by angiotensin converting enzyme inhibitor in Dahl salt-sensitive rats. J Hypertens 12: 909-918, 1994.

HIRAWA N, UEHARA Y, SUZUKI T, KAWABATA Y, NUMABE A, GOMI T, LKEDA T, KIZUKI K, OMATA M: Regression of glomerular injury by kallikrein infusion in Dahl salt-sensitive rats is a bradykinin $\mathrm{B}_{2}$-receptormediated event. Nephron 81: 183-193, 1999.

HISAKI R, FUJITA H, SAITO F, KUSHIRO T: Tempol attenuates the development of hypertensive renal injury in Dahl salt-sensitive rats. Am J Hypertens 18: 707-713, 2005.

HITOMI H, FUKUI T, MORIWAKI K, MATSUBARA K, SUN GP, RAHMAN M, NISHIYAMA A, KIYOMOTO H, KIMURA S, OHMORI K, ABE Y, KOHNO M: Synergistic effect of mechanical stretch and angiotensin II on superoxide production via NADPH oxidase in vascular smooth muscle cells. J Hypertens 24: 1089-1095, 2006.

HOAGLAND KM, FLASCH AK, ROMAN RJ: Inhibitors of 20-HETE formation promote salt-sensitive hypertension in rats. Hypertension 42: 669-673, 2003.

HOAGLAND KM, FLASCH AK, DAHLY-VERNON AJ, DOS SANTOS EA, KNEPPER MA, ROMAN RJ: Elevated BSC-1 and ROMK expression in Dahl salt-sensitive rat kidneys. Hypertension 43: 860-865, 2004.

HOJNÁ S, KADLECOVÁ M, ZICHA J, KUNEŠ J: Polymorphism in Nos2 gene is absent in Prague colony of Dahl/Rapp salt-sensitive and salt-resistant rats. Physiol Res 54: 201-206, 2005.

HOJNÁ S, KUNEŠ J, ZICHA J: Alterations of NO synthase isoforms in brain and kidney of rats with genetic and salt hypertension. Physiol Res 59: 997-1009, 2010.

HU L, MANNING RD JR: Role of nitric oxide in regulation of long-term pressure-natriuresis relationship in Dahl rats. Am J Physiol 268: H2375-H2383, 1995.

HUA JL, KASKEL FJ, JUNO CJ, MOORE LC, MCCAUGHRAN JA JR: Salt intake and renal hemodynamics in immature and mature Dahl salt-sensitive (DS/JR) and salt-resistant (DR/JR) rats. Am J Hypertens 3: 268-273, 1990.

HUANG BS, LEENEN FH: Brain "ouabain" mediates the sympathoexcitatory and hypertensive effects of high sodium intake in Dahl salt-sensitive rats. Circ Res 74: 586-595, 1994.

HUANG BS, LEENEN FH: Both brain angiotensin II and "ouabain" contribute to sympathoexcitation and hypertension in Dahl S rats on high salt intake. Hypertension 32: 1028-1033, 1998. 
HUANG BS, LEENEN FH: Mineralocorticoid actions in the brain and hypertension. Curr Hypertens Rep 13: 214-220, 2011.

HUANG BS, WANG H, LEENEN FH: Enhanced sympathoexcitatory and pressor responses to central $\mathrm{Na}^{+}$in Dahl saltsensitive vs. -resistant rats. Am J Physiol 281: H1881-H1889, 2001.

HUANG BS, VAN VLIET BN, LEENEN FH: Increases in CSF $\left[\mathrm{Na}^{+}\right]$precede the increases in blood pressure in Dahl S rats and SHR on a high-salt diet. Am J Physiol 287: H1160-H166, 2004.

HUANG BS, WANG H, LEENEN FH: Chronic central infusion of aldosterone leads to sympathetic hyperreactivity and hypertension in Dahl S but not Dahl R rats. Am J Physiol 288: H517-H524, 2005.

HUANG BS, WHITE RA, AHMAD M, JENG AY, LEENEN FH: Central infusion of aldosterone synthase inhibitor prevents sympathetic hyperactivity and hypertension by central $\mathrm{Na}^{+}$in Wistar rats. Am J Physiol 295: R166R172, 2008.

HUANG BS, WHITE RA, JENG AY, LEENEN FH: Role of central nervous system aldosterone synthase and mineralocorticoid receptors in salt-induced hypertension in Dahl salt-sensitive rats. Am J Physiol 296: R994R1000, 2009.

HUSTED RF, TAKAHASHI T, STOKES JB: IMCD cells cultured from Dahl S rats absorb more $\mathrm{Na}^{+}$than Dahl R rats. Am J Physiol 271: F1029-F1036, 1996.

HUSTED RF, TAKAHASHI T, STOKES JB: The basis of higher $\mathrm{Na}^{+}$transport by inner medullary collecting duct cells from Dahl salt-sensitive rats: implicating the apical membrane $\mathrm{Na}^{+}$channel. J Membr Biol 156: 9-18, 1997.

IDEISHI M, MIURA S, SAKAI T, SASAGURI M, MISUMI Y, ARAKAWA K: Taurine amplifies renal kallikrein and prevents salt-induced hypertension in Dahl rats. J Hypertens 12: 653-661, 1994.

ISHIDA M, ISHIDA T, MATSUURA H, OZONO R, KAJIYAMA G, OSHIMA T: Lack of increase in platelet $\mathrm{Ca}^{2+}$ and $\mathrm{Na}^{+}$in deoxycorticosterone acetate-salt hypertensive rats. Am J Physiol 267: R1288-R1293, 1994.

ISHIDA T, ISHIDA M, MATSUURA H, OZONO R, KAJIYAMA G, OSHIMA T: Dietary salt decreases cytosolic calcium in platelets from Dahl salt-sensitive rats. Am J Physiol 269: R1225-R1229, 1995.

ISHIMITSU T, UEHARA Y, IWAI J, SUGIMOTO T, HIRATA Y, MATSUOKA H, SUGIMOTO T: Vascular eicosanoid production in experimental hypertensive rats with different mechanisms. Prostaglandins Leukot Essent Fatty Acids 43: 179-184, 1991.

ISHIMITSU T, UEHARA Y, NUMABE A, TSUKADA H, OGAWA Y, IWAI J, IKEDA T, MATSUOKA H, SUGIMOTO T, YAGI S: Interferon gamma attenuates hypertensive renal injury in salt-sensitive Dahl rats. Hypertension 19: 804-808, 1992.

ISHIMITSU T, UEHARA Y, NUMABE A, TSUKADA H, OGAWA Y, YAGI S: Antihypertensive effect of interleukin-2 in salt-sensitive Dahl rats. Hypertension 23: 68-73, 1994.

ITO S, KOMATSU K, TSUKAMOTO K, SVED AF: Tonic excitatory input to the rostral ventrolateral medulla in Dahl salt-sensitive rats. Hypertension 37: 687-691, 2001.

ITO S, HIRATSUKA M, KOMATSU K, TSUKAMOTO K, KANMATSUSE K, SVED AF: Ventrolateral medulla AT 1 receptors support arterial pressure in Dahl salt-sensitive rats. Hypertension 41: 744-750, 2003.

IWAI J, HEINE M: Dahl salt-sensitive rats and human essential hypertension. J Hypertens 4 (Suppl 3): S29-S31, 1986.

IWAI J, OHANIAN EV, DAHL LK: Influence of thiazide on salt hypertension. Circ Res 40 (Suppl 1): I-131-I-134, 1977.

IWAI N, YASUI N, NARABA H, TAGO N, YAMAWAKI H, SUMIYA H: Klkl as one of the genes contributing to hypertension in Dahl salt-sensitive rat. Hypertension 45: 947-953, 2005.

JELÍNEK J, ALBRECHT I, MUSILOVÁ H: The age factor in experimental hypertension: hypertension due to adrenal regeneration. Physiol Bohemoslov 15: 424-433, 1966.

JOHN AE, MORICH FJ: ANP concentrations of atria, plasma and brain in Dahl S (DS) and Dahl R (DR) rats. Clin Exp Hypertens A 12: 191-204, 1990.

JOHNSON FK, DURANTE W, PEYTON KJ, JOHNSON RA: Heme oxygenase inhibitor restores arteriolar nitric oxide function in Dahl rats. Hypertension 41: 149-155, 2003.

JOHNSON FK, JOHNSON RA, PEYTON KJ, DURANTE W: Arginase inhibition restores arteriolar endothelial function in Dahl rats with salt-induced hypertension. Am J Physiol 288: R1057-R1062, 2005. 
JOSE PA, EISNER GM, DRAGO J, CAREY RM, FELDER RA: Dopamine receptor signaling defects in spontaneous hypertension. Am J Hypertens 9: 400-405, 1996.

KAHLE KT, RING AM, LIFTON RP: Molecular physiology of the WNK kinases. Annu Rev Physiol 70: 329-355, 2008.

KAKIZOE Y, KITAMURA K, KO T, WAKIDA N, MAEKAWA A, MIYOSHI T, SHIRAISHI N, ADACHI M, ZHANG Z, MASILAMANI S, TOMITA K: Aberrant ENaC activation in Dahl salt-sensitive rats. J Hypertens 27: 1679-1689, 2009.

KARLSEN FM, ANDERSEN CB, LEYSSAC PP, HOLSTEIN-RATHLOU NH: Dynamic autoregulation and renal injury in Dahl rats. Hypertension 30: 975-983, 1997.

KARLSEN FM, LEYSSAC PP, HOLSTEIN-RATHLOU NH: Tubuloglomerular feedback in Dahl rats. Am J Physiol 274: R1561-R1569, 1998.

KAWARAZAKI H, ANDO K, NAGAE A, FUJITA M, MATSUI H, FUJITA T: Mineralocorticoid receptor activation contributes to salt-induced hypertension and renal injury in prepubertal Dahl salt-sensitive rats. Nephrol Dial Transplant 25: 2879-2889, 2010.

KAZDA S: Effects of nitrendipine on vascular integrity. Am J Cardiol 58: 31D-34D, 1986.

KAZDA S, GARTHOFF B, DYCKA J, IWAI J: Prevention of malignant hypertension in salt loaded "S" Dahl rats with the calcium antagonist nifedipine. Clin Exp Hypertens A 4: 1231-1241, 1982.

KAZDA S, GARTHOFF B, LUCKHAUS G: Calcium and malignant hypertension in animal experiment: effects of experimental manipulation of calcium influx. Am J Nephrol 6 (Suppl 1): 145-150, 1986.

KIDO M, ANDO K, OBA S, FUJITA T: Renoprotective effect of pravastatin in salt-loaded Dahl salt-sensitive rats. Hypertens Res 28: 1009-1015, 2005.

KIDO M, ANDO K, ONOZATO ML, TOJO A, YOSHIKAWA M, OGITA T, FUJITA T: Protective effect of dietary potassium against vascular injury in salt-sensitive hypertension. Hypertension 51: 225-231, 2008.

KIEFER CR, MCKENNEY JB, TRAINOR JF, SNYDER LM: Maturation-dependent acquired coronary structural alterations and atherogenesis in the Dahl sodium-sensitive hypertensive rat. Circulation 106: 2486-2490, 2002.

KIRCHNER KA: Greater loop chloride uptake contributes to blunted pressure natriuresis in Dahl salt sensitive rats. J Am Soc Nephrol 1: 180-186, 1990.

KOBAYASHI N, HORINAKA S, MITA S, NAKANO S, HONDA T, YOSHIDA K, KOBAYASHI T, MATSUOKA $\mathrm{H}$ : Critical role of Rho-kinase pathway for cardiac performance and remodeling in failing rat hearts. Cardiovasc Res 55: 757-767, 2002.

KOBAYASHI N, YOSHIDA K, MITA S, HONDA T, HARA K, NAKANO S, TSUBOKOU Y, MATSUOKA H: Betaxolol stimulates eNOS production associated with LOX-1 and VEGF in Dahl salt-sensitive rats. J Hypertens 22: 1397-1402, 2004.

KOBAYASHI N, HARA K, TOJO A, ONOZATO ML, HONDA T, YOSHIDA K, MITA S, NAKANO S, TSUBOKOU Y, MATSUOKA H: Eplerenone shows renoprotective effect by reducing LOX-1-mediated adhesion molecule, PKCE-MAPK-p90RSK, and Rho-kinase pathway. Hypertension 45: 538-544, 2005.

KOBAYASHI N, YOSHIDA K, NAKANO S, OHNO T, HONDA T, TSUBOKOU Y, MATSUOKA H: Cardioprotective mechanisms of eplerenone on cardiac performance and remodeling in failing rat hearts. Hypertension 47: 671-679, 2006a.

KOBAYASHI N, HONDA T, YOSHIDA K, NAKANO S, OHNO T, TSUBOKOU Y, MATSUOKA H: Critical role of bradykinin-eNOS and oxidative stress-LOX-1 pathway in cardiovascular remodeling under chronic angiotensin-converting enzyme inhibition. Atherosclerosis 187: 92-100, 2006b.

KOTCHEN TA, ZHANG HY, COVELLI M, BLEHSCHMIDT N: Insulin resistance and blood pressure in Dahl rats and in one-kidney, one-clip hypertensive rats. Am J Physiol 261: E692-E697, 1991a.

KOTCHEN TA, BLEHSCHMIDT NG, REDDY SR: Effect of dietary $\mathrm{NaCl}$ on norepinephrine turnover in the Dahl rat. J Lab Clin Med 117: 383-389, 1991 b.

KŘEČEK J: The theory of critical developmental periods and postnatal development of endocrine functions. In: The Biopsychology of Development. E TOBACH, LR ARONSON, E SHAW (eds), Academic Press, New York, 1971, pp 233-248. 
KŘEČEK J, DOLEŽEL S, DLOUHÁ H, ZICHA J: Sympathetic nervous system and age-dependent salt hypertension in Brattleboro rats. Clin Exp Hypertens A 9: 2075-2093, 1987.

KUBISCH HM, MATHIALAGAN S, GÓMEZ-SÁNCHEZ EP: Modulation of blood pressure in the Dahl SS/jr rat by embryo transfer. Hypertension 31: 540-545, 1998.

KUNEŠ J, JELÍNEK J: Influence of age on saline hypertension in subtotally nephrectomized rats. Physiol Bohemoslov 33: 123-128, 1984.

KUNEŠ J, ZICHA J: Developmental windows and environment as important factors in the expression of genetic information: a cardiovascular physiologist's view. Clin Sci 111: 295-305, 2006.

KUNEŠ J, ZICHA J: The interaction of genetic and environmental factors in the etiology of hypertension. Physiol Res 58 (Suppl 2): S33-S41, 2009.

KUNEŠ J, ŠTOLBA P, POHLOVÁ I, JELÍNEK J, ZICHA J: The importance of endogenous digoxin-like factors in rats with various forms of experimental hypertension. Clin Exp Hypertens A 7: 707-720, 1985.

KUNEŠ J, ZICHA J, HAMET P: Effects of dietary calcium on the development of salt hypertension in young and adult Dahl rats. J Hypertens 6 (Suppl 4): S225-S227, 1988.

KUNEŠ J, LEONTJEVA GR, BYŠKOVÁ E, POHLOVÁ I, GOVYRIN VA, ZICHA J: Adrenergic innervation of blood vessels in Dahl rats with salt hypertension. Clin Exp Hypertens A 13: 1343-1355, 1991.

KUNEŠ J, ZICHA J, DEVYNCK M-A: Erythrocyte membrane microviscosity and blood pressure in rats with saltinduced and spontaneous hypertension. J Hypertens 12: 229-234, 1994.

KUNEŠ J, MAZEAUD MM, DEVYNCK MA, ZICHA J: Platelet hypoagregability in hereditary hypertriglyceridemic rats: relation to plasma triglycerides. Thromb Res 88: 347-353, 1997.

KUNEŠ J, DEVYNCK MA, ZICHA J: Chronic changes in plasma triglyceride levels do modify membrane microviscosity. Life Sci 67: 959-967, 2000.

KUNEŠ J, DOBEŠOVÁ Z, ZICHA J: Altered balance of main vasopressor and vasodepressor systems in rats with genetic hypertension and hypertriglyceridaemia. Clin Sci 102: 269-277, 2002.

KUNEŠ J, HOJNÁ S, KADLECOVÁ M, DOBEŠOVÁ Z, RAUCHOVÁ H, VOKURKOVÁ M, LOUKOTOVÁ J, PECHÁŇOVÁ O, ZICHA J: Altered balance of vasoactive systems in experimental hypertension: the role of relative NO deficiency. Physiol Res 53 (Suppl 1): S23-S34, 2004a.

KUNEŠ J, DOBEŠOVÁ Z, ZICHA J: Chronic N-acetylcysteine treatment prevents the development of salt hypertension in young Dahl rats. J Hypertens 22 (Suppl 2): S336, $2004 \mathrm{~b}$.

KURTZ TW, MORRIS RC JR: Hypertension in the recently weaned Dahl salt-sensitive rat despite a diet deficient in sodium chloride. Science 230: 808-810, 1985.

LE QUAN SANG KH, KUNEŠ J, ZICHA J, VINCENT M, SASSARD J, DEVYNCK MA: Platelet and erythrocyte membrane microviscosity in Lyon hypertensive rats. Am J Hypertens 7: 276-281, 1994a.

LE QUAN SANG KH, KUNEŠ J, ZICHA J, LACOUR B, BEN-ISHAY D, DEVYNCK MA: Platelet membrane microviscosity in Sabra rats with early salt hypertension. Clin Sci 86: 263-268, 1994b.

LEE RMKW, TRIGGLE CR: Morphometric study of mesenteric arteries from genetically hypertensive Dahl strain rats. Blood Vessels 23: 199-224, 1986.

LEENEN FH: The central role of the brain aldosterone-"ouabain" pathway in salt-sensitive hypertension. Biochim Biophys Acta 1802: 1132-1139, 2010.

LEENEN FH, HARMSEN E, YU H: Dietary sodium and central vs. peripheral ouabain-like activity in Dahl saltsensitive vs. salt-resistant rats. Am J Physiol 267: H1916-H1920, 1994.

LENDA DM, BOEGEHOLD MA: Effect of a high salt diet on microvascular antioxidant enzymes. $J$ Vasc Res 39: 41$50,2002 \mathrm{a}$.

LENDA DM, BOEGEHOLD MA: Effect of a high-salt diet on oxidant enzyme activity in skeletal muscle microcirculation. Am J Physiol 282: H395-H402, 2002b.

LENDA DM, SAULS BA, BOEGEHOLD: MA Reactive oxygen species may contribute to reduced endotheliumdependent dilation in rats fed high salt. Am J Physiol 279: H7-H14, 2000.

LEWANCZUK RZ, PANG PK: The occurrence of parathyroid hypertensive factor (PHF) in Dahl rats. Am J Hypertens 6: 758-762, 1993. 
LEWANCZUK RZ, CHEN A, PANG PK: The effects of dietary calcium on blood pressure in spontaneously hypertensive rats may be mediated by parathyroid hypertensive factor. Am J Hypertens 3: 349-353, 1990.

LI Y, ADACHI T, BOLOTINA VM, KNOWLES C, AULT KA, COHEN RA: Abnormal platelet function and calcium handling in Dahl salt-hypertensive rats. Hypertension 37: 1129-1135, 2001.

LIANG B, LEENEN FH: Prevention of salt-induced hypertension and fibrosis by $\mathrm{AT}_{1}$-receptor blockers in Dahl S rats. J Cardiovasc Pharmacol 51: 457-466, 2008.

LICLICAN EL, DOUMAD AB, WANG J, LI J, FALCK JR, STIER CT JR, CARROLL MA: Inhibition of the adenosine2A receptor-epoxyeicosatrienoic acid pathway renders Dahl salt-resistant rats hypertensive. Hypertension 54: 1284-1290, 2009.

LIN KF, CHAO J, CHAO L: Atrial natriuretic peptide gene delivery attenuates hypertension, cardiac hypertrophy, and renal injury in salt-sensitive rats. Hum Gene Ther 9: 1429-1438, 1998.

LINDSAY RS, LINDSAY RM, EDWARDS CRW, SECKL JR: Inhibition of 11ß-hydroxysteroid dehydrogenase in pregnant rats and the programming of blood pressure in the offspring. Hypertension 27: 1200-1204, 1996.

LÍŠKOVÁ S, PETROVÁ M, KAREN P, KUNEŠ J, ZICHA J: Effects of aging and hypertension on the participation of endothelium-derived constricting factor (EDCF) in norepinephrine-induced contraction of rat femoral artery. Eur J Pharmacol 667: 265-270, 2011.

LIU Y, SINGH RJ, USA K, NETZEL BC, LIANG M: Renal medullary 11 $\beta$-hydroxysteroid dehydrogenase type 1 in Dahl salt-sensitive hypertension. Physiol Genomics 36: 52-58, 2008.

LUCKHAUS G, GARTHOFF B, KAZDA S: Prevention of hypertensive vasculopathy by nifedipine in salt-loaded Dahl rats. Arzneimittelforschung 32: 1421-1425, 1982.

LUIPPOLD G, ZIMMERMANN C, MAI M, KLOOR D, STARCK D, GROSS G, MÜHLBAUER B: Dopamine $\mathrm{D}_{3}$ receptors and salt-dependent hypertension. J Am Soc Nephrol 12: 2272-2279, 2001.

LUNDIN SA, HALLBÄCK-NORDLANDER M: Background of hyperkinetic circulatory state in young spontaneously hypertensive rats. Cardiovasc Res 14: 561-567, 1980.

LÜSCHER TF, RAIJ L, VANHOUTTE PM: Endothelium-dependent vascular responses in normotensive and hypertensive Dahl rats. Hypertension 9: 157-163, 1987.

MA YH, SCHWARTZMAN ML, ROMAN RJ: Altered renal P-450 metabolism of arachidonic acid in Dahl saltsensitive rats. Am J Physiol 267: R579-R589, 1994.

MAEKAWA A, KAKIZOE Y, MIYOSHI T, WAKIDA N, KO T, SHIRAISHI N, ADACHI M, TOMITA K, KITAMURA K: Camostat mesilate inhibits prostasin activity and reduces blood pressure and renal injury in salt-sensitive hypertension. J Hypertens 27: 181-189, 2009.

MAITLAND K, BRIDGES L, DAVIS WP, LOSCALZO J, POINTER MA: Different effects of angiotensin receptor blockade on end-organ damage in salt-dependent and salt-independent hypertension. Circulation 114: 905-911, 2006.

MANGER WM, SIMCHON S, STIER CT JR, LOSCALZO J, JAN KM, JAN R, HADDY F: Protective effects of dietary potassium chloride on hemodynamics of Dahl salt-sensitive rats in response to chronic administration of sodium chloride. J Hypertens 21: 2305-2313, 2003.

MARCHE P, HEREMBERT T, ZHU DL: Molecular mechanisms of vascular hypertrophy in the spontaneously hypertensive rat. Clin Exp Pharmacol Physiol 22 (Suppl 1): S114-S116, 1995.

MARK AL: Sympathetic neural contribution to salt-induced hypertension in Dahl rats. Hypertension 17 (Suppl I): I-86I-90, 1991.

MASHBURN NA, UNLAP MT, RUNQUIST J, ALDERMAN A, JOHNSON GV, BELL PD: Altered protein kinase C activation of $\mathrm{Na}^{+} / \mathrm{Ca}^{2+}$ exchange in mesangial cells from salt-sensitive rats. Am J Physiol 276: F574-F580, 1999.

MATSUDA H, FUKUDA N, UENO T, TAHIRA Y, AYAME H, ZHANG W, BANDO T, SUGIYAMA H, SAITO S, MATSUMOTO K, MUGISHIMA H, SERIE K: Development of gene silencing pyrrole-imidazole polyamide targeting the TGF- $\beta 1$ promoter for treatment of progressive renal diseases. $J$ Am Soc Nephrol 17: 422-432, 2006.

MATSUDA H, FUKUDA N, UENO T, KATAKAWA M, WANG X, WATANABE T, MATSUI S, AOYAMA T, SAITO K, BANDO T, MATSUMOTO Y, NAGASE H, MATSUMOTO K, SUGIYAMA H: Transcriptional 
inhibition of progressive renal disease by gene silencing pyrrole-imidazole polyamide targeting of the transforming growth factor- $\beta 1$ promoter. Kidney Int 79: 46-56, 2011.

MATSUI H, SHIMOSAWA T, UETAKE Y, WANG H, OGURA S, KANEKO T, LIU J, ANDO K, FUJTA T: Protective effect of potassium against the hypertensive cardiac dysfunction: association with reactive oxygen species reduction. Hypertension 48: 225-231, 2006.

MATSUOKA H, ITOH S, KIMOTO M, KOHNO K, TAMAI O, WADA Y, YASUKAWA H, IWAMI G,OKUDA S, IMAIZUMI T: Asymmetrical dimethylarginine, an endogenous nitric oxide synthase inhibitor, in experimental hypertension. Hypertension 29: 242-247, 1997.

MATTSON DL, WU F: Control of arterial blood pressure and renal sodium excretion by nitric oxide synthase in the renal medulla. Acta Physiol Scand 168: 149-154, 2000.

MAZANCOVÁ K, MIKŠÍK I, KUNEŠ J, PÁCHA J: Placental 11ß-hydroxysteroid dehydrogenase in Dahl and spontaneously hypertensive rats. Am J Hypertens 16: 401-406, 2003a.

MAZANCOVÁ K, MIKŠÍK I, KUNEŠ J, ZICHA J, PÁCHA J: Sexual dimorphism of 11ß-hydroxysteroid dehydrogenase in hypertensive and normotensive rats. Hypertens Res 26: 333-338, $2003 \mathrm{~b}$.

MCCARRON DA, YUNG NN, UGORETZ BA, KRUTZIK S: Disturbances of calcium metabolism in the spontaneously hypertensive rat. Hypertension 3 (Suppl I): I-162-I-167, 1981.

MCCAUGHRAN JA JR, JUNO CJ: Altered renal $\alpha_{2}$-adrenoceptor density in Dahl rats prenatally exposed to a high salt diet. Clin Exp Hypertens B 5: 231-252, 1986.

MCCAUGHRAN JA JR, JUNO CJ: Calcium channel blockade with verapamil. Effects on blood pressure, renal, and myocardial adrenergic, cholinergic, and calcium channel receptors in inbred Dahl hypertension-sensitive (S/JR) and hypertension-resistant (R/JR) rats. Am J Hypertens 1: 255S-262S, 1988.

MCCAUGHRAN JA JR, JUNO CJ, O'MALLEY E, ROSENTHAL M: The ontogeny of renal $\alpha_{1}$ - and $\alpha_{2}$-adrenoceptors in the Dahl rat model of experimental hypertension. J Auton Nerv Syst 17: 1-20, 1986a.

MCCAUGHRAN JA JR, JUNO CJ, FRIEDMAN R: Pre- and neonatal exposure of the Dahl rat to NaCl: development and regional distribution of myocardial $\alpha 1$-adrenergic and cholinergic receptor sites. J Auton Nerv Syst 16: 137-152, 1986b.

MCCAUGHRAN JA JR, JUNO CJ, FRIEDMAN R, ZYLAN K, O'MALLEY E: Pre- and neonatal exposure to a high salt diet and the susceptibility to hypertension in the Dahl rat. Clin Exp Hypertens B 5: 159-193, 1986c.

MCCORMICK CP, HENNESSY JF, RAUCH AL, BUCKALEW VM JR: Erythrocyte sodium concentration and ${ }^{86} \mathrm{Rb}$ uptake in weanling Dahl rats. Am J Hypertens 2: 604-609, 1989.

MENEELY GR, TUCKER RG, DARBY WJ, AUERBACH SH: Chronic sodium chloride toxicity in the albino rat. II. Occurrence of hypertension and of a syndrome of edema and renal failure. $J$ Exp Med 98: 71-80, 1953.

MENEELY GR, BALL CO, YOUMANS JB: Chronic sodium chloride toxicity: the protective effect of added potassium chloride. Ann Intern Med 47: 263-273, 1957.

MENG S, ROBERTS LJ, CASON GW, CURRY TS, MANNING RD JR: Superoxide dismutase and oxidative stress in Dahl salt-sensitive and -resistant rats. Am J Physiol 283: R732-R738, 2002.

MENG S, CASON GW, GANNON AW, RACUSEN LC, MANNING RD JR: Oxidative stress in Dahl salt-sensitive hypertension. Hypertension 41: 1346-1352, 2003.

MISANKO BS, EVAN AP, BENGELE HH, SOLOMON S: Renal response to Ringer expansion in developing rats. Biol Neonate 35: 52-59, 1979.

MITA S, KOBAYASHI N, YOSHIDA K, NAKANO S, MATSUOKA H: Cardioprotective mechanisms of Rho-kinase inhibition associated with eNOS and oxidative stress-LOX-1 pathway in Dahl salt-sensitive hypertensive rats. J Hypertens 23: 87-96, 2005.

MIYAJIMA E, BUÑAG RD: Exacerbation of central baroreflex impairment in Dahl rats by high-salt diets. $A m J$ Physiol 252: H402-H409, 1987.

MIYATA N, COWLEY AW JR: Renal intramedullary infusion of L-arginine prevents reduction of medullary blood flow and hypertension in Dahl salt-sensitive rats. Hypertension 33: 446-450, 1999.

MOKRY M, CUPPEN E: The Atpla1 gene from inbred Dahl salt sensitive rats does not contain the A1079T missense transversion. Hypertension 51: 922-927, 2008. 
MÖLLER B, HANSELL P: Sodium and dopamine excretion in prehypertensive Dahl rats during severe hypervolaemia. Acta Physiol Scand 155: 165-171, 1995.

MORI T, O'CONNOR PM, ABE M, COWLEY AW JR: Enhanced superoxide production in renal outer medulla of Dahl salt-sensitive rats reduces nitric oxide tubular-vascular cross-talk. Hypertension 49: 1336-1341, 2007.

MORI T, POLICHNOWSKI A, GLOCKA P, KALDUNSKI M, OHSAKI Y, LIANG M, COWLEY AW JR: High perfusion pressure accelerates renal injury in salt-sensitive hypertension. $J$ Am Soc Nephrol 19: 1472-1482, 2008.

MU S, SHIMOSAWA T, OGURA S, WANG H, UETAKE Y, KAWAKAMI-MORI F, MARUMO T, YATOMI Y, GELLER DS, TANAKA H, FUJITA T: Epigenetic modulation of the renal $\beta$-adrenergic-WNK4 pathway in salt-sensitive hypertension. Nat Med 17: 573-580, 2011.

MUKAI H, FITZGIBBON WR, PLOTH DW, MARGOLIUS HS: Effect of chronic bradykinin B2 receptor blockade on blood pressure of conscious Dahl salt-resistant rats. Br J Pharmacol 124: 197-205, 1998.

MURAKAWA K, KANAYAMA Y, KOHNO M, KAWARABAYASHI T, YASUNARI K, TAKEDA T, HYONO A: Cytoplasmic free $\left[\mathrm{Ca}^{2+}\right]$ is not increased in the platelets of deoxycorticosterone-salt and spontaneously hypertensive rats. Clin Sci (Lond) 71: 121-123, 1986.

MURPHY CA, MCCARTY R: Maternal environment and development of high blood pressure in Dahl hypertensive rats. Am J Physiol 257: H1396-H1401, 1989.

MURPHY CA, FIELDS-OKOTCHA C, MCCARTY R: Shared maternal influences in the development of high blood pressure in the spontaneously hypertensive (SHR) and Dahl salt-sensitive (SS/Jr) rat strains. Behav Neural Biol 57: 144-148, 1992.

MUSILOVÁ H, JELÍNEK J, ALBRECHT I: The age of factor in experimental hypertension of the DCA type in rats. Physiol Bohemoslov 15: 525-531, 1966.

NAGASE M, ANDO K, KATAFUCHI T, KATO A, HIROSE S, FUJITA T: Role of natriuretic peptide receptor type C in Dahl salt-sensitive hypertensive rats. Hypertension 30: 177-183, 1997.

NAGASE M, KANAME S, NAGASE T, WANG G, ANDO K, SAWAMURA T, FUJITA T: Expression of LOX-1, an oxidized low-density lipoprotein receptor, in experimental hypertensive glomerulosclerosis. J Am Soc Nephrol 11: 1826-1836, 2000.

NAKAGAWA H, DAIHARA M, TAMAKAWA H, NOZUE T, KAWAHARA K: Effects of quinapril and losartan on insulin sensitivity in genetic hypertensive rats with different metabolic abnormalities. J Cardiovasc Pharmacol 34: 28-33, 1999.

NAKAMURA K, COWLEY AW JR: Sequential changes of cerebrospinal fluid sodium during the development of hypertension in Dahl rats. Hypertension 13: 243-249, 1989.

NAKAYA H, SASAMURA H, MIFUNE M, SHIMIZU-HIROTA R, KURODA M, HAYASHI M, SARUTA T: Prepubertal treatment with angiotensin receptor blocker causes partial attenuation of hypertension and renal damage in adult Dahl salt-sensitive rats. Nephron 91: 710-718, 2002.

NEDVÍDEK J, ZICHA J: Baroreflex control of heart rate in young and adult salt hypertensive inbred Dahl rats. Physiol Res 49: 323-330, 2000.

NELSON LD, UNLAP MT, LEWIS JL, BELL PD: Renal arteriolar $\mathrm{Na}^{+} / \mathrm{Ca}^{2+}$ exchange in salt-sensitive hypertension. Am J Physiol 276: F567-F573, 1999.

NI Z, VAZIRI ND: Effect of salt loading on nitric oxide synthase expression in normotensive rats. Am J Hypertens 14: 155-163, 2001.

NISHI A, BERTORELLO AM, APERIA A: High salt diet down-regulates proximal tubule $\mathrm{Na}^{+}, \mathrm{K}^{+}$-ATPase activity in Dahl salt-resistant but not in Dahl salt-sensitive rats: evidence of defective dopamine regulation. Acta Physiol Scand 144: 263-267, 1992.

NISHI A, EKLÖF AC, BERTORELLO AM, APERIA A: Dopamine regulation of renal $\mathrm{Na}^{+}, \mathrm{K}^{+}$-ATPase activity is lacking in Dahl salt-sensitive rats. Hypertension 21: 767-771, 1993.

NISHIDA Y, DING J, ZHOU MS, CHEN QH, MURAKAMI H, WU XZ, KOSAKA H: Role of nitric oxide in vascular hyper-responsiveness to norepinephrine in hypertensive Dahl rats. J Hypertens 16: 1611-1618, 1998.

NISHIDA Y, CHEN QH, TANDAI-HIRUMA M, TERADA S, HORIUCHI J: Neuronal nitric oxide strongly suppresses sympathetic outflow in high-salt Dahl rats. J Hypertens 19: 627-634, 2001. 
NISHIKIMI T, MORI Y, KOBAYASHI N, TADOKORO K, WANG X, AKIMOTO K, YOSHIHARA F, KANGAWA K, MATSUOKA H: Renoprotective effect of chronic adrenomedullin infusion in Dahl salt-sensitive rats. Hypertension 39: 1077-1082, 2002.

NISHIKIMI T, AKIMOTO K, WANG X, MORI Y, TADOKORO K, ISHIKAWA Y, SHIMOKAWA H, ONO H, MATSUOKA H: Fasudil, a Rho-kinase inhibitor, attenuates glomerulosclerosis in Dahl salt-sensitive rats. J Hypertens 22: 1787-1796, 2004.

NISHIYAMA A, YOSHIZUMI M, HITOMI H, KAGAMI S, KONDO S, MIYATAKE A, FUKUNAGA M, TAMAKI T, KIYOMOTO H, KOHNO M, SHOKOJI T, KIMURA S, ABE Y: The SOD mimetic tempol ameliorates glomerular injury and reduces mitogen-activated protein kinase activity in Dahl salt-sensitive rats. $J$ Am Soc Nephrol 15: 306-315, 2004.

O'CONNOR PM, LU L, SCHRECK C, COWLEY AW JR: Enhanced amiloride-sensitive superoxide production in renal medullary thick ascending limb of Dahl salt-sensitive rats. Am J Physiol 295: F726-F733, 2008.

O'CONNOR PM, LU L, LIANG M, COWLEY AW JR: A novel amiloride-sensitive $\mathrm{H}^{+}$transport pathway mediates enhanced superoxide production in thick ascending limb of salt-sensitive rats, not $\mathrm{Na}^{+} / \mathrm{H}^{+}$exchange. Hypertension 54: 248-254, 2009.

OGIHARA T, ASANO T, ANDO K, SAKODA H, ANAI M, SHOJIMA N, ONO H, ONISHI Y, FUJISHIRO M, ABE M, FUKUSHIMA Y, KIKUCHI M, FUJITA T: High-salt diet enhances insulin signaling and induces insulin resistance in Dahl salt-sensitive rats. Hypertension 40: 83-89, 2002.

OHBU K, KASKEL FJ, KINOSHITA S, FELDER RA: Dopamine-1 receptors in the proximal convoluted tubule of Dahl rats: defective coupling to adenylate cyclase. Am J Physiol 268: R231-R235, 1995.

OHYA Y, FUJII K, ONAKA U, ABE I, FUJISHIMA M: Enhanced electrical activity in mesenteric arteries from saltloaded Dahl salt-sensitive rats: actions of prostaglandin $\mathrm{H}_{2}$ on membrane channels. Am J Hypertens 10: 112S$115 \mathrm{~S}, 1997$.

OHYA Y, FUJII K, ETO K, ABE I, FUJISHIMA M: Voltage-dependent $\mathrm{Ca}^{2+}$ channels in resistance arteries from Dahl salt-sensitive rats. Hypertens Res 23: 701-707, 2000.

OKI K, GOMEZ-SANCHEZ EP, GOMEZ-SANCHEZ CE: Role of mineralocorticoid action in the brain in saltsensitive hypertension. Clin Exp Pharmacol Physiol 39: 90-95, 2012.

ONOZATO ML, TOJO A, KOBAYASHI N, GOTO A, MATSUOKA H, FUJITA T: Dual blockade of aldosterone and angiotensin II additively suppresses TGF- $\beta$ and NADPH oxidase in the hypertensive kidney. Nephrol Dial Transplant 22: 1314-1322, 2007.

ONWOCHEI MO, RAPP JP: Hyposecretion of atrial natriuretic factor by prehypertensive Dahl salt-sensitive rat. Hypertension 13: 440-448, 1989.

ONWOCHEI MO, SNAJDAR RM, RAPP JP: Release of atrial natriuretic factor from heart-lung preparations of inbred Dahl rats. Am J Physiol 253: H1044-H1052, 1987.

OTSUKA F, YAMAUCHI T, KATAOKA H, MIMURA Y, OGURA T, MAKINO H: Effects of chronic inhibition of $\mathrm{ACE}$ and $\mathrm{AT}_{1}$ receptors on glomerular injury in Dahl salt-sensitive rats. Am J Physiol 274: R1797-R1806, 1998.

OTSUKA K, OHNO Y, SASAKI T, YAMAKAWA H, HAYASHIDA T, SUZAWA T, SUZUKI H, SARUTA T: Ovariectomy aggravated sodium induced hypertension associated with altered platelet intracellular $\mathrm{Ca}^{2+}$ in Dahl rats. Am J Hypertens 10: 1396-1403, 1997.

OVERBECK HW, KU DD, RAPP JP: Sodium pump activity in arteries of Dahl salt-sensitive rats. Hypertension 3: 306-312, 1981.

OZAWA Y, HAYASHI K, KANDA T, HOMMA K, TAKAMATSU I, TATEMATSU S, YOSHIOKA K, KUMAGAI $\mathrm{H}$, WAKINO S, SARUTA T: Impaired nitric oxide- and endothelium-derived hyperpolarizing factordependent dilation of renal afferent arteriole in Dahl salt-sensitive rats. Nephrology (Carlton) 9: 272-277, 2004.

PARAI K, TABRIZCHI R: Impact of nitric oxide synthase inhibitor and chloride channel antagonist on mesenteric vascular conductance in anesthetized Dahl normotensive and hypertensive rats. J Cardiovasc Pharmacol 45: 569-579, 2005a. 
PARAI K, TABRIZCHI R: Effects of chloride substitution in isolated mesenteric blood vessels from Dahl normotensive and hypertensive rats. J Cardiovasc Pharmacol 46: 105-114, 2005 b.

PAULIS L, LÍŠKOVÁ S, PINTÉROVÁ M, DOBEŠOVÁ Z, KUNEŠ J, ZICHA J: Nifedipine-sensitive noradrenergic vasoconstriction is enhanced in spontaneously hypertensive rats: the influence of chronic captopril treatment. Acta Physiol (Oxford) 191: 255-266, 2007.

PAULIS L, ZICHA J, KUNEŠ J, HOJNÁ S, BEHULIAK M, CELEC P, KOJŠOVÁ S, PECHÁŇOVÁ O, ŠIMKO F: Regression of L-NAME-induced hypertension: the role of nitric oxide and endothelium-derived constricting factor. Hypertens Res 31: 793-803, 2008.

PATEL A, LAYNE S, WATTS D, KIRCHNER KA: L-arginine administration normalizes pressure natriuresis in hypertensive Dahl rats. Hypertension 22: 863-869, 1993.

PECHÁŇOVÁ O, ZICHA J, KOJŠOVÁ S, DOBEŠOVÁ Z, JENDEKOVÁ L, KUNEŠ J: Effect of chronic $\mathrm{N}$-acetylcysteine treatment on the development of spontaneous hypertension. Clin Sci 110: 235-242, 2006.

PECHÁŇOVÁ O, ZICHA J, PAULIS L, ZENEBE W, DOBEŠOVÁ Z, KOJŠOVÁ S, JENDEKOVÁ L, SLÁDKOVÁ M, DOVINOVÁ I, ŠIMKO F, KUNEŠ J: The effect of N-acetylcysteine and melatonin in adult spontaneously hypertensive rats with established hypertension. Eur J Pharmacol 561: 129-136, 2007.

PERNOLLET MG, DAVID-DUFILHO M, ZICHA J, KUNEŠ J, DEVYNCK MA: Alterations of membrane properties in erythrocytes of salt hypertensive Sabra rats. Life Sci 55: 1625-1632, 1994.

PERNOLLET MG, KUNEŠ J, ZICHA J, DEVYNCK MA: Cyclic nucleotides in platelets of genetically hypertriglyceridemic and hypertensive rats: thrombin and nitric oxide responses are unrelated to plasma triglyceride levels. Thromb Res 104: 29-37, 2001.

PETTINGER WA, GANDLER T, SANCHEZ A, SAAVEDRA JM: Dietary sodium and renal $\alpha_{2}$-adrenergic receptors in Dahl hypertensive rats. Clin Exp Hypertens A 4: 819-828, 1982a.

PETTINGER WA, SANCHEZ A, SAAVEDRA J, HAYWOOD JR, GANDLER T, RODES T: Altered renal alpha $2^{-}$ adrenergic receptor regulation in genetically hypertensive rats. Hypertension 4: 188-192, 1982b.

PEULER JD, MORGAN DA, MARK AL: High calcium diet reduces blood pressure in Dahl salt-sensitive rats by neural mechanisms. Hypertension 9 (Suppl III): III-159-III-165, 1987.

PEULER JD, PATEL KP, MORGAN DA, WHITEIS CA, LUND DD, PARDINI BJ, SCHMID PG: Altered peripheral noradrenergic activity in intact and sinoaortic denervated Dahl rats. Can J Physiol Pharmacol 67: 442-449, 1989.

PINTÉROVÁ M, LÍŠKOVÁ S, DOBEŠOVÁ Z, BEHULIAK M, KUNEŠ J, ZICHA J: Impaired control of L-type voltage-dependent calcium channels in experimental hypertension. Physiol Res 58 (Suppl 2): S43-S54, 2009.

POHLOVÁ I, MIKŠÍK I, KUNEŠ J, PÁCHA J: 11ß-hydroxysteroid dehydrogenase activity in spontaneously hypertensive and Dahl rats. Am J Hypertens 13: 927-933, 2000.

QUASCHNING T, D'USCIO LV, SHAW S, LÜSCHER TF: Vasopeptidase inhibition exhibits endothelial protection in salt-induced hypertension. Hypertension 37: 1108-1113, 2001.

RACZ K, KUCHEL O, BUU NT, GUTKOWSKA J, DEBINSKI W, CANTIN M, GENEST J: Zona glomerulosa cell responses to atrial natriuretic factor in genetically hypertensive rats. Am J Physiol 251: H689-H692, 1986.

RACZ K, KÜCHEL O, BUU NT: Abnormal adrenal catecholamine synthesis in salt-sensitive Dahl rats. Hypertension 9: 76-80, 1987.

RAFFAI G, WANG J, ROMAN RJ, ANJAIAH S, WEINBERG B, FALCK JR, LOMBARD JH: Modulation by cytochrome P450-4A $\omega$-hydroxylase enzymes of adrenergic vasoconstriction and response to reduced $\mathrm{PO}_{2}$ in mesenteric resistance arteries of Dahl salt-sensitive rats. Microcirculation 17: 525-535, 2010.

RAIJ L, LÜSCHER TF, VANHOUTTE PM: High potassium diet augments endothelium-dependent relaxations in the Dahl rat. Hypertension 12: 562-567, 1988.

RAPP JP: Dahl salt-susceptible and salt-resistant rats. A review. Hypertension 4: 753-763, 1982.

RAPP JP: Genetic analysis of inherited hypertension in the rat. Physiol Rev 80: 135-172, 2000.

RAPP JP, DENE H: Development and characteristics of inbred strains of Dahl salt-sensitive and salt-resistant rats. Hypertension 7: 340-349, 1985.

RAPP JP, MCPARTLAND RP, BATTEN CL: Isoelectric focusing patterns of urinary kallikrein in Dahl salthypertension susceptible and resistant rats. Hypertension 6: 519-525, 1984. 
RAPP JP, NGHIEM CX, ONWOCHEI MO: Aortic calcium uptake and efflux in spontaneously hypertensive and inbred Dahl rats. J Hypertens 4: 493-499, 1986.

RAPP JP, WANG SM, DENE H: A genetic polymorphism in the renin gene of Dahl rats cosegregates with blood pressure. Science 243: 542-544, 1989.

RAPP JP, WANG SM, DENE H: Effect of genetic background on cosegregation of renin alleles and blood pressure in Dahl rats. Am J Hypertens 3: 391-396, 1990.

RAUCHOVÁ H, PECHÁŇOVÁ O, KUNEŠ J, VOKURKOVÁ M, DOBEŠOVÁ Z, ZICHA J: Chronic $\mathrm{N}$-acetylcysteine administration prevents development of hypertension in $\mathrm{N}^{\omega}$-nitro-L-arginine methyl estertreated rats: the role of reactive oxygen species. Hypertens Res 28: 475-482, 2005.

REAVEN GM, TWERSKY J, CHANG H: Abnormalities of carbohydrate and lipid metabolism in Dahl rats. Hypertension 18: 630-635, 1991a.

REAVEN GM, TWERSKY J, HO H, CHANG H: Hypertriglyceridemia in Dahl rats: effect of sodium intake and gender. Horm Metab Res 23: 44-45, 1991b.

RIKITAKE Y, LIAO JK: Rho GTPases, statins, and nitric oxide. Circ Res 97: 1232-1235, 2005.

ROMAN RJ: Abnormal renal hemodynamics and pressure-natriuresis relationship in Dahl salt-sensitive rats. Am $J$ Physiol 251: F57-F65, 1986.

ROMAN RJ: P-450 metabolites of arachidonic acid in the control of cardiovascular function. Physiol Rev 82: 131-185, 2002.

ROMAN RJ, KALDUNSKI M: Pressure natriuresis and cortical and papillary blood flow in inbred Dahl rats. Am $J$ Physiol 261: R595-R602, 1991.

ROMAN RJ, MA YH, FROHLICH B, MARKHAM B: Clofibrate prevents the development of hypertension in Dahl salt-sensitive rats. Hypertension 21: 985-988, 1993.

ROMAN RJ, COWLEY AW JR, GREENE A, KWITEK AE, TONELLATO PJ, JACOB HJ: Consomic rats for the identification of genes and pathways underlying cardiovascular disease. Cold Spring Harb Symp Quant Biol 67: 309-315, 2002.

ROMAN RJ, HOAGLAND KM, LOPEZ B, KWITEK AE, GARRETT MR, RAPP JP, LAZAR J, JACOB HJ, SARKIS A: Characterization of blood pressure and renal function in chromosome 5 congenic strains of Dahl S rats. Am J Physiol 290: F1463-F1471, 2006.

ROSSI NF, BLACK SM, TELEMAQUE-POTTS S, CHEN H: Neuronal nitric oxide synthase activity in the paraventricular nucleus buffers central endothelin-1-induced pressor response and vasopressin secretion. J Cardiovasc Pharmacol 44 (Suppl 1): S283-S288, 2004.

ROWLAND NE, FREGLY MJ: Role of gonadal hormones in hypertension in the Dahl salt-sensitive rat. Clin Exp Hypertens A 14: 367-375, 1992.

RUDD MA, TROLLIET M, HOPE S, SCRIBNER AW, DAUMERIE G, TOOLAN G, CLOUTIER T, LOSCALZO J: Salt-induced hypertension in Dahl salt-resistant and salt-sensitive rats with NOS II inhibition. Am J Physiol 277: H732-H739, 1999.

SAAVEDRA JM, DEL CARMINE R, MCCARTY R, GUICHENEY P, WEISE V, IWAI J: Increased adrenal catecholamines in salt-sensitive genetically hypertensive Dahl rats. Am J Physiol 245: H762-H766, 1983.

SAKAMOTO T, CHEN C, LOKHANDWALA MF: Lack of renal dopamine production during acute volume expansion in Dahl salt-sensitive rats. Clin Exp Hypertens 16: 197-206, 1994.

SARTORI-VALINOTTI JC, VENEGAS-PONT MR, LAMARCA BB, ROMERO DG, YANES LL, RACUSEN LC, JONES AV, RYAN MJ, RECKELHOFF JF: Rosiglitazone reduces blood pressure in female Dahl saltsensitive rats. Steroids 75: 794-799, 2010.

SASAKI S, BUÑAG RD: Methyclothiazide attenuates salt-induced hypertension without affecting sympathetic responsiveness in Dahl rats. J Cardiovasc Pharmacol 5: 378-383, 1983.

SATOH M, HARUNA Y, FUJIMOTO S, SASAKI T, KASHIHARA N: Telmisartan improves endothelial dysfunction and renal autoregulation in Dahl salt-sensitive rats. Hypertens Res 33: 135-142, 2010.

SATOH S, UEDA Y, KOYANAGI M, KADOKAMI T, SUGANO M, YOSHIKAWA Y, MAKINO N: Chronic inhibition of Rho kinase blunts the process of left ventricular hypertrophy leading to cardiac contractile dysfunction in hypertension-induced heart failure. J Mol Cell Cardiol 35: 59-70, 2003. 
SCHULMAN IH, ZHOU MS, RAIJ L: Interaction between nitric oxide and angiotensin II in the endothelium: role in atherosclerosis and hypertension. J Hypertens 24 (Suppl 1): S45-S50, 2006.

SECHI LA, GRIFFIN CA, ZINGARO L, CATENA C, DE CARLI S, SCHAMBELAN M, BARTOLI E: Glucose metabolism and insulin receptor binding and mRNA levels in tissues of Dahl hypertensive rats. Am J Hypertens 10: 1223-1230, 1997.

SEN S, HOFFMAN GC, STOWE NT, SMEBY RR, BUMPUS FM: Erythrocytosis in spontaneously hypertensive rats. J Clin Invest 51: 710-714, 1972.

SERINO R, UETA Y, HANAMIYA M, NOMURA M, YAMAMOTO Y, YAMAGUCHI KI, NAKASHIMA Y, YAMASHITA H: Increased levels of hypothalamic neuronal nitric oxide synthase and vasopressin in saltloaded Dahl rat. Auton Neurosci 87: 225-235, 2001.

SHARMA JN, FERNANDEZ PG, LAHER I, TRIGGLE CR: Differential sensitivity of Dahl salt-sensitive and Dahl salt-resistant rats to the hypotensive action of acute nifedipine administration. Can J Physiol Pharmacol 62: 241-243, 1984.

SHEHATA MF, LEENEN FH, TESSON F: Sequence analysis of coding and 3' and 5' flanking regions of the epithelial sodium channel $\alpha, \beta$, and $\gamma$ genes in Dahl S versus R rats. BMC Genet 8:35, 2007.

SHIBATA S, NAGASE M, YOSHIDA S, KAWARAZAKI W, KURIHARA H, TANAKA H, MIYOSHI J, TAKAI Y, FUJITA T: Modification of mineralocorticoid receptor function by Rac1 GTPase: implication in proteinuric kidney disease. Nat Med 14: 1370-1376, 2008.

SHIMOKUBO T, SAKATA J, KITAMURA K, KANGAWA K, MATSUO H, ETO T: Adrenomedullin: changes in circulating and cardiac tissue concentration in Dahl salt-sensitive rats on a high-salt diet. Clin Exp Hypertens 18: 949-961, 1996.

SIMCHON S, MANGER WM, CARLIN RD, PEETERS LL, RODRIGUEZ J, BATISTA D, BROWN T, MERCHANT NB, JAN KM, CHIEN S: Salt-induced hypertension in Dahl salt-sensitive rats. Hemodynamics and renal responses. Hypertension 13: 612-621, 1989.

SIMCHON S, MANGER WM, BROWN TW: Dual hemodynamic mechanisms for salt-induced hypertension in Dahl salt-sensitive rats. Hypertension 17: 1063-1071, 1991.

SIMCHON S, MANGER WM, SHI GS, BRENSILVER J: Impaired renal vascular reactivity in prehypertensive Dahl salt-sensitive rats. Hypertension 20: 524-532, 1992.

SIMCHON S, MANGER W, BLUMBERG G, BRENSILVER J, CORTELL S: Impaired renal vasodilation and urinary cGMP excretion in Dahl salt-sensitive rats. Hypertension 27: 653-657, 1996.

SIMCHON S, MANGER W, GOLANOV E, KAMEN J, SOMMER G, MARSHALL CH: Handling ${ }^{22} \mathrm{NaCl}$ by the blood-brain barrier and kidney: its relevance to salt-induced hypertension in Dahl rats. Hypertension 33: 517$523,1999$.

SKELTON FR, GUILLEBEAU J: The influence of age on the development of adrenal-regeneration hypertension. Endocrinology 59: 201-212, 1956.

SMITH TL, HUTCHINS PM: Central hemodynamics in the developmental stage of spontaneous hypertension in the unanesthetized rat. Hypertension 1: 508-517, 1979.

SNAJDAR RM, RAPP JP: Atrial natriuretic factor in Dahl rats. Atrial content and renal and aortic responses. Hypertension 7: 775-782, 1985.

SNAJDAR RM, RAPP JP: Elevated atrial natriuretic polypeptide in plasma of hypertensive Dahl salt-sensitive rats. Biochem Biophys Res Commun 137: 876-883, 1986.

SOLTIS EE, KATOVICH MJ: Reduction in aortic smooth muscle beta-adrenergic responsiveness results in enhanced norepinephrine responsiveness in the Dahl salt-sensitive rat. Clin Exp Hypertens A 3: 117-132, 1991.

SONNENBERG H, HONRATH U, CHONG CK, MILOJEVIC S, VERESS AT: Renal responses to saline and atrial natriuretic factor infusions in Dahl rats. Can J Physiol Pharmacol 65: 1680-1683, 1987.

STASCH JP, KAZDA S, HIRTH-DIETRICH C, NEUSER D: Effects of nisoldipine on atrial natriuretic peptides, blood pressure and cardiac hypertrophy in Dahl rats. Clin Exp Hypertens A 12: 1419-1436, 1990.

STEC DE, DENG AY, RAPP JP, ROMAN RJ: Cytochrome P4504A genotype cosegregates with hypertension in Dahl S rats. Hypertension 27: 564-568, 1996. 
STEC DE, MATTSON DL, ROMAN RJ: Inhibition of renal outer medullary 20-HETE production produces hypertension in Lewis rats. Hypertension 29: 315-319, 1997.

STEELE TH, CHALLONER-HUE L: Dihydropyridine calcium antagonists and agonists in the isolated perfused Dahl rat kidney. J Cardiovasc Pharmacol 9 (Suppl 1): S44-S48, 1987.

STEELE TH, CHALLONER-HUE L: Genetics and salt modulate renal responses to atrial natriuretic factor. Hypertension 11: 745-749, 1988a.

STEELE TH, CHALLONER-HUE L: Increased vascular response to calcium channel agonist by Dahl S rat kidney. Am J Physiol 254: F533-F539, 1988 b.

STERZEL RB, LUFT FC, GAO Y, LANG RE, RUSKOAHO H, GANTEN D: Atrial natriuretic factor in sodiumsensitive and sodium-resistant Dahl rats. J Hypertens 5: 17-24, 1987.

STEWART RE, SWITHERS SE, MCCARTY R: Alterations in binding sites for atrial natriuretic factor in kidneys and adrenal glands of Dahl hypertension-sensitive rats. J Hypertens 5: 481-487, 1987.

STEWART RE, SWITHERS SE, MCCARTY R: Brain binding sites for atrial natriuretic factor (ANF): alterations in prehypertensive Dahl salt-sensitive (S/JR) rats. Brain Res Bull 20: 1-8, 1988.

SUDHIR K, KURTZ TW, YOCK PG, CONNOLLY AJ, MORRIS RC JR: Potassium preserves endothelial function and enhances aortic compliance in Dahl rats. Hypertension 22: 315-322, 1993.

SWEI A, LACY F, DELANO FA, SCHMID-SCHÖNBEIN GW: Oxidative stress in the Dahl hypertensive rat. Hypertension 30: 1628-1633, 1997.

SWEI A, LACY F, DELANO FA, PARKS DA, SCHMID-SCHÖNBEIN GW: A mechanism of oxygen free radical production in the Dahl hypertensive rat. Microcirculation 6: 179-187, 1999.

SZENTIVÁNYI M JR, ZOU AP, MATTSON DL, SOARES P, MORENO C, ROMAN RJ, COWLEY AW JR: Renal medullary nitric oxide deficit of Dahl S rats enhances hypertensive actions of angiotensin II. Am J Physiol 283: R266-R272, 2002.

TAHIRA Y, FUKUDA N, ENDO M, UENO T, MATSUDA H, SAITO S, MATSUMOTO K, MUGISHIMA H: Chimeric DNA-RNA hammerhead ribozyme targeting transforming growth factor- $\beta 1$ mRNA ameliorates renal injury in hypertensive rats. J Hypertens 25: 671-678, 2007.

TAKEDA Y, MIYAMORI I, YONEDA T, IKI K, HATAKEZAMA H, TAKEDA R: Gene expression of $11 \beta-$ hydroxysteroid dehydrogenase in the mesenteric arteries of genetically hypertensive rats. Hypertension 23: 577-580, 1994.

TAKEDA Y, ZHU A, YONEDA T, USUKURA M, TAKATA H, YAMAGISHI M: Effects of aldosterone and angiotensin II receptor blockade on cardiac angiotensinogen and angiotensin-converting enzyme 2 expression in Dahl salt-sensitive hypertensive rats. Am J Hypertens 20: 1119-1124, 2007.

TAKENAKA T, SUZUKI H, IKENAGA H, ITAYA Y, YAMAKAWA H, SAKAMAKI Y, SARUTA T: Effects of a calcium channel blocker, nicardipine, on pressure-natriuresis in Dahl salt-sensitive rats. Clin Exp Hypertens 16: 77-88, 1994.

TAKESHITA A, MARK AL: Neurogenic contribution to hindquarters vasoconstriction during high salt intake in Dahl strain of genetically hypertensive rats. Circ Res $\mathbf{4 3}$ (Suppl I): I-86-I-91, 1978.

TAKESHIMA H, KOBAYASHI N, KOGUCHI W, ISHIKAWA M, SUGIYAMA F, ISHIMITSU T: Cardioprotective effect of a combination of Rho-kinase inhibitor and P38 MAPK inhibitor on cardiovascular remodeling and oxidative stress in Dahl rats. $J$ Atheroscler Thromb 19: 326-336, 2012.

TAMAKI K, OKUDA S, NAKAYAMA M, YANAGIDA T, FUJISHIMA M: Transforming growth factor- $\beta 1$ in hypertensive renal injury in Dahl salt-sensitive rats. J Am Soc Nephrol 7: 2578-2589, 1996.

TAN DY, MENG S, MANNING RD JR: Role of neuronal nitric oxide synthase in Dahl salt-sensitive hypertension. Hypertension 33: 456-461, 1999.

TAN DY, MENG S, CASON GW, MANNING RD JR: Mechanisms of salt-sensitive hypertension: role of inducible nitric oxide synthase. Am J Physiol 279: R2297-R2303, 2000.

TANAKA I, INAGAMI T: Increased concentration of plasma immunoreactive atrial natriuretic factor in Dahl salt sensitive rats with sodium chloride-induced hypertension. J Hypertens 4: 109-112, 1986. 
TANDAI-HIRUMA M, HORIUCHI J, SAKAMOTO H, KEMURIYAMA T, HIRAKAWA H, NISHIDA Y: Brain neuronal nitric oxide synthase neuron-mediated sympathoinhibition is enhanced in hypertensive Dahl rats. J Hypertens 23: 825-834, 2005.

TAWAR U, KOTLO K, JAIN S, SHUKLA S, SETTY S, DANZIGER RS: Renal phosphodiesterase 4B is activated in the Dahl salt-sensitive rat. Hypertension 51: 762-766, 2008.

TAYLOR NE, COWLEY AW JR: Effect of renal medullary $\mathrm{H}_{2} \mathrm{O}_{2}$ on salt-induced hypertension and renal injury. Am $J$ Physiol 289: R1573-R1579, 2005.

TAYLOR NE, GLOCKA P, LIANG M, COWLEY AW JR: NADPH oxidase in the renal medulla causes oxidative stress and contributes to salt-sensitive hypertension in Dahl S rats. Hypertension 47: 692-698, $2006 \mathrm{a}$.

TAYLOR NE, MAIER KG, ROMAN RJ, COWLEY AW JR: NO synthase uncoupling in the kidney of Dahl S rats: role of dihydrobiopterin. Hypertension 48: 1066-1071, $2006 \mathrm{~b}$.

TERAN FJ, JOHNSON RA, STEVENSON BK, PEYTON KJ, JACKSON KE, APPLETON SD, DURANTE W, JOHNSON FK: Heme oxygenase-derived carbon monoxide promotes arteriolar endothelial dysfunction and contributes to salt-induced hypertension in Dahl salt-sensitive rats. Am J Physiol 288: R615-R622, 2005.

TIAN N, GANNON AW, KHALIL RA, MANNING RD JR: Mechanisms of salt-sensitive hypertension: role of renal medullary inducible nitric oxide synthase. Am J Physiol 284: R372-R379, 2003.

TIAN N, THRASHER KD, GUNDY PD, HUGHSON MD, MANNING RD JR: Antioxidant treatment prevents renal damage and dysfunction and reduces arterial pressure in salt-sensitive hypertension. Hypertension 45: 934-399, 2005.

TIAN N, ROSE RA, JORDAN S, DWYER TM, HUGHSON MD, MANNING RD JR: N-Acetylcysteine improves renal dysfunction, ameliorates kidney damage and decreases blood pressure in salt-sensitive hypertension. J Hypertens 24: 2263-70, 2006.

TIAN N, GU JW, JORDAN S, ROSE RA, HUGHSON MD, MANNING RD JR: Immune suppression prevents renal damage and dysfunction and reduces arterial pressure in salt-sensitive hypertension. Am J Physiol 292: H1018H1025, 2007a.

TIAN N, MOORE RS, BRADDY S, ROSE RA, GU JW, HUGHSON MD, MANNING RD JR: Interactions between oxidative stress and inflammation in salt-sensitive hypertension. Am J Physiol 293: H3388-H3395, 2007b.

TIAN N, MOORE RS, PHILLIPS WE, LIN L, BRADDY S, PRYOR JS, STOCKSTILL RL, HUGHSON MD, MANNING RD JR: NADPH oxidase contributes to renal damage and dysfunction in Dahl salt-sensitive hypertension. Am J Physiol 295: R1858-R1865, 2008.

TOBIAN L, LANGE J, AZAR S, IWAI J, KOOP D, COFFEE K, JOHNSON MA: Reduction of natriuretic capacity and renin release in isolated, blood-perfused kidneys of Dahl-hypertension-prone rats. Circ Res 43 (Suppl I): I-92-I-98, 1978.

TOJO A, ONOZATO ML, KOBAYASHI N, GOTO A, MATSUOKA H, FUJITA T: Angiotensin II and oxidative stress in Dahl salt-sensitive rat with heart failure. Hypertension 40: 834-839, 2002.

TOJO A, ONOZATO ML, KOBAYASHI N, GOTO A, MATSUOKA H, FUJTA T: Antioxidative effect of p38 mitogen-activated protein kinase inhibitor in the kidney of hypertensive rat. J Hypertens 23: 165-174, 2005.

TOMODA F, TAKATA M, KINUNO H, TOMITA S, YASUMOTO K, INOUE H: Renal structural properties in prehypertensive Dahl salt-sensitive rats. Hypertension 36: 68-72, 2000.

TROLLIET MR, RUDD MA, LOSCALZO J: Oxidative stress and renal dysfunction in salt-sensitive hypertension. Kidney Blood Press Res 24: 116-123, 2001.

TSUCHIHASHI T, KAGIYAMA S, ONAKA U, ABE I, FUJISHIMA M: Pressor and sympathetic responses to excitatory amino acids are not augmented in the ventrolateral medulla of Dahl salt-sensitive rats. Brain Res 750: 195-200, 1997.

TSUTSUI H, IDE T, HAYASHIDANI S, KINUGAWA S, SUEMATSU N, UTSUMI H, TAKESHITA A: Effects of ACE inhibition on left ventricular failure and oxidative stress in Dahl salt-sensitive rats. $J$ Cardiovasc Pharmacol 37: 725-733, 2001.

UEHARA Y, TOBIAN L, IWAI J, ISHII M, SUGIMOTO T: Alterations of vascular prostacyclin and thromboxane $\mathrm{A}_{2}$ in Dahl genetical strain susceptible to salt-induced hypertension. Prostaglandins 33: 727-738, 1987. 
UEHARA Y, ISHIMITSU T, IWAI J, ISHII M, SUGIMOTO T: Relevance of vascular PGI $_{2}$ synthase to vascular prostacyclin production in Dahl rats susceptible to salt-induced hypertension. Am J Hypertens 3: 313-316, 1990.

UEHARA $\mathrm{Y}$, HIRAWA N, KAWABATA Y, AKIE Y, ICHIKAWA A, FUNAHASHI N, OMATA M: Immunosuppressant HR-325 attenuates progression of malignant arteritis in the kidney of Dahl salt-sensitive rats. Hypertens Res 20: 91-97, 1997.

UENO T, KANAME S, TAKAICHI K, NAGASE M, TOJO A, ONOZATO ML, FUJITA T: LOX-1, an oxidized lowdensity lipoprotein receptor, was upregulated in the kidneys of chronic renal failure rats. Hypertens Res 26: 117-122, 2003.

USUKURA M, ZHU A, YONEDA T, KARASHIMA S, YAGI K, YAMAGISHI M, TAKEDA Y: Effects of a highsalt diet on adipocyte glucocorticoid receptor and $11 \beta$ hydroxysteroid dehydrogenase 1 in salt-sensitive hypertensive rats. Steroids 74: 978-982, 2009.

VAN HUYSSE JW: Endogenous brain Na pumps, brain ouabain-like substance and the $\alpha_{2}$ isoform in salt-dependent hypertension. Pathophysiology 14: 213-220, 2007.

VASDEV S, PRABHAKARAN VM, FERNANDEZ P, SAMPSON C: The role of vascular Na,K-ATPase activity in salt induced hypertension in Dahl rats. Res Commun Chem Pathol Pharmacol 62: 79-91, 1988.

VASDEV S, PRABHAKARAN VM, FERNANDEZ P, SAMPSON CA: Increased calcium uptake in vascular tissue by plasma of salt induced hypertensive Dahl rats. Can J Cardiol 5: 51-54, 1989.

VASDEV S, PRABHAKARAN V, SAMPSON CA: Elevated ${ }^{22} \mathrm{Na}$ uptake in aortae of Dahl salt-sensitive rats with high salt diet. Artery 17: 289-296, 1990a.

VASDEV S, PRABHAKARAN V, SAMPSON CA: Deuterium oxide normalizes blood pressure and vascular calcium uptake in Dahl salt-sensitive hypertensive rats. Hypertension 15: 183-189, $1990 \mathrm{~b}$.

VASDEV S, SAMPSON CA, LONGERICH L, PARAI S: Oral heparin prevents hypertension and elevated cytosolic calcium in salt-sensitive rats. Artery 19: 225-245, 1992.

VIEL EC, LEMARIÉ CA, BENKIRANE K, PARADIS P, SCHIFFRIN EL: Immune regulation and vascular inflammation in genetic hypertension. Am J Physiol 298: H938-H944, 2010.

VOKURKOVÁ M, DOBEŠOVÁ Z, KUNEŠ J, ZICHA J: Membrane ion transport in erythrocytes of salt hypertensive Dahl rats and their $\mathrm{F}_{2}$ hybrids: the role of cholesterol. Hypertens Res 26: 397-404, 2003.

VOKURKOVÁ M, NOVÁKOVÁ O, DOBEŠOVÁ Z, KUNEŠ J, ZICHA J: Relationships between membrane lipids and ion transport in red blood cells of Dahl rats. Life Sci 77: 1452-1464, 2005a.

VOKURKOVÁ M, LOUKOTOVÁ J, DOBEŠOVÁ Z, KUNEŠ J, ZICHA J: Age-dependent ion transport in rat erythrocytes. Physiol Res 53: 4P, 2005b.

WANG C, CHAO C, CHEN LM, CHAO L, CHAO J: High-salt diet upregulates kininogen and downregulates tissue kallikrein expression in Dahl-SS and SHR rats. Am J Physiol 271: F824-F830, 1996.

WANG H, LEENEN FH: Brain sodium channels mediate increases in brain "ouabain" and blood pressure in Dahl S rats. Hypertension 40: 96-100, 2002.

WANG H, WHITE R, LEENEN FH: Stimulation of brain $\mathrm{Na}^{+}$channels by FMRFamide in Dahl SS and SR rats. Am $J$ Physiol 285: H2013-H2018, 2003.

WANG J, SCHMIDT JR, ROMAN RJ, ANJAIAH S, FALCK JR, LOMBARD JH: Modulation of vascular $\mathrm{O}_{2}$ responses by cytochrome 450-4A $\omega$-hydroxylase metabolites in Dahl salt-sensitive rats. Microcirculation 16: 345-354, 2009.

WANG JM, VEERASINGHAM SJ, TAN J, LEENEN FH: Effects of high salt intake on brain $\mathrm{AT}_{1}$ receptor densities in Dahl rats. Am J Physiol 285: H1949-H955, 2003a.

WANG Y, WANG DH: A novel mechanism contributing to development of Dahl salt-sensitive hypertension: role of the transient receptor potential vanilloid type 1. Hypertension 47: 609-614, 2006.

WELLMAN GC, CARTIN L, ECKMAN DM, STEVENSON AS, SAUNDRY CM, LEDERER WJ, NELSON MT: Membrane depolarization, elevated $\mathrm{Ca}^{2+}$ entry, and gene expression in cerebral arteries of hypertensive rats. Am J Physiol 281: H2559-H2567, 2001.

WILCOX CS, WELCH WJ: TGF and nitric oxide: effects of salt intake and salt-sensitive hypertension. Kidney Int Suppl 55: S9-S13, 1996. 
WILLIAMS JM, SARKIS A, HOAGLAND KM, FREDRICH K, RYAN RP, MORENO C, LOPEZ B, LAZAR J, FENOY FJ, SHARMA M, GARRETT MR, JACOB HJ, ROMAN RJ: Transfer of the CYP4A region of chromosome 5 from Lewis to Dahl S rats attenuates renal injury. Am J Physiol 295: F1764-F1777, 2008.

WILSON TA, MCCAUGHRAN JA JR, JUNO CJ, KASKEL FJ, PARTIN JS: Ontogeny of plasma renin activity in the Dahl rat model of essential hypertension. $J$ Hypertens 4 (Suppl 5): S23-S26, 1986.

WILSON TA, DOLAN LM, MCCAUGHRAN JA, DOBROZSI DJ, JUNO CJ, YOUNG CA: Atrial natriuretic factor in the developing Dahl hypertensive rat. Am J Hypertens 1: 61-63, 1988.

WILSON TW, ALONSO-GALICIA M, ROMAN RJ: Effects of lipid-lowering agents in the Dahl salt-sensitive rat. Hypertension 31: 225-231, 1998.

WU X, SCHOLEY JW, SONNENBERG H: Renal vascular morphology in male Dahl rats on high-salt diet: effect of potassium. J Am Soc Nephrol 7: 338-344, 1996.

WU X, ACKERMANN U, SONNENBERG H: Hypertension development in Dahl S and R rats on high salt-low potassium diet: calcium, magnesium and sympathetic nervous system. Clin Exp Hypertens 20: 795-815, 1998.

YAMAMOTO E, KATAOKA K, YAMASHITA T, TOKUTOMI Y, DONG YF, MATSUBA S, OGAWA H, KIMMITSUYAMA S: Role of xanthine oxidoreductase in the reversal of diastolic heart failure by candesartan in the salt-sensitive hypertensive rat. Hypertension 50: 657-662, 2007.

YAMAZAKI K, KATOH H, YAMAMOTO N, KURIHARA K, IOBE H, SONODA J, KUWABARA M, KODAMA M, KAWAGUCHI A, FUNAMI Y, KUMAZAWA A, WAKABAYASHI T: Characterization of new inbred strains of Dahl-Iwai salt-sensitive and salt-resistant rats. Lab Anim Sci 44: 462-467, 1994.

YANES LL, SARTORI-VALINOTTI JC, ILIESCU R, ROMERO DG, RACUSEN LC, ZHANG H, RECKELHOFF JF: Testosterone-dependent hypertension and upregulation of intrarenal angiotensinogen in Dahl salt-sensitive rats. Am J Physiol 296: F771-F779, 2009.

YING WZ, SANDERS PW: The interrelationship between TGF- $\beta_{1}$ and nitric oxide is altered in salt-sensitive hypertension. Am J Physiol 285: F902-F908, 2003.

YOKOTA K, KISHIDA M, OGURA T, SUZUKI J, OTSUKA F, MIMURA Y, TAKEDA M, NAKAMURA Y, MAKINO H: Role of bradykinin in renoprotective effects by angiotensin II type 1 receptor antagonist in saltsensitive hypertension. Hypertens Res 26: 265-272, 2003.

YONEDA T, KIHARA Y, TAKENAKA H, ONOZAWA Y, SARAI N, KITA T: RhoA expression is not a critical determinant in hypertension evolution in salt-sensitive Dahl rats. Med Sci Monit 9: BR399-BR402, 2003.

YOSHIDA K, KOBAYASHI N, OHNO T, FUKUSHIMA H, MATSUOKA H: Cardioprotective effect of angiotensin II type 1 receptor antagonist associated with bradykinin-endothelial nitric oxide synthase and oxidative stress in Dahl salt-sensitive hypertensive rats. $J$ Hypertens 25: 1633-1642, 2007.

YOSHIHARA F, SUGA S, YASUI N, HORIO T, TOKUDOME T, NISHIKIMI T, KAWANO Y, KANGAWA K: Chronic administration of adrenomedullin attenuates the hypertension and increases renal nitric oxide synthase in Dahl salt-sensitive rats. Regul Pept 128: 7-13, 2005.

ZENG C, SANADA H, WATANABE H, EISNER GM, FELDER RA, JOSE PA: Functional genomics of the dopaminergic system in hypertension. Physiol Genomics 19: 233-246, 2004.

ZHANG JJ, YOSHIDA H, CHAO L, CHAO J: Human adrenomedullin gene delivery protects against cardiac hypertrophy, fibrosis, and renal damage in hypertensive Dahl salt-sensitive rats. Hum Gene Ther 11: 1817$1827,2000$.

ZHANG JJ, BLEDSOE G, KATO K, CHAO L, CHAO J: Tissue kallikrein attenuates salt-induced renal fibrosis by inhibition of oxidative stress. Kidney Int 66: 722-732, 2004.

ZHANG L, FUJII S, IGARASHI J, KOSAKA H: Effects of thiol antioxidant on reduced nicotinamide adenine dinucleotide phosphate oxidase in hypertensive Dahl salt-sensitive rats. Free Radic Biol Med 37: 1813-1820, 2004.

ZHAO X, WHITE R, HUANG BS, VAN HUYSSE J, LEENEN FH: High salt intake and the brain renin-angiotensin system in Dahl salt-sensitive rats. J Hypertens 19: 89-98, 2001.

ZHOU MS, NISHIDA Y, YONEYAMA H, CHEN QH, KOSAKA H: Potassium supplementation increases sodium excretion and nitric oxide production in hypertensive Dahl rats. Clin Exp Hypertens 21: 1397-1411, 1999a. 
ZHOU MS, NISHIDA Y, CHEN QH, KOSAKA H: Endothelium-derived contracting factor in carotid artery of hypertensive Dahl rats. Hypertension 34: 39-43, 1999 b.

ZHOU MS, KOSAKA H, YONEYAMA H: Potassium augments vascular relaxation mediated by nitric oxide in the carotid arteries of hypertensive Dahl rats. Am J Hypertens 13: 666-672, 2000.

ZHOU MS, KOSAKA H, TIAN RX, ABE Y, CHEN QH, YONEYAMA H, YAMAMOTO A, ZHANG L: L-Arginine improves endothelial function in renal artery of hypertensive Dahl rats. J Hypertens 19: 421-429, 2001.

ZHOU MS, ADAM AG, JAIMES EA, RAIJ L: In salt-sensitive hypertension, increased superoxide production is linked to functional upregulation of angiotensin II. Hypertension 42: 945-951, 2003.

ZHOU MS, JAIMES EA, RAIJ L: Atorvastatin prevents end-organ injury in salt-sensitive hypertension: role of eNOS and oxidant stress. Hypertension 44: 186-190, 2004.

ZHOU MS, SCHUMAN IH, JAIMES EA, RAIJ L: Renoprotection by statins is linked to a decrease in renal oxidative stress, TGF- $\beta$, and fibronectin with concomitant increase in nitric oxide bioavailability. Am J Physiol 295: F53F59, 2008a.

ZHOU MS, SCHULMAN IH, JAIMES EA, RAIJ L: Thiazide diuretics, endothelial function, and vascular oxidative stress. J Hypertens 26: 494-500, 2008b.

ZHOU MS, SCHULMAN IH, RAIJ L: Role of angiotensin II and oxidative stress in vascular insulin resistance linked to hypertension. Am J Physiol 296: H833-H839, 2009.

ZHOU MS, SCHULMAN IH, RAIJ L: Vascular inflammation, insulin resistance, and endothelial dysfunction in saltsensitive hypertension: role of nuclear factor kappa B activation. J Hypertens 28: 527-535, 2010.

ZICHA J, DUHM J: Kinetics of $\mathrm{Na}^{+}$and $\mathrm{K}^{+}$transport in red cells of Dahl rats: effects of age and salt. Hypertension 15: 612-627, 1990.

ZICHA J, KUNEŠ J: Ontogenetic aspects of hypertension development: analysis in the rat. Physiol Rev 79: 1227-1282, 1999a.

ZICHA J, KUNEŠ J: Membrane defects and the development of hypertension. In: Handbook of Hypertension, Vol. 19, Development of Hypertensive Phenotype: Basic and Clinical Studies. R MCCARTY, DA BLIZARD, RL CHEVALIER (eds), Elsevier, Amsterdam 1999b, pp 213-251.

ZICHA J, K ǨEČEK J, DLOUHÁ H: Age-dependent salt hypertension in Brattleboro rats: a hemodynamic analysis. Ann N Y Acad Sci 394: 330-342, 1982.

ZICHA J, ŠTOLBA P, POHLOVÁ I, KUNEŠ J, JELÍNEK J: A different role of digoxin-like factor in the maintenance of elevated blood pressure in rats treated with DOCA and saline in youth or only in adulthood. $J$ Hypertens 2 (Suppl 3): 481-484, 1984.

ZICHA J, KUNEŠ J, ŠTOLBA P: Endogenous digoxin-like factor contributes to the elevation of systemic resistance in rats exposed to high salt intake from prepuberty. J Hypertens 3 (Suppl 3): S17-S19, 1985.

ZICHA J, KUNEŠ J, JELÍNEK J: Experimental hypertension in young and adult animals. Hypertension 8: 1096-1104, 1986.

ZICHA J, BYŠKOVÁ E, KUNEŠ J, POHLOVÁ I, JELÍNEK J: Sodium pump activity in young and adult salt hypertensive Dahl rats. Klin Wochenschr 65 (Suppl VIII): 76-81, 1987a.

ZICHA J, KUNEŠ J, LÉBL M, POHLOVÁ I, JELÍNEK J: Haemodynamics and the participation of pressor systems in young and adult rats with age-dependent DOCA-salt hypertension. Physiol Bohemoslov 36: 89-92, 1987b.

ZICHA J, KUNEŠ J, LÉBL M, POHLOVÁ I, SLANINOVÁ J, JELÍNEK J: Antidiuretic and pressor actions of vasopressin in age-dependent DOCA-salt hypertension. Am J Physiol 256: R138-R145, 1989.

ZICHA J, PERNOLLET MG, KUNEŠ J, LACOUR B, VINCENT M, SASSARD J, DEVYNCK MA: Alterations of cytosolic calcium in platelets and erythrocytes of Lyon hypertensive rats. Am J Hypertens 8: 842-849, 1995.

ZICHA J, KUNEŠ J, DAVID-DUFILHO M, PERNOLLET MG, DEVYNCK MA: Cell calcium handling and intracellular $\mathrm{pH}$ regulation in hereditary hypertriglyceridemic rats: reduced platelet response to thrombin stimulation. Life Sci 59: 803-813, 1996a.

ZICHA J, KUNEŠ J, BEN-ISHAY D, DEVYNCK MA: Abnormal regulation of cytosolic calcium and pH in platelets of Sabra rats in early phases of salt hypertension development. Can J Physiol Pharmacol 74: 1222-1228, 1996b. 
ZICHA J, KUNEŠ J, DEVYNCK MA: Platelet calcium handling is different in rats with salt-dependent and spontaneous forms of genetic hypertension. Am J Hypertens 9: 812-818, 1996c.

ZICHA J, DAVID-DUFILHO M, KUNEŠ J, PERNOLLET MG, DEVYNCK MA: Cytosolic pH and calcium in Dahl salt-sensitive and salt-resistant rats: the relationship to plasma lipids. J Hypertens 15: 1715-1721, 1997.

ZICHA J, KUNEŠ J, DEVYNCK MA: Abnormalities of membrane function and lipid metabolism in hypertension: a review. Am J Hypertens 12: 315-331, 1999a.

ZICHA J, LE QUAN SANG KH, KUNEŠ J, DEVYNCK MA: Membrane microviscosity, blood pressure and cytosolic pH in Dahl rats: the influence of plasma lipids. J Hypertens 17: 785-792, $1999 \mathrm{~b}$.

ZICHA J, NEGRIN CD, DOBEŠOVÁ Z, CARR F, VOKURKOVÁ M, MCBRIDE MW, KUNEŠ J, DOMINICZAK AF: Altered $\mathrm{Na}^{+}-\mathrm{K}^{+}$pump activity and plasma lipids in salt-hypertensive Dahl rats: relationship to Atplal gene. Physiol Genomics 6: 99-104, 2001a.

ZICHA J, DOBEŠOVÁ Z, KUNEŠ J: Relative deficiency of nitric oxide-dependent vasodilation in salt hypertensive Dahl rats: the possible role of superoxide anions. J Hypertens 19: 247-254, $2001 \mathrm{~b}$.

ZICHA J, DOBEŠOVÁ Z, KUNEŠ J: Antihypertensive mechanisms of chronic captopril or N-acetylcysteine treatment in L-NAME hypertensive rats. Hypertens Res 29: 1021-1027, 2006.

ZICHA J, DOBEŠOVÁ Z, BEHULIAK M, KUNEŠ J, VANĚČKOVÁ I: Preventive dietary potassium supplementation in young salt-sensitive Dahl rats attenuates development of salt hypertension by decreasing sympathetic vasoconstriction. Acta Physiol (Oxf) 202: 29-38, 2011.

ZICHA J, DOBEŠOVÁ Z, KUNEŠ J, VANĚČKOVÁ I: Chronic endothelin a receptor blockade attenuates contribution of sympathetic nervous system to salt hypertension development in adult but not in young dahl rats. Acta Physiol (Oxf) 205: 124-132, 2012.

ZOU AP, COWLEY AW JR: Role of nitric oxide in the control of renal function and salt sensitivity. Curr Hypertens Rep 1: 178-186, 1999. 